Florida International University

FIU Digital Commons

\title{
We're Here, We Exist: An Exploration of how Second-Generation Afro-Caribbean College Women Make Meaning of their Race, Ethnicity, and Gender
}

Emmanuela P. Stanislaus

Florida International University, estan016@fiu.edu

Follow this and additional works at: https://digitalcommons.fiu.edu/etd

Part of the Higher Education Commons

\section{Recommended Citation}

Stanislaus, Emmanuela P., "We're Here, We Exist: An Exploration of how Second-Generation AfroCaribbean College Women Make Meaning of their Race, Ethnicity, and Gender" (2020). FIU Electronic Theses and Dissertations. 4486.

https://digitalcommons.fiu.edu/etd/4486

This work is brought to you for free and open access by the University Graduate School at FIU Digital Commons. It has been accepted for inclusion in FIU Electronic Theses and Dissertations by an authorized administrator of FIU Digital Commons. For more information, please contact dcc@fiu.edu. 


\section{FLORIDA INTERNATIONAL UNIVERSITY}

Miami, Florida

WE'RE HERE, WE EXIST:

AN EXPLORATION OF HOW SECOND-GENERATION AFRO-CARIBBEAN COLLEGE WOMEN MAKE MEANING OF THEIR RACE, ETHNICITY, AND GENDER

A dissertation submitted in partial fulfillment of the requirements for the degree of DOCTOR OF PHILOSOPHY in

HIGHER EDUCATION

by

Emmanuela Pierre Stanislaus 
To: Dean Michael R. Heithaus

College of Arts, Sciences and Education

This dissertation, written by Emmanuela Pierre Stanislaus, and entitled We're Here, We Exist: An Exploration of How Second-Generation Afro-Caribbean College Women Make Meaning of their Race, Ethnicity, and Gender, having been approved in respect to style and intellectual content, is referred to you for judgment.

We have read this dissertation and recommend that it be approved.

Sarah Mathews

Heather Russell

Maria Lovett

Benjamin Baez, Major Professor

Date of Defense: June 30, 2020

The dissertation of Emmanuela Pierre Stanislaus is approved.

Dean Michael R. Heithaus

College of Arts, Sciences and Education

Andrés G. Gil

Vice President for Research and Economic Development and Dean of the University Graduate School

Florida International University, 2020 
C Copyright 2020 by Emmanuela Pierre Stanislaus

All rights reserved. 


\section{DEDICATION}

To my guardian angels, Lalee, Joy, Tonton Etienne, and Mignon thank you for watching over me and pushing me to the finish line. To my parents, Samuel and Rose Marie Pierre, you made the journey to this new country with so many hopes and dreams. You had no idea that your future child would complete her doctorate. Thank you for always believing in me and pushing me to be the best in everything that I pursue. Thank you for your love and sacrifice which inspires me every day.

Also, to my nine research participants. Thank you for sharing your stories and trusting me to represent your life experiences. I hope that I do you justice. 


\section{ACKNOWLEDGMENTS}

The completion of this degree would not be possible without the love and support of countless individuals. First, I'd like to thank my amazing committee members - Dr. Benjamin Baez, Dr. Heather Russell, Dr. Sarah Mathews, and Dr. Maria Lovett. Thank you all for making this such a positive and supportive experience. I couldn't have done this without your guidance.

To my loving and supportive husband, Michael. You really are the real MVP. You sacrificed the most and witnessed the ups and downs. You saw me through so many tough times and motivated me throughout the process. Thank you for always believing in me and motivating me to press forward. I couldn't have done this without you.

My mom, dad, and sisters, thank you for always encouraging me even if you didn't really understand what I was going through. Thank you for keeping me lifted in prayer and for always giving me a break from this major task. I also want to thank the father figures in my life who loved and cared for me - Toto, Dede, Henry, Uncle Lou, VerVer, and Cleophat.

Ivette Duarte, thank you for your real support. Your continuous questions about where I was in the process, really helped me to relieve stress and get out of my head. Words can't express how much I appreciate you "putting me on ice" so that I can carve out time to step away from work and make progress on my dissertation.

To my support circle that helped me throughout this journey, thank you so much. Special shout out to Dr. Joy Gaston-Gayles, Dr. Lamesha Brown, Dr. Nashira Williams,

Dr. Bronwen Bares Pelaez, Dr. Cathy Akens, Dr. Suzanne Onorato, Dr. Carolyn Meeker, Dr. David Jones, Dr. Stephanie Loudone-Jones, Dr. Katrina Amie, Gerson Sanchez, and 
Suzy Gomez, and Barbara Bader. Dr. Lynell Hodge, thank you for making it your mission to see me through to the finish line. Thank you for being an inspiration and keeping me motivated. Special thanks to a couple of individuals who helped me along the road to discovering Higher Education Administration as a career path - Dr. Paige Crandall and Dr. Shari Crandall. 


\author{
ABSTRACT OF THE DISSERTATION \\ WE'RE HERE, WE EXIST: \\ AN EXPLORATION OF HOW SECOND-GENERATION AFRO-CARIBBEAN \\ COLLEGE WOMEN MAKE MEANING OF THEIR RACE, ETHNICITY, AND \\ GENDER \\ by
}

Emmanuela Pierre Stanislaus

Florida International University, 2020

Miami, Florida

Professor Benjamin Baez, Major Professor

The present single-case study was situated within Florida International University and explored how second-generation Afro-Caribbean college women make meaning of their race, ethnicity, and gender. My dissertation expands the existing scholarship on Black college students who have historically been presented as monolithic. Furthermore, my study illuminates how the race, ethnicity, and gender intersect to complicate the experiences of these women. Additionally, my research highlights how the surrounding college campus community impacts second-generation Afro-Caribbean college women's ideas of belonging.

This study involved two semi-structured interviews with nine undergraduate college women attending FIU. All women self-identified as second-generation AfroCaribbean. This two-interview scheme is a modification of Seidman's (2013) three-phase interview process. The first interview focused on the life history of the participants, and the second interview centers on the lived experiences of the participants within the 
context of FIU. The women represent backgrounds that include Haiti, Dominican Republic, Jamaica, Guyana, and Belize.

Four overarching themes emerged from the study. First, the study revealed that early childhood experiences, particularly religion, played a major role in gender identity. Second, their physical appearance impact how others viewed and treated them which influenced how the participants made meaning of their racial identity. Third, the women shared experiences where both their racial and ethnic identities were challenged by others within their racial and ethnic groups. Finally, participants expressed concern of feeling excluded from notions of diversity within the university.

Findings illuminate the factors influencing college choices among secondgeneration Afro-Caribbean college women. My participants shared powerful stories of how their physical appearance and hair influence how they are viewed and treated. Specifically, these women spoke of engaging in the process of self-love and challenging traditional standards of beauty and professionalism in the media as well within their circle of family and friends. The importance of peer groups where they could be their authentic selves and find comfort against systems of oppression selves were also discussed. 


\section{TABLE OF CONTENTS}

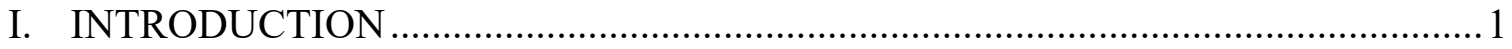

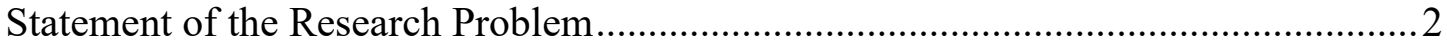

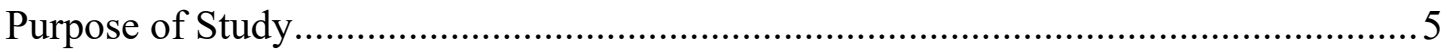

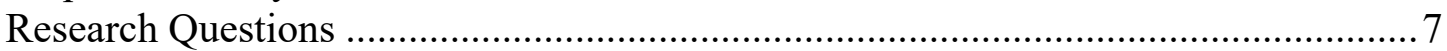

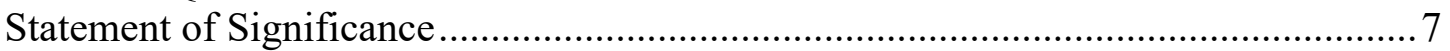

Delimitations/Assumptions of Study.................................................................... 10

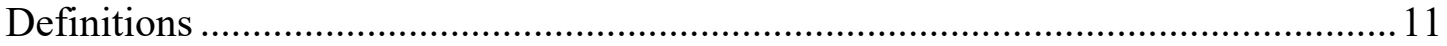

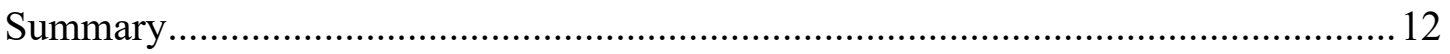

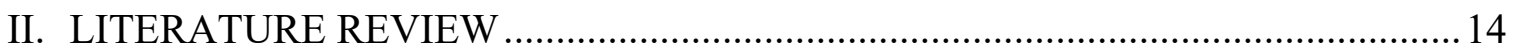

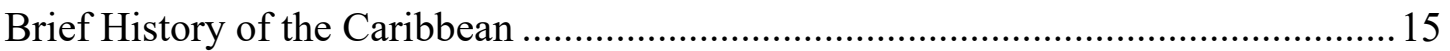

History of Black Caribbean Immigration to the U.S. ................................................. 17

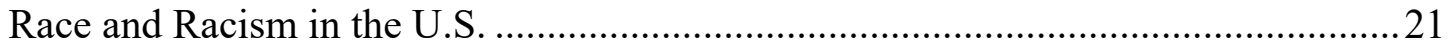

Race and Racism in Higher Education ..............................................................2

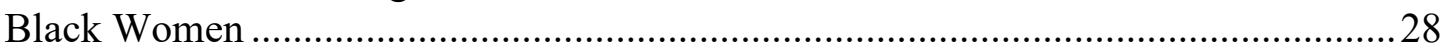

Racial and Ethnicity Identification of Afro-Caribbeans ...............................................34

History of Hispanic Serving Institutions ..................................................................

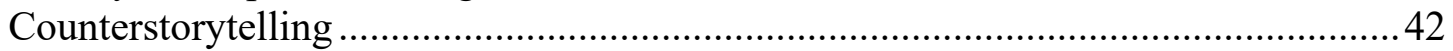

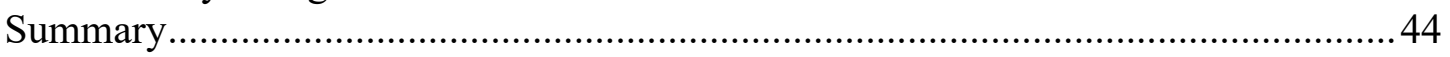

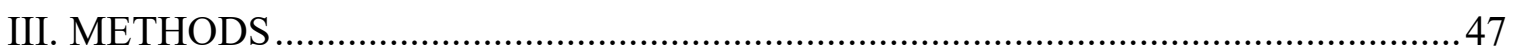

Research Design/Methodology …………………….......................................4

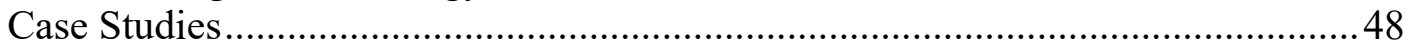

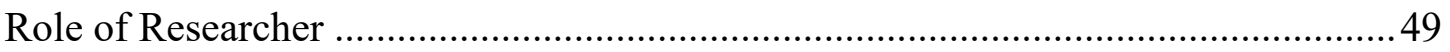

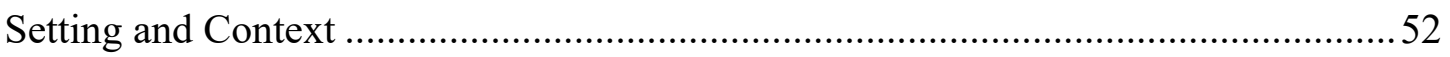

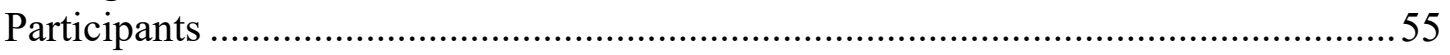

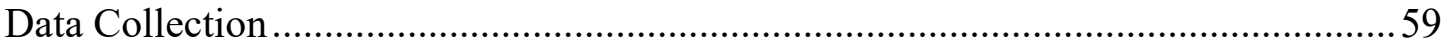

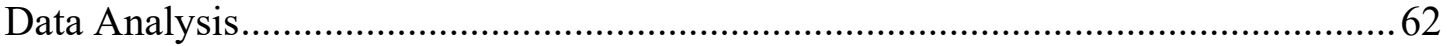

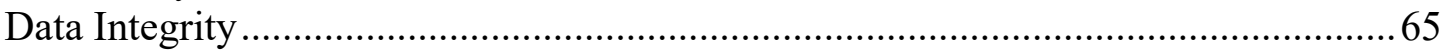

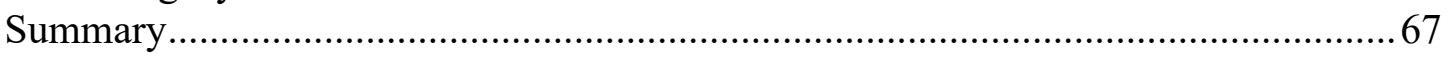

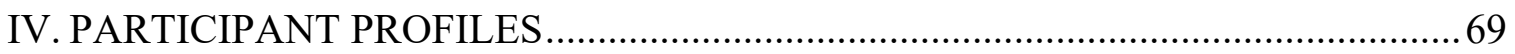

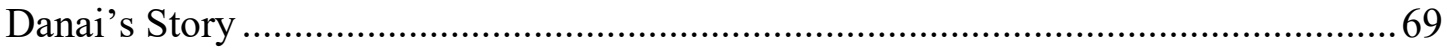

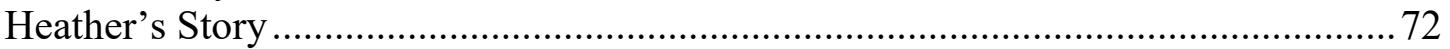

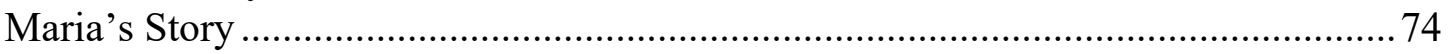

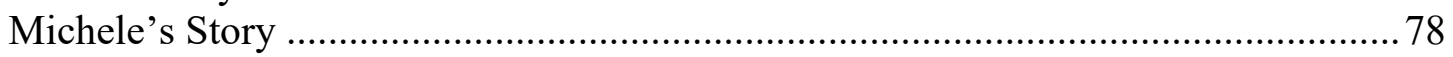

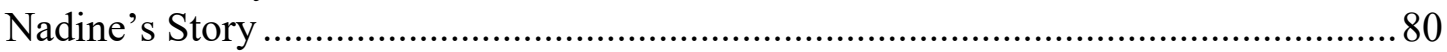

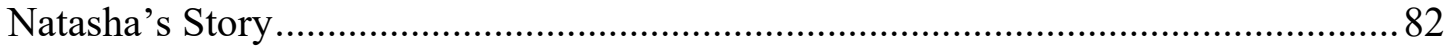

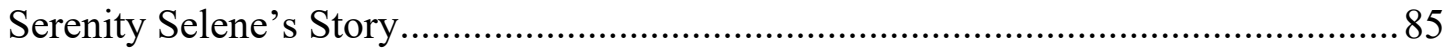

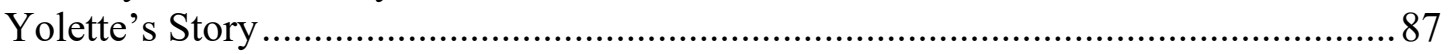

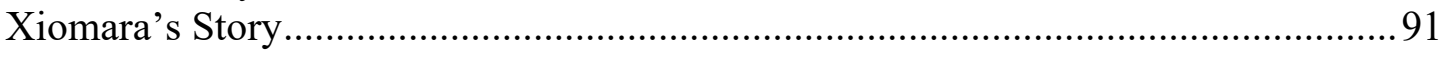

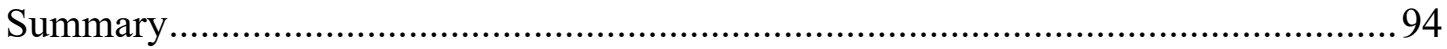




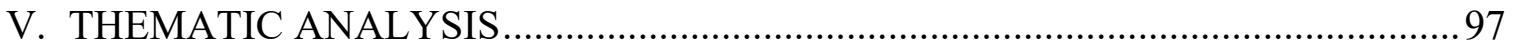

Role of Religion and Family Dynamics ...................................................................98

Understanding of Self through Religion.............................................................99

Understanding of Self through Family Dynamics ................................................. 102

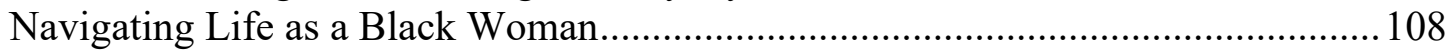

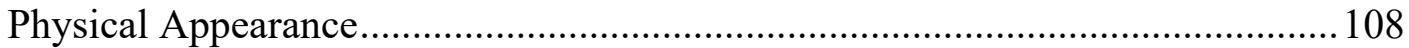

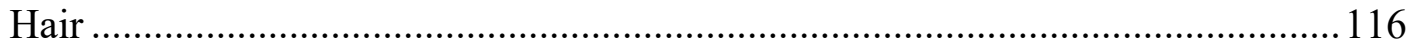

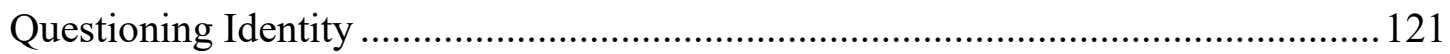

Challenging Prejudicial Racial and Ethnic Norms ............................................... 121

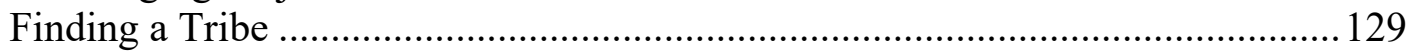

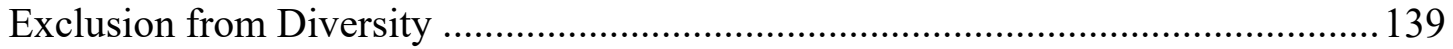

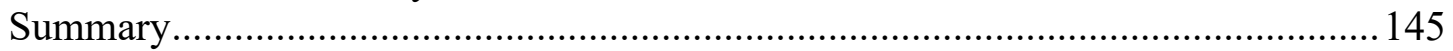

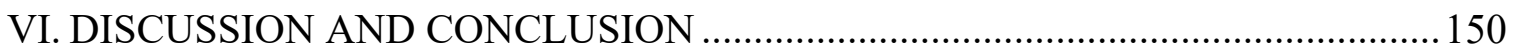

Findings and Interpretations ................................................................................ 152

Religion and Family Dynamics Play a Significant Role for Afro-Caribbean

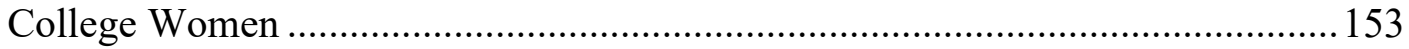

Physical Appearance and Ideas of Race and Gender for Afro-Caribbean

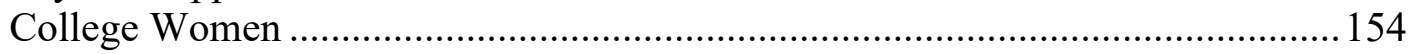

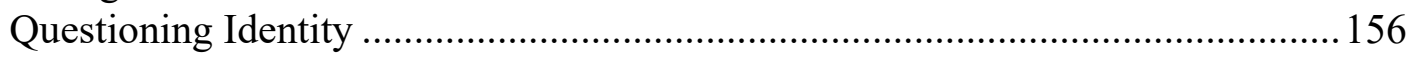

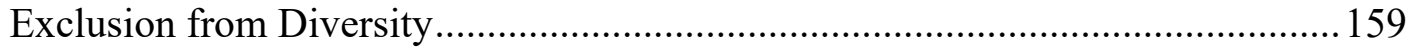

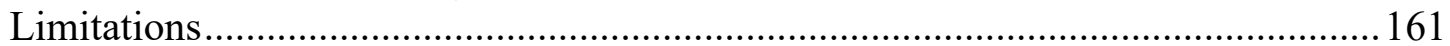

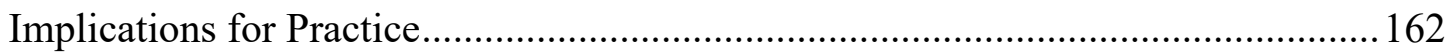

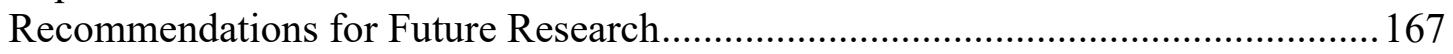

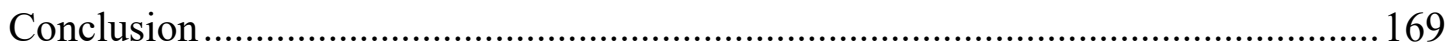

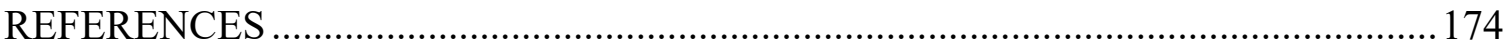

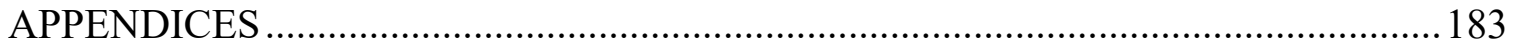

VITA 


\section{CHAPTER I}

\section{INTRODUCTION}

The future of higher education in the United States may well depend on our ability to address the needs of the immigrant student or the student who is a child of immigrants (Conway, 2009, p. 321).

Institutions of higher education continue to admit diverse students each year. As diversity changes, it is fascinating to see the evolution of the Black student population across higher education institutions in the U.S. During the 2004 Harvard University Black Alumni Reunion, Lani Guinier, Harvard law professor, and Henry Louis Gates Jr., Chair of the Harvard African and African American Studies Department, applauded the increase in the number of Black students at Harvard but questioned the makeup of the group (Rimer \& Arenson, 2004). The professors both revealed that out of the 530 Black students attending Harvard in 2004, two-thirds were West Indian, African immigrants, or the children of these immigrants. Their revelation shed light on what some higher education professionals have been noticing on their campuses for quite some time: Black enrollment is increasing, but it is increasingly less African American. Thus, the distinction in Black enrollment warrants further exploration.

Despite research that explores diverse populations on campus, there continues to be a gap in what is known about Afro-Caribbean college students. Many existing studies focus on race, overlooking the importance of ethnicity in the lives of students (JohnstonGuerrero, 2016, p. 44). I found no existing research that examines how race and ethnicity for second-generation Afro-Caribbean students are constructed and how that affects their sense of belonging. In particular, the physical features of Black Caribbean people lead to a status of invisibility that ignores their distinct needs (Guy, 2002). In other words, the 
shared racial identity of African American and Afro-Caribbean people often ignores the ethnic identity of Afro-Caribbeans. Current scholarship often depicts Black students as a monolithic group, which thus fails to explore the diversity of Black Americans (George Mwangi, 2014; George Mwangi \& Fries-Britt, 2015). Additionally, existing studies about Black ethnic groups have mostly grouped all immigrants, even though purporting findings on Black people from Africa, Latin America, the Caribbean, and other regions of the African Diaspora. The practice of reducing these ethnic groups into one monolithic category ignores the unique needs of each of these populations.

Exploring the experiences of second-generation Afro-Caribbean college women is important to learn more about Black women on college campuses. My dissertation examines how their racial and ethnic identities and gender play a role in their experiences and inform how they navigate campus. The larger goal of my study is to expand the literature about Black women and illuminate the within-group differences that exist within the Black population. Chapter I will present the importance of the topic, explain the purpose of the study, detail the research questions, and will define key terms related to my dissertation study.

\section{Statement of the Research Problem}

"Americans have generally paid a great deal of attention to ethnic differences within the white race, while treating Black Americans as if they were both a racial and an ethnic group with no intraracial differences" (Waters, 1999, p. 45). It is estimated that first- or second-generation Americans make up 13 percent of Blacks; however, they account for 35 percent and 24 percent of the Black students at the most elite U.S. colleges and universities and at the least selective schools, respectively (Kent, 2007). Despite this 
diversity among Black students, little research has been conducted to illuminate the heterogeneity of Black students.

Griffin and McIntosh (2015) stated that there is a lack of research specifically addressing Afro-Caribbean students and their experiences in higher education. Higher education institutions are far behind assessing the experiences and successes of ethnic minority students (Singh, 1990). Further complicating the issue is the fact that universities do not capture or track the ethnicities of their students (Singh, 1990). The omission of ethnicities makes it difficult to understand the ethnic makeup of institutions of higher education. Nonetheless, research has shown that some ethnic groups attach a high value to education and view education as a vehicle for future success (Singh, 1990). Research has contradicted ideas that Black Americans do not value education (Cooper, 2007). However, Singh (1990) points out that much like Black Americans, Caribbean families see education as a significant role in increasing social status. As such, parents encourage students to attend college in hopes of attaining recognition in, and pride of, their community. Naturally, the parents of second-generation Afro-Caribbean students and their community are aspects that can affect how they view and experience their time in college.

According to Carter (2006), "racial or ethnic minority students have a higher probability of leaving post-secondary education than ethnic majority students" (p. 33). Furthermore, minority student persistence is linked to debt, employment, and family demands (Woodfield, 2017). Studying how second-generation Afro-Caribbean students construct their racial and ethnic identity is crucial to gaining an understanding of their 
experience as well as any obstacles that might prevent them from being successful in higher education.

Waters (1999) showed that there are differences in how first-generation and second-generation Afro-Caribbean individuals view themselves racially and ethnically (Waters, 1999). This research points out that the ways second-generation immigrants experience racial discrimination influence their understanding of their racial and ethnic identities (Waters, 1999). First-generation Afro-Caribbeans, especially, generally view themselves transnationally or ethnically, while second-generation Afro-Caribbeans have three paths ahead of them - seeing themselves as American, ethnic American, or Immigrant (Waters, 1999). Moreover, Waters (1999) found that there were differences between women and men with women aligning themselves with more of an ethnic American identification.

For these reasons, I focus my dissertation study on undergraduate women. Women continue to be represented highly on college campuses; however, none of the existing research on second-generation Afro-Caribbean students has focused on women's experiences - at least explicitly. Porter (2017) argues that little is known about Black women students, which also means that even less is known about Afro-Caribbean women students. Existing research on Black college women show they face a number of obstacles from stereotypes, isolation, and lack of support (Shaw, 2017). Additionally, research has pointed to the success of Black women, which may result in institutions of higher education, ignoring the possibly unique needs of Black college women. Phinney (1996) argued that "The importance and centrality of ethnic identity are strongly associated with one's situation and experiences within society" (p. 923). The same could 
be said about the experiences of Afro-Caribbean women in college, however more research needs to be conducted to determine the centrality of ethnic identity within this group.

As the higher education student demographic continues to diversify every year, it is imperative for higher education faculty and practitioners to learn more about these new groups of students. Increased knowledge of these ethnically diverse populations will help institutions to support these students better. Various researchers (George Mwangi \& Fries-Britt, 2015; George Mwangi, 2014; Fries-Britt, George Mwangi, \& Peralta, 2014) studied the topic of Afro-Caribbean college students, but more can be done to explore the subject. Of the existing studies that examine the experiences of either first- or secondgeneration ethnic-minority students, they have done so within the context of Predominantly White Institutions (PWIs) or Historically Black Colleges and Universities (HBCUs). In contrast, my study plans to explore second-generation Afro-Caribbean women attending Florida International University, which is a Hispanic Serving Institution (HSI).

\section{Purpose of Study}

The purpose of my study was to explore the experiences of second-generation Afro-Caribbean students to discover how student affairs professionals, higher education administrators, and faculty can better understand and support these students. Specifically, my study explores how second-generation Afro-Caribbean college women make meaning of their race, ethnicity, and gender.

Meaning making impacts the ways in which we navigate the world. Kegan (1982) states "meaning is in its origins, a physical activity (grasping, seeing), a social activity (it 
requires another), a survival activity (in doing it, we live)" (p. 19). Within the aforementioned context, meaning is provided and dependent on the individual. The meaning that is assigned to an object, event, or feeling develops on the basis of what is occurring or has occurred to the person and who or what they encounter. Moreover, Chen (2001) shared "life experience generates and enriches meanings, while meanings provide explanation and guidance for the experience" (p. 317). Within my study, the women's meanings were shaped by their past experiences and present negotiations through life circumstances. Therefore, meanings are always evolving. Meanings are not static because of social contexts that continuously shape how they make meaning of their race, ethnicity, and gender. Specifically to my dissertation, I concentrate on episodes within my participants' lives that relate to race, ethnicity, and gender and how those play a role in the way second-generation Afro-Caribbean women navigate campus.

Second-generation Afro-Caribbean college women have unique backgrounds and experiences when compared to African American students whose background involves generations living in the United States (U.S.). My research was conducted through a qualitative study at Florida International University (FIU). My dissertation study utilizes a case study approach following the framework of Merriam (1998). Merriam (1998) defines qualitative case studies as "an intensive, holistic description and analysis of a bounded phenomenon" (p. 12). My study is bounded by location, which is FIU. Semistructured interviews were utilized to explore the research question. Data were collected through in-depth interviews to gain an understanding of the experiences of secondgeneration Afro-Caribbean college women. 
Kent (2007) states that "Blacks from Spanish-speaking countries often are not included in the 'Afro-Caribbean' term" (p. 5). Furthermore, he shared that, "about 8 percent of black immigrants are from Spanish speaking countries...the vast majority [of these immigrants] do not self-identify as Black" (p. 8). Despite Kent's assertions, I chose to include students from Spanish speaking countries in my dissertation. Since my study focused on second-generation Afro-Caribbean women, I believed that it was important to include students from all Caribbean countries who identify as Afro-Caribbean. As a result, it was important to include anyone from Spanish speaking countries who claimed the Afro-Caribbean identity. Despite Kent's thoughts, I believe that the inclusion of students from Spanish speaking countries provide diverse and rich data to explore the topic of race, ethnicity, and gender.

\section{Research Questions}

My study aimed to provide insight into the experiences of second-generation Afro-Caribbean college students. My research study answers the following research question:

How do second-generation Afro-Caribbean college women at FIU experience and make meaning of their race, ethnicity, and gender?

\section{Statement of Significance}

The expansion of literature of what is known about Black college women is extremely important. Current unrest as a result of the culmination of recent deaths of unarmed Black people by police officers or surrogates has called for police reform and the dismantling of systemic racism. The killing of Black people is not new as Black lives

have been terrorized by police officers and white vigilantes throughout the history of the 
United States. The recent deaths of George Floyd, Breonna Taylor, Ahmaud Aubery, and Rayshard Brooks along with the initial decision to not charge the individuals involved sparked nationwide and international Black Lives Matter protests to bring awareness of state sanctioned violence of Black people as well as systematic racism that persists in the U.S. As a result, Black college students are challenging institutions who have expressed support for Black lives, yet these students have voiced feeling othered and a general lack of support by universities. My study provides insight into the experiences of Black women and offers recommendations for higher education leadership, faculty, and staff.

My dissertation study found that my participants' race, ethnicity, and gender were influenced by their religion and family dynamics, their physical appearance, challenges to their identity, and exclusion from campus diversity. Findings uncovered that their sense of self was constantly evolving, depending on the participants' experience. However, early childhood experiences within the home and in school helped form my participants' ideas of self-identification and continued to play a role in present day situations. Additionally, my study's findings surpass the institution to encompass the community and relationships. My dissertation illuminates the microaggressions, racism, and discrimination that second-generation Afro-Caribbean college women experience. Particularly, my study shows how the unique cultural makeup of Miami plays into the understanding of the experiences of second-generation Afro-Caribbean college women. Furthermore, my dissertation study sheds light on the ways in which second-generation Afro-Caribbean college women build community when they experience challenges to their racial and ethnic identifications. 
Patton and Croom (2007) state, "beyond the numerical conversation, little is known about how Black women access college, what shapes their college choice, which experiences and opportunities contribute to their retention" (p. 3). The purpose of my research was to expand the scholarship of Black women to include second-generation Afro-Caribbean college women. Specifically, my study explores how second-generation Afro-Caribbean college women make meaning of their race, ethnicity, and gender. The exploration of my topic is vital as the demographics of institutions of higher education increase in diversity. My participant stories can influence faculty and practitioners to establish ways to support second-generation Afro-Caribbean college women better and to find best practices to make these students feel welcome on campus. Moreover, my dissertation challenges the assumptions of a monolithic experience among Black college women. My study illuminates the historical ties to racism and sexism that are pervasive in higher education institutions beyond Predominantly White Institutions.

Given the findings of my study, I recommend that higher education leaders can provide diversity and sensitivity training to broaden understandings of Black student populations, educate faculty and staff about the within-group difference and the heterogeneity that exists among Black people, and address anti-Black racism, sexism, and other forms of oppression. Moreover, the need for the establishment of required diversity courses for students that addresses various forms of oppression is apparent. The findings complicate understandings of minority-majority institutions and experiences of Black students within those contexts. As a result, faculty and higher education administrators must continue to find ways to critique operations and behaviors that marginalize Black college women on campuses. 


\section{Delimitations/Assumptions of Study}

It is important to state what my research is not. It is not the purpose of the research to compare Afro-Caribbean to African American students as doing so is divisive and unproductive. While there are cultural differences between both groups, I do not believe that one group is better than the other. My study rejects the tendency to pit African American against Black immigrant groups. The focus of my dissertation study is to shed light on the heterogeneity that exists within the Black population. Additionally, my study adds to the knowledge of the Black student experiences from an AfroCaribbean lens. Second-generation populations have unique experiences which I would like to bring to the forefront. Johnston-Guerrero (2016) expressed similar sentiments when she stated, "students of color who experience discrimination may have to ask whether it was because of their race (due to racism) or ethnicity (due to ethnocentrism), but most likely it is because of both" (p. 47).

To provide focus to my research study, I employed several precautions. My study was limited to women who identify as Black and whose parents were born in the Caribbean. My study was also restricted to undergraduate students. Additionally, my research was limited to the experiences of second-generation Afro-Caribbean college women within the context of FIU.

Every study encompasses assumptions, and my study is no different. By utilizing interviews, it is assumed that individuals are the best source to capture information about the experience being examined. Additionally, it is assumed that the participants will provide honest and accurate information that pertains to the research questions of this 
study. Precautions were executed to ensure the validity and trustworthiness of the data collected and I share in more detail in Chapter 3.

\section{Definitions}

The definitions provided in this section will be utilized throughout this paper.

Afro-Caribbean - persons from non-Spanish-speaking islands in the West Indies

(Massey, Mooney, Torres, \& Charles, 2007). For the purposes of this study, Afro-

Caribbean also includes individuals of African descent who are from anglophone, hispanophone, and francophone Caribbean islands as well as Guyana, Surinam, Panama, and Belize.

African American or Black American - someone who is a citizen of the U.S. and comes from a line of generations of Americans.

Black Immigrant - someone with African descent who was born outside of the U.S. Most of this population is from the continent of Africa, the Caribbean, Latin America, and South America (Kent, 2007).

First-Generation - someone born outside of the U.S.

Generation 1.5 - someone born outside of the U.S. but arriving before the age of 13 (Stebleton, Soria, Huesman, \& Torres, 2014).

Generation 2.5 - someone born in the U.S. with one parent born outside of the U.S. and the other parent born within the U.S. (George Mwangi \& Fries-Britt, 2015).

Native Black - someone who is a citizen of the U.S. and comes from a line of generations of Americans.

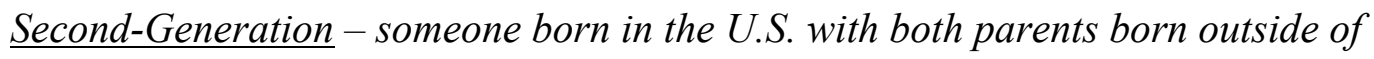
the U.S. 
Tribes - supportive circles where individuals are accepted and can be their authentic selves.

West Indian - Individuals from anglophone, hispanophone, and francophone Caribbean islands in the Caribbean Sea including Guyana, Surinam, Panama, and Belize.

\section{Summary}

Heterogeneity exists within the Black community. However, much of the existing research in higher education portrays Black students as a monolithic group. Moreover, the Black college student population has morphed in recent years to include Black students from Caribbean, African, Latinx, and other backgrounds. Although this student demographic change has taken place, institutions and research continue to treat these groups as one or similar groups. This practice ignores the uniqueness of each group as well as does not account for their specific needs. My dissertation study seeks to expand the scholarship about Black women but, more specifically, second-generation AfroCaribbean college women.

Current data shows that Black college women excel in institutions of higher education. Black women are highly represented on college campuses throughout the country and are graduating at high rates. While the successes of Black women are great, what is missing is information that illuminates their experiences. Interviews could provide insight into what mechanisms second-generation Afro-Caribbean women use to be successful in college.

This dissertation study is guided by the following research question: How do second-generation Afro-Caribbean college women at FIU experience and make meaning 
of their race, ethnicity, and gender? I explored answers to the research question through the use of a case-study using face-to-face semi-structured interviews with nine secondgeneration Afro-Caribbean women attending an HSI. The HSI setting provides a unique context to explore the experiences of Black women who have typically been studied within the PWI or HBCU settings.

This dissertation study consists of six chapters. Chapter II explores the topics of race, ethnicity, and gender. I provide an overview of the literature that currently exists on second-generation college students, which includes a variety of populations including African, Caribbean, and Latin America. Additionally, I provide a brief overview of the history of migration from the Caribbean. Limited literature exists on second-generation Afro-Caribbean women, however, what currently exists is interwoven into the chapter to provide insight about this group. 


\section{CHAPTER II}

\section{LITERATURE REVIEW}

The United States Black population has never been homogeneous and the rise in the number of Black immigrants with distinct and historically specific experiences will no doubt affect the nature of research about Black populations (Pierre, 2004, p. 161).

Existing research often depicts Black students as a monolithic group, which does not account for the within-group differences that exist. Ignoring the within-group differences overlooks how the many characteristics, including ethnicity, shape the reality of each person differently (Rogers, 2001). As such, the purpose of this research is to explore how second-generation Afro-Caribbean college women make meaning of their race, ethnicity, and gender. According to Rogers (2001), second-generation populations offer a unique lens to explore as these groups share similar racial identities as African Americans yet have a distinct and independent ethnic identity. Furthermore, Rogers (2001) shares, "they [second-generation populations] are thus black ethnics, with access to both racial and ethnic markers of group identification" (p. 165).

The ultimate goal of my study is to expand the knowledge of second-generation Afro-Caribbean college women to learn more about their experiences through the lens of their race, ethnicity, and gender. This topic is critical, as the demographics of those entering college gates continue to increase in diversity. This literature review will provide a brief history of the Caribbean, an overview of Caribbean migration to the U.S., discuss race in the U.S., Black women, and racial and ethnic identification among AfroCaribbean people. 


\section{Brief History of the Caribbean}

To understand the views and identity of second-generation Afro-Caribbean students, I believe it may be advantageous to provide a brief overview of the history of the Caribbean. The Caribbean islands are rich in history and are diverse in its people, culture, and size. There are various thoughts on what countries are considered part of the Caribbean. Most agree that the Caribbean includes the islands located in the Caribbean Sea in what is called the Greater and Lesser Antilles (Waters, 1999). Some may even include Guyana, Surinam, Panama, and Belize, although those countries are a part of either South America or Central America.

While Spain was the original colonizer of the Caribbean, the power changed at least once for most of the islands between the British, Spain, French, and the Dutch (Waters, 1999). In fact, the island of Tobago has changed colonial rule 22 times (Gilkes, 2007). The change in power brought about multiple wars to the region, which altered the face of the Caribbean. Prior to colonialism, the Caribbean region included cultures which encompassed the Caribs and Arawaks (Gilkes, 2007). Colonialism's ideology of European supremacy led to the denigration of many native cultural traditions.

Furthermore, early settlers brought diseases and conflicts that nearly wiped out the native population. Colonizers also influenced the official languages on the islands. Most of the islands have officially adopted English as a result of British rule, however, some islands, including Haiti, Martinique, and Guadeloupe speak French or Creole. Islands and countries such as Dominica, St. Lucia, and Belize have English as their official language, yet they also speak a version of Creole. Meanwhile, Spain's influence has led to Spanish as the official language of Cuba, Puerto Rico, and the Dominican Republic. 
The Caribbean region shares a history of European colonization, enslavement, and indentured servitude. The multiracial and multiethnic identities of its citizens have been a result of over four million enslaved people brought to the islands from Africa, primarily between the $17^{\text {th }}-19^{\text {th }}$ century) and later with the advent of indentured laborers from East India and China during the mid $19^{\text {th }}$ century (Waters, 1999, p. 21). Enslaved Africans were captured and shipped to the Caribbean, designated chattel and their labor was used to generate unprecedented profits for European wealth generation and capitalist expansion. Chattel slavery has had a profound impact on the region, as described by Waters (1999):

The production of sugar on extensive plantations with imported African slaves, from which European planters reaped enormous profits, dominated the region for centuries and left its mark on the land, the peoples, the culture, and the very form of Caribbean society (p. 20).

As a result of various factors, including demographics and many other militating factors, more enslaved people died compared to those in the U.S (Waters, 1999). Relatedly, there were fewer white slavemasters and slavemistresses relative to the African populations on the islands, which created a distance between colonizers and the activities that took place on the island. Given that reality, colonizers largely retreated from the islands after the abolishment of slavery. The U.S. is different in that African Americans have to navigate the white hegemonic oppression as a numerical minority.

Black individuals are the majority or dominant group on the Caribbean islands, which is markedly different from the U.S. Subsequently, individuals are categorized differently in the Caribbean with the shade of skin color, income, education, access to wealth, and power playing a role in how individuals are organized (Vickerman, 2001). Social order within the Caribbean is dictated primarily by socioeconomic status and 
shade of skin color. Those with lighter skin are conventionally positioned higher on the social ladder than those with darker skin. However, access to money can allow individuals to ascend to higher ranks regardless of their skin color.

The Caribbean's less structured view of race runs in contrast to the strict Black and White dichotomy that exists in the U.S. As a result, Hintzen and Rahier (2003) explained:

When new immigrants of color are perceived and classified or perceived by native-born Americans according to the invented categories of the U.S. racial order, they are commonly labeled as Black or nonwhite, irrespective of the newcomers' own understanding and preferences with regard to race/color and ethnicity (p. 26).

Furthermore, Pierre (2004) states, "upon entering the United States, Black/African immigrants have to negotiate different identities in a context where the social and political constructs of race significantly inform the meanings of culture, national allegiance, gender, and other forms of identification" (p. 157). First-generation Black immigrants are quickly racialized and are limited in terms of the neighborhoods they can choose to live, the job opportunities that are available to them, and their path to social mobility. Undoubtedly, these constraints influenced the experience of first-generation immigrants, however, the goal of my study is to explore how the background of secondgeneration Afro-Caribbean college women inform the way that they experience college campuses and the implications that has on their sense of belonging. Next, I provide some insight into Black Caribbean immigration to the U.S.

\section{History of Black Caribbean Immigration to the U.S.}

It is well documented that the majority of the Black population in the U.S is a result of the Atlantic slave trade in which these individuals arrived in the U.S. 
involuntarily. The Caribbean shares this same horrid history of slavery. Moreover, "emigration has long been a primary means of economic advancement, from the emancipation in 1834 of black slaves in the islands until today" (Bashi Bobb \& Clarke, 2001, p. 222). Initially, emigration was mostly within islands (Bashi Bobb \& Clarke, 2001; Waters, 1999), however, since 1940, emigration has shifted mainly to the United States, United Kingdom, and Canada. Showers Johnson (2008) outlines the arrival of Afro-Caribbeans to the U.S., indicating that some started trickling in since the late nineteenth century, however, the first significant wave took place between the year 1900 and the Great Depression. According to Showers Johnson (2008), in 1900, seven hundred and fourteen Black immigrants were admitted into the U.S., and that number increased to 12,000 by 1924 . Most of those individuals arrived from anglophone islands such as Barbados, Jamaica, and Montserrat to large cities along the eastern coast like New York, Miami, and Boston (Showers Johnson, 2008). Various immigration laws caused the number of new Black immigrants to increase and decrease over the years. The most significant immigration policy to influence the current makeup of Afro-Caribbean individuals in the U.S. is the Hart Celler Act, which passed in 1965, thereby alleviating restrictions placed on Black countries and preferences to European immigrants (Kent, 2007; Pierre, 2004).

The largest group of foreign-born Blacks in the U.S. are Afro-Caribbeans (Rogers, 2006). As of 2013, there were over 1.9 million Black Caribbean (AfroCaribbean) immigrants living in the U.S. (Anderson, 2015). According to Anderson (2015), Black immigrants account for $8.7 \%$ of the Black population in the U.S.; however, the Census Bureau predicts that it will increase to $16.5 \%$ by the year 2060 . The recent 
Black immigrant population growth has been tied to immigration from the continent of Africa, whereas, fifty percent of the Black immigrants are from the Caribbean (Anderson, 2015). Among the top migrating countries were Jamaica at 30 percent, Haiti 25 percent, and Trinidad and Tobago 9 percent (Kent, 2007); Haiti being a francophone country while Jamaica and Trinidad and Tobago being anglophone.

Motives of voluntary Black immigration to the U.S. varied; economic and political reasons influenced most of the Black immigrants from the Caribbean and Latin America (Kent, 2007). Additionally, many were driven to the U.S. to seek out educational and employment opportunities that are not available in their home countries (Kent, 2007) precisely because of the very legacies of colonialism and contemporary forms of neocolonialism which create conditions of underdevelopment and lack of access. Additionally, "scarce resources, overpopulation, high unemployment and underemployment, limited opportunities for advancement- these have long spurred West Indians to look abroad for economic security and better job prospects, improved living standards, and ways to get ahead" (Foner, 2001, p. 4).

Upon arriving in the U.S., Caribbean immigrants sought connection to a church as a primary action. According to Forde (2002), "in the Caribbean, perhaps more so than in the United States, spirituality in its organized form was regarded as an essence of civility and social bearing" (p. 87). As a result, earlier Caribbean immigrants adopted an affiliation to established European religions as well as adhering to a consistent churchgoing philosophy. Waters (1999) found that religion was the most important aspect in the lives of her research participants, with many finding supportive networks in ethnic churches. Connection with a church helped Afro-Caribbean people to increase their sense 
of ethnic identification and belonging (Waters, 1999). Fellowship with others from Caribbean backgrounds help Afro-Caribbeans to build community and assist with the new struggles of navigating a racialized country.

Chatters, Taylor, Jackson, and Lincoln (2008) also found that religion played an important role among Afro-Caribbean people. Chatters et al. (2008) explored religious coping, such as praying and seeking God for guidance and support among African Americans, Afro-Caribbean, and White non-Hispanic populations when dealing with difficulties in life. The authors share that Black Americans are likely to be Baptist, however Afro-Caribbeans are mostly Catholics, Seventh Day Adventists, and Episcopalians (Chatters et al., 2008). Chatters et al. (2008) found that Afro-Caribbean individuals from Haiti were more likely to use religious coping methods when compared to those from Jamaica. Furthermore, they found that Afro-Caribbeans who have lived in the U.S for more than 11 years reported more religious coping when compared to secondgeneration Afro-Caribbeans. Women were also more likely to engage in religious coping when compared to men.

Aligning with religion as well as education was a means to position oneself and family with those in high society. As shared by Forde (2002), "it [education] was the only vehicle that allowed one to move up freely from the lowest station to the highest, unencumbered" (p. 75). The United States was regarded as a destination with limitless potential since opportunities for advanced education were limited in the Caribbean. One could get ahead with determination and hard work, which continues to be a stronghold of Caribbean populations today. As such, the Caribbean population generally view education as a vehicle toward social mobility and encourage their children to pursue and 
succeed in education. These thoughts are tied to the views of first-generation AfroCaribbean individuals and do not disclose how they impact the beliefs and actions of second-generation populations. My research provides some insight into how the personal stories that led to their parents' migration, their religion, and their parents' reaction to the racialized country has implications for the second-generation Afro-Caribbean women population.

\section{Race and Racism in the U.S.}

To fully explore the experiences of second-generation Afro-Caribbean women, it is necessary to understand race within the context of the United States of America. I briefly explore the topic of race and racism in the U.S. in this section. Race is widely understood to be a social construct. Historians have detailed the early origins of race and linked it to before the Atlantic Slave Trade. However, the construct of race was used as a means to support African slavery by inventing a discourse of Black people as intrinsically and essentially inferior to whites, and therefore subhuman and designated chattel (Coates, 2017; Gates, 2019).

Before the Atlantic Slave Trade, enslaved individuals came from all backgrounds and were not restricted to those of African descent. The nature and characteristics of those of African descent were crafted to be viewed as beasts, unintelligent, uncivilized, and in need of salvation. This mischaracterization was achieved through a series of deliberate events that included the manipulation of the bible and scholarly works of academicians. Holding African descent individuals in captivity was seen as a mechanism towards their civilization and redemption. At the same time, within the slavery system, Black people were viewed and treated as property. The offspring of enslaved Black 
women were by law, designated property even if the children's father was "free". As a result, Black women were forced to reproduce babies to increase the profitability of slave trade. Stories of babies ripped from the hands of their mothers to be sold were commonplace. Moreover, enslaved Black women exercised a tenuous control over their bodies; physical and psychological torture, including rape, was commonplace and customary (Kendi, 2016; Sublette \& Sublette, 2015).

The story of Sara Baartman, a young Khoisan woman, is one that illustrates the objectification of the Black woman's body. Sara Baartman's body was rightfully returned to South Africa in 2002 after being taken in 1810 to London then France whereas Osha (2008) explains, "her body was commodified, fetishized, and exoticized" (p. 80). In the case of Baartman, her body was not her own and rendered her not to be regarded as human. Additionally, her body was not hers to control but to be controlled by those in power. Furthering this idea are the circumstances of her body's return. After France refused to return her body to South Africa, a battle ensued between the two that resulted in an unprecedented drafting of a law that detailed the return of her remains. These terms were ironic for a body that did not rightfully belong to them, which further illustrates the power over Black bodies and specifically Black women bodies. All of these acts have implications for how Black women are regarded in the present day. Specifically, these actions were a concerted effort to devalue Black womanhood through their perpetual sexual exploitation (Hooks, 2014). Black women are seen as subhuman; as objects that can be discarded. These oppressive views can negatively impact the ways that Black women think, act, and their self-esteem. 
The enslavement of millions of African descendants in the U.S. took place between 1619 and 1865 . Through years of debates and one of the deadliest wars, President Lincoln emancipated enslaved African Americans. Following the emancipation of enslaved African Americans was the swift action of former confederate states to apply discriminatory acts to limit and disenfranchise the newly freed population (Blackmon, 2008; Gates, 2019). "Black codes" were introduced to restrict African Americans through effectively painting the group as innately lazy and oversexualized (Kendi, 2016).

Emancipation also brought about a series of propaganda that was utilized and executed to promote stereotypes of African Americans effectively. Stereotypes emphasize false beliefs associated with a group of people that media and individuals mass-produce (Yosso, 2006). These narratives "portray working class people and People of Color as irresponsible and less intelligent while depicting White middle- and upperclass people as just the opposite" (Yosso, 2006, p. 9). Blackmon (2008) explains that stereotypes were created because "the human livestock on which they had relied for generations now threatened to rule in their place" (p. 14). Stereotypes were used as a way to perpetuate racist ideas as a means to discriminate against African Americans among other groups. Additionally, stereotypes were used to limit political gains from African Americans. Common stereotypes of Black individuals include lazy, unambitious, criminals, unintelligent, poor, and inferior. As a result, those who attain advanced education and successful careers are regarded by whites as exceptional. Exceptionalism does not allow for a critique of systemic power structures as these examples are used to challenge ideas of the existence of racism. While I outline the ways in which racism 
impacted and continue to impact general society, societal issues tend to reproduce themselves in higher education, which I will detail in the next section.

\section{Race and Racism in Higher Education}

During slavery, African Americans were systematically kept from education as denying literacy was believed to be an avenue to keep the enslaved population subservient (Willie, 2003). There were laws enacted that prohibited African Americans from gaining literacy. Following the emancipation of enslaved African Americans, segregation and Jim Crow laws were issued to attempt to economically and politically disenfranchise African Americans. The time period also promoted separate colleges and universities, now known as Historically Black Colleges and Universities (HBCUs), for African Americans. While private HBCUs were established either before or after the abolishment of slavery, public HBCUs did not exist until the Second Morrill Act of 1890. Redd (1998) explained that the Second Morrill Act included the following requirement:

All states that maintained dual segregated higher education systems for white and African American students to provide at least one land-grant college for African Americans, and the funding used to establish and maintain the black college had to be equal to that of the white college ( $\mathrm{p}$. $34)$.

Despite the mandate for equal funding, HBCUs were and continue to be underfunded and under-resourced. Even still, HBCUs have played a pivotal role in educating what would become the Black elite in the early twentieth century.

It is estimated that two hundred African Americans graduated between 1865 and 1895 , but the number had increased to over 2,500 by 1900 (Willie, 2003). Stereotypes and other racist tactics systematically limited African Americans' access to institutions of higher education. African Americans were thought to be inferior to whites in all ways, 
especially in terms of intelligence when it related to education. Although the number of college-educated African Americans increased, racial characteristics overrode educational attainment. Vestiges of slavery and racism can be seen in the underrepresentation of Black college students attending selective four-year institutions (Allen, McLewis, Jones, \& Harris, 2018). This conversation is part of a larger discussion of whether or not higher education is a privilege or right. In fact, Allen, McLewis, Jones, \& Harris (2018) point out that African American college students are highly represented in community colleges and for-profit institutions, which is not necessarily tied to social mobility.

Specific to my dissertation study, African American and Black students, express instances of stereotyping, discrimination, and racism on college campuses. One of the ideologies that advanced racist stereotypes was the eugenics movement. Pseudo-scholars within the eugenics movement professed that individuals who were not white were deemed inferior in every way, including intelligence. These white supremacist beliefs which were formalized in the late $19^{\text {th }}$ century and held great sway through WWII, have, as we can plainly see today, never fully gone away, nor have the stereotypes which work to give them legitimacy. Consequently, Black students have been known to experience both stereotype threat and stereotype lift. Stereotype threat is where performance and self-esteem are impacted as a result of perceived negative views about one's ethnic group's abilities (Deaux, Bikmen, Gilkes, Ventuneac, Joseph, Payne, \& Steele, 2007). Stereotype lift occurs when performance is improved in light of negative stereotypes about one's ethnic group (as cited by Deaux et al., 2007). The ideas of the eugenic movement were used as a foundation to establish standardized tests such as the Scholastic 
Achievement Test (SAT) which established certain criteria by which to deem those appropriate and intelligent enough for college admission (Kendi, 2016). Thus, standardized tests were developed with intentional bias that restricted Black students from successfully passing the exam. The result was a limited number of Black students were admitted to white colleges. Today, the SAT's prediction for college readiness and student success has been challenged and deemed to have built-in cultural biases, however, even today the exam remains as the primary avenue for college entry (Fleming \& Garcia, 1998).

Furthermore, the early twentieth century brought about court cases to delegitimize the separate but equal edict that ruled the south. Most notably is the Brown v. Board of Education of Topeka U.S. Supreme Court ruling, which determined that separate but equal was unconstitutional. One of the previous decisions to lay the foundation for the Brown v. Board of Education of Topeka case was Sweatt v. Painter. In Sweatt v. Painter, the University of Texas Law School was forced to admit Sweatt, who was initially denied admission because of his race. The decision was ruled in Sweatt's favor because of the existing Black law school's unequal state when compared to the University of Texas Law School. Despite the ruling, Southern schools were slow to desegregate. Ultimately, it took the passing of the Civil Rights Act of 1964 to witness changes in the makeup of higher education. The African American college student population increased as a result of the Civil Rights Act of 1964, which prohibited discrimination based on race, color, gender, and national origin for institutions that received federal funds (Willie, 2003).

Despite the increase in Black students on college campuses, racism continues to persist. Racism plays a role in the climate of college campuses, which plagued campuses 
in the sixties and seventies. Hurtado, Milem, Clayton-Pedersen, and Allen (1998) provide a framework to understand college campus racial climates. They outline four aspects that incorporate a campus's climate, which include the institution's historical legacy of inclusion or exclusion, its structural diversity, its psychological climate, and its behavioral climate.

The institution's historical legacy of inclusion or exclusion can be understood in terms of the history that preceded desegregation and of how the institution responded to the desegregation mandate. The legacy of exclusion can have an impact on present-day practices. The dimension of structural diversity refers to the actual composition of racial/ethnic students on campus. Hurtado et al. (1998) state that while it is essential to increase the diversity on campus, it is crucial that these populations feel supported and attention is paid to educate the community on topics related to diversity. The psychological dimension of climate relates to how students view campus relations and their perceptions of discrimination. Intentional efforts should be made to address bias toward creating a more welcoming campus for all. Finally, behavioral climate involves the opportunities that exist for students of different backgrounds to engage with one another. All of these factors impact how students view college campuses. As such, higher education institutions must examine their climates and focus on creating a welcoming environment for all students. While Hurtado and her colleagues shed light on the campus climates, their study's findings were specific to predominantly white institutions. My dissertation fills the gap that exists in examining the climates within HSIs and what that means for Black college women attending those institutions. 


\section{Black Women}

America's understanding of Black women has been influenced by colonialism, imperialism, racism, and sexism. From the time the first enslaved Africans were captured, white colonizers began the active process of dehumanizing the Black women (Hooks, 2014). The women were brutally raped by their white captures from the time they were stolen from Africa and throughout their time enslaved in the U.S. The character of Black women were crafted as sexual beasts who the white slave masters were incapable of resisting. Hooks (2014) explains:

White women and men justified the sexual exploitation of enslaved black women by arguing that they were the initiators of sexual relationships with men. From such thinking emerged the stereotype of black women as sexual savages, and in sexist terms a sexual savage, a non-human, an animal cannot be raped (p. 52).

This characterization was used to justify the offspring that were produced through the rape of enslaved Black women by white slave masters. Effectively, the depiction of Black women created contempt from the white slave mistresses as well as fostered an overall mistrust of Black women. Black women were villainized as evil beasts that took advantage of vulnerable white men. While Black women were labeled as whores, white women were depicted as the definition of womanhood - pure, delicate, and in need of protection (Hooks, 2014). Born was the oversexualized stereotype that continues to plague Black women today.

In addition to the oversexualized stereotype, Black women have been represented and characterized as either mammies, jezebels, angry Black women, and breeder women of slavery (Collins, 1990; Hooks, 2014). These labels and characterizations of Black women date back to slavery where white colonizers and slavers were engaged in 
subjugating Black women. These representations worked to oppress Black women by furthering and working to justify their objectification. Jezebels are characterized as hypersexual beings who are out of control. The messages of their hypersexual tendencies are used to justify sexual misconduct as it is not believed that these women could be raped. Furthermore, James Alexander (2014) shares "this trend leads to the black female subject being denied ownership of her body; meanwhile, her worth defined by the profits that can be had from her body, even as the body's worthlessness, its vulgarity, is underscored" (p. 11). The mammy image is portrayed in terms of being unattractive and non-feminine. This image, if internalized by Black women, can manifest in terms of not viewing yourself as beautiful. Similarly, media can further these messages by continuously producing representations of beauty that are the opposite of Black women. The angry Black woman image is usually depicted as aggressive, intimidating, and loud. This perpetual depiction leads Black women to continually think about how others perceive them in an attempt to avoid being viewed as an angry Black woman. As shared by Collins (1990), "these controlling images are designed to make racism, sexism, and poverty appear to be natural, normal, and an inevitable part of everyday life" (p. 68). Morgan \& Bennett (2006) further explains the view of angry Black women:

The stereotype of the "Angry Black Woman" is a resilient one in American society. It is both autonomous and parasitic; it easily attaches itself to the more widely discussed stereotypes of the whore and the mammy, making women who embody those stereotypes appear, if possible, even more pathological. In fact, the stereotype of the angry, mean Black woman goes unnamed not because it is insignificant, but because it is considered an essential characteristic of Black femininity regardless of the other stereotypical roles a Black woman may be accused of occupying. These stereotypes are more than representations; they are representations that shape realities (p. 490). 
In other words, if a Black woman is angry for any reason, it is viewed as an inevitable occurrence. As a concept, it holds Black women hostage as they navigate how they will respond to injustices they encounter in their lives. As noted by Harris-Perry (2011), "these assumptions shape the social world that black women must accommodate or resist in an effort to preserve their authentic selves and to secure recognition as citizens" (p. 5).

Likewise, notions of strong Black women are also perpetuated and are often detrimental to Black women. The suggestion is that Black women can handle more than the average woman. This idea is related to the racist beliefs of Black women being more animalistic than human. Specifically related to my research topic, strong Black women narratives may lead others to believe that Black women are superhuman and not in need of support. These thoughts can manifest themselves on college campuses, where the Black woman population can be rendered invisible and self-sufficient. Existing studies speak to the success of Black college women yet do not interrogate the racist and patriarch systems of oppression that they maneuver (Patton \& Croom, 2017).

Corbin, Smith, and Garcia (2018) explored how stereotypes and negative media concerning Black women impacted eleven college women attending predominantly white institutions. They found that the women constantly found themselves responding to microaggressions by battling both the strong Black woman and angry Black woman tropes that resulted in experiencing racial battle fatigue. Additionally, they found that the media's portrayal of angry Black women played a significant and negative role in the lives of Black college women. Black college women actively challenge the angry Black woman label which in turn promotes the strong Black woman theory. The women in their study were acutely aware of the angry Black woman stereotype. They internally thought 
through various responses and subsequent scenarios to negate being labeled as an angry Black woman.

Furthermore, the authors found that the women negotiated racial battle fatigue by being expected to be the experts on all things related to Black culture, facing limiting views of what it means to be a Black woman, and being forced to adhere to respectability politics in the face of challenges. While this study provided an important glimpse into how Black college women navigate the angry Black woman and strong Black woman labels, it does so by examining their experiences within the context of predominantly white institutions. In contrast, my dissertation study seeks to expand knowledge by examining Black college women experiences within an HSI. More specifically, I provide insight into a subgroup of Black women - second-generation Afro-Caribbean college women, which is a group that has not been explicitly explored in higher education. It is important to know if the experiences shared above are constant with second-generation Afro-Caribbean college women which would provide insight into the stereotypical notions governing Black women.

According to Collins (1990), the experience of Black women can be understood through the historical practice of exploiting Black women's labor, denying Black women's rights reserved for white men, and controlling the images of Black women. Black women have been hyper-visible through their features, including their skin and hair. There are constant messages that share that Black women should tame themselves in all aspects of their lives. Black women's voices and hair are all aspects of being that seem to take up too much space. Although the hyper-visibility exists, Black women are noticeably absent in the media. Furthermore, "as members of a stigmatized group, 
African American women lack opportunities for accurate, affirming recognition of the self and yet must contend with hyper visibility imposed by their lower social status" (Harris-Perry, 2011, p. 39).

Most of the first Black land grant institutions consisted of mostly women, and their training was based in education (Perkins, 2017). Existing studies show their struggles and challenges on college campuses were dealt with through the support of their family and through building personal support groups (Winkle-Wagner, 2009). These struggles included alienation and marginalization in the college setting.

Porter (2017) argued that little is known about Black college women, which implies that even less is known about Afro-Caribbean college women. Patton \& Croom (2017) state that Black college women experiences are rarely shared, and when they are, they are presented in terms of outcomes or are typically buried within the stories of diverse student populations or combined with the stories of Black men. Davies (2003) supported this idea by sharing that the act of exclusion of Black women and their stories is a form of violence on the population. In her book detailing her journey to Black Feminism, Cooper (2018) furthers Davies's thoughts by sharing that Black women are both hyper-visible and invisible. No need to look further for an example than the feminist movement of the 1960s. Within this context, Black women were a part of the revolution, although tensions grew as they saw that the larger feminist movement, neither did the larger Civil Rights movement, meet their needs for gender equality. They found that women's liberation did not make room for Black women or women of color. What was ignored is the unique position of Black women to be susceptible to both racism and sexism because of their intersecting identities. This position situates them uniquely to 
view the world both as Black and as a woman. The conflict within the larger feminist movement made way for a collective of Black feminists to split from the main feminist group to broaden the scope of politics (The Combahee River Collective, 2015). They saw it as their focus to combat the interlocking systems of oppression that impact all women of color.

Despite oppressive structures, Black women are highly represented on college campuses. Sixty-four percent of bachelor's degrees awarded to Black students during the 2015-2016 academic year were to Black women (U.S. Department of Education, National Center for Education Statistics, 2017). As a result of their success in terms of graduation rates, Black women are often overlooked as a population in need of support. In fact, research has centered on the need to save Black men because of the challenging environments they come from prior to attending college campuses. What is often ignored is that most Black women come from those same environments. Why does this not translate to Black women requiring the same attention? Stewart (2017) highlighted the tendency for existing research of Black women to highlight their resilience:

Black women in college have been incredibly resilient, defying decades of hostile campus climates and atrophied social lives by focusing on their goals and finding support faculty and staff mentors. However, it cannot be ignored that this resilience has been provoked by racism, not by the inherent qualities of Black womanhood (p. 41).

Additionally, Stewart argued that concentrating on resilience, shifts the focus away from higher education institutions' deconstruction of racist behaviors. Focusing on resilience also ignores the challenges that Black women face on college campuses. For example, Shahid, Nelson, and Cardemil (2017) found that Black women's experience with 
negative campus environments has impacted their level of stress and mental health. Stress and mental health are invisible factors that can influence student success.

As previously shared, more could be done to explore the experiences of secondgeneration Afro-Caribbean women. The one article that I was able to find was from Griffin, George Mwangi, \& Patterson (2017), which explored the experiences of secondgeneration Black women transitioning into college. The research findings indicated that the ethnic backgrounds of these women, combined with their race and gender, worked in concert to shape their experiences. The intersection of their multiple identities influenced their interaction with faculty and peers as they negotiated how others perceived them. However, the researchers found that these women experienced motivation that linked to cultural and family expectations, which is different from the research of Black Americans that links motivation to disproving stereotypes (Fries-Britt \& Griffin, 2007). While Griffin et al. (2017) contribute to the understanding of Black women with immigrant backgrounds, it is only one study that examines their experiences. Additionally, this study does not focus specifically on the experiences of Afro-Caribbean women, which is the intent of my study as I hope to enlarge the general body of literature.

\section{Racial and Ethnicity Identification of Afro-Caribbeans}

An important area to explore with second-generation Afro-Caribbean women is the concept surrounding their racial and ethnic identification. Race is socially constructed and is based primarily on physical appearance, while ethnicity is based on national origin, language, food, and other cultural characteristics (Butterfield, 2004). Social identity is that which is constructed based on being a part of or being excluded from another group (Deaux, 1993). In his book, Identity: Youth and Crisis, Erikson (1968) spoke to how the 
historical aspect of an individual impacted the present identity. Deaux (1993) linked the importance of meaning an individual places on identity and views personal and social identity as interrelated. Additionally, Waters (1999) stated, "the construction and adoption of a racial and ethnic social identity represent an ongoing negotiation between self and other identification, which reflects the meanings attached to possible identities and boundaries" (p. 46). To Waters and others, it is the meaning that an individual places on the identity that operationalizes it.

According to Rumbaut (1996), the ethnic identity formation of youth is dependent on how an individual views themselves in comparison to those in close proximity to them. Specifically, claiming an ethnic identification is tied to experiencing discrimination. For example, if an individual experienced discrimination, they were more likely to claim an ethnic identity as opposed to an American one. Additionally, discrimination was associated with parent-child conflict and was more apt to be tied to women. Rumbaut described the conflict between parent and child as one that is a result of differing views of situations. Rumbaut (1996) shared, "immigrant parents tend to define the situation in instrumental terms (extolling the virtues of hard work and good grades), whereas their children, who seek to fit in socially, tend to experience in expressive terms the impact of disparagement within an ethnic minority status" (p. 164). Also, similarly to Waters (1999), Rumbaut (1996) found that ethnic identity was associated with gender as those who identified as women were likely to identify with hyphenated identities.

Although the research on Afro-Caribbean college students continues to grow, one subject area has had considerable history and that is the area of ethnic identification. There are a variety of researchers who have studied the topic (Benson, 2006; Deaux, 
2008; Fries-Britt, George Mwangi, \& Peralta, 2014; Johnston-Guerrero, 2016; Jones \& McEwen, 2000; Phinney, 1992; Waters, 1994). Phinney $(1990,1992)$ defined ethnic identity as encompassing a sense of belonging, involvement in ethnic group activities, positive view of the group, and interest and knowledge of ethnic group. Early researchers, including Waters, have contributed to the area; however, their work paints AfroCaribbeans as model immigrants who would prefer to identify as Caribbean or West Indian instead of Black or African American. Waters (1999) shared that choosing to identify by national origin or ethnicity is an effort to keep their elevated status.

Waters (1999) analysis is steeped in a problematic discourse of African American deficiency and fails to account for the historical and contemporary political, economic, and social structural impediments that have attempted to thwart African American achievement. Several scholars critiqued Waters' narratives, including Pierre (2004) who stated, "the discourse of Black/African immigrant 'ethnicity' can be used to propagate the 'culture of poverty' myths of Black cultural inferiority” (p. 152). Further critiques exist, however, listing or describing them is beyond the scope of this literature review. Instead, Pierre (2004) offered the following recommendations to social scientists "our work should be attentive to the ways in which various Black groups experience race and, in response, create racial meanings for themselves" (p. 161-162).

Much of existing research combines African American and Immigrant Black (both first- and second-generation) under the racial demographic of Black or African American (Daoud, George Mwangi, English, \& Griffin, 2018). As shared previously, the combining of these groups does not allow for an understanding of the nuances within the group. Nonetheless, research of both college students and adolescents demonstrate that 
first-generation Afro-Caribbeans view themselves more in terms of their ethnic identity versus their race as Black or African American (George Mwangi \& Fries-Britt, 2015; Waters, 1994). Research further indicates that immigrants are continuously negotiating their identity, most choosing to do the complicated dance of navigating both their culture and the culture of the new country that they have entered (Berry, Phinney, Sam, \& Vedder, 2006). This act is known as a bicultural identity. Butterfield (2004) shared that the bicultural experiences of second-generation immigrants are far more complex because of issues associated with race and ethnic identity. Some immigrants primarily orient themselves to their ethnic group with very limited interaction with the national society (Berry et al., 2006). Although studies have offered insight into these complex identities of both first- and second-generation individuals, there is still room to explore how these racial and ethnic identifications may influence their experiences on college campuses. Awokoya (2012) found that the identity formation of 1.5- and second-generation Nigerian college students were influenced by family, school, peers, and media. Participants vocalized the act of having to authenticate or prove their African or Nigerian identities to others. Conversely, they were also expected to prove or identify with Black Americans. Ultimately, these experiences created conflicts within the students, where they did not feel quite African or American enough. Awokoya (2012) argued that African immigrant youth are negotiating multiple identities based on the context and deploy specific identities depending on the group that they seek to engage. While this provides insight into how the children of African immigrants navigate their identities, what is not known is how identity is constructed or reconstructed during college years for secondgeneration Afro-Caribbean college students. 
Portes and Rumbaut (2001) conducted a longitudinal study on second-generation immigrants in South Florida and Southern California. Their study followed eighth and ninth graders through their last year of high school. While not focused on AfroCaribbeans, this study did include individuals who would be considered Afro-Caribbean. Portes and Rumbaut (2001) found that early school environments impact how race and ethnic identities are constructed. Additionally, the participants classified themselves ethnically with a foreign national-origin identity, a hyphenated American identity, an American identity, or an ethnic identity (i.e., Hispanic). Their findings showed a significant increase in a national or ethnic identity when comparing students' responses in eighth and ninth to their twelfth-grade responses. Furthermore, there was a link in students' identification and how their parents identify. Similar to Rumbaut (1996), discrimination can increase ethnic identification, thereby increasing the likelihood of individuals aligning more with an ethnic identification.

Assimilation and acculturation are themes that arose in past studies on racial and ethnic identity. Assimilation refers to the new group taking on the behaviors, beliefs, and identity of either the American culture or the Black racial minority (Benson, 2006; Waters, 1999). Acculturation involves the changing of both the new group and the dominant group (Benson, 2006). Assimilation is what is said to take place with secondgeneration immigrants. Jaret and Reitzes (2009) found that there was a decline in ethnic activity that was tied to the generation of the participants. In other words, the further a student was removed from immigrant status generationally, the less ethnic activity exists, and the more the person has assimilated. Ethnic activities were categorized as participating in ethnic organizations, eating or preparing food associated with their 
culture, and wearing ethnic clothing. Moreover, this research supports previous research indicating that the self-identification of college students differ depending on ethnicity and immigrant status. While Jaret and Reitzes (2009) offer insight into the ethnic identity of college students, their study involved a mixed group of Black, White, and Asian students who were immigrant, second-, and third-generations.

\section{History of Hispanic Serving Institutions}

The Hispanic Association of Colleges and Universities (HACU) was created in 1986, specifically to focus on the unique challenges faced by HSIs. At the time, the organization recognized that there were at least 50 institutions nationwide that enrolled at least $25 \%$ of Hispanic students, yet, they received no special designation or funding. From HACU's creation, 18 higher education institutions started the charter to establish the organization with a focus on bringing awareness to the special needs of HSIs and influencing legislation (Galdeano, Flores, \& Moder, 2012). HACU took the lead in pressuring Congress not only to recognize institutions with significant Hispanic student populations but also to provide funding for their efforts. HACU's labor was rewarded when in 1991, the Higher Education Act of 1965 was amended to include HSIs. Consequently, funding was later included for institutions designated as HSIs in 1995.

Officially, HSIs are defined as any "accredited, degree-granting, public or private, nonprofit colleges or universities with $25 \%$ or more Hispanic enrollment" (Galdeano, Flores, \& Moder, 2012, p. 158). The number of HSIs has grown significantly throughout the years resulting in 525 HSIs as of 2018 (Hispanic Association of Colleges and Universities, 2018). Furthermore, as of 2018, there are 328 emerging HSIs with between $15 \%$ to $24 \%$ Hispanic student enrollment (Excelencia in Education, 2019), which 
illustrates that the number of HSIs will continue to increase over time. What is problematic about the HSI designation is that it is enrollment driven and not missiondriven. Therefore, some institutions may not necessarily focus resources to benefit Hispanic identifying students specifically. This characteristic of HSIs is inherently different from HBCUs that were created specifically to provide higher education for Black populations that were essentially and effectively shut out of PWIs. One study that illuminates the disconnect is one by Nelson Laird, Williams, Bridges, Holmes, \& Morelon-Quainoo (2007). Laird et al. (2007) examined the impact of HSIs on Hispanic students and found that the engagement of Hispanic seniors at HSIs was similar to Hispanic seniors that attend PWIs. This finding is revealing as HSIs are expected to promote greater engagement, which is typically found when research has compared Black students attending PWIs to HBCUs.

HSIs enroll not only Hispanic students but also include significant Black, Asian American, and Euro-American students (Galdeano, Flores, \& Moder, 2012). Interestingly, existing HSI research has primarily focused on the success of Hispanic students and the role of HSIs in their success. The student body composition begs the question, how do those student populations who do not identify as Hispanic experience these HSIs? As such, HSIs enroll more Black students than HBCUs, with 16\% compared to $10 \%$ (Nunez, Hurtado, \& Calderon, 2015). Similar to Hispanic students, Black students tend to be first-generation and are more likely to attend high schools with minoritized groups from low socio-economic backgrounds. Given this information, it is particularly interesting that more research has not focused on the experiences of Black 
students who attend HSIs. As such, I close this gap through my research on the experiences of second-generation Afro-Caribbean college women attending an HSI.

In Garcia's (2019) recent book, she provides an extensive look into HSIs and their history. She argues that institutions of higher education are racialized in terms of excellence being related to whiteness. Garcia (2019) shared, "despite efforts to become more compositionally diverse or inclusive of racially minoritized groups, whiteness continues to be valued, even at racially minoritized institutions such as HSIs" (p. 11). Specifically, Garcia believes and provides evidence that illustrates that whiteness is "privileged at the individual and organizational level" (p. 12). This phenomenon has played out in HSIs comparing their diverse student population to other white student populations and HSIs receiving fewer resources when compared to other institutions. Even ranking systems used to validate or establish the best schools in the country seem to reward predominantly white and prestigious institutions. It appears that institutions are rewarded for their whiteness. The list of top universities does not include HSIs, which Garcia (2019) believes places HSIs in a second-class position.

One may ask, what differentiates HSIs from predominantly white institutions? Some have criticized HSIs for having no tangible difference. Garcia (2019) stated "they teach a white curriculum, employ white faculty and administrators, and foster racism and discrimination in similar ways as racially white institutions" (p. 16). As a result, it could be implied that the HSI status may be incidental and not intentional as the institution may not specifically service the large, diverse population enrolled at their institutions. If that is the case, what then of the Black student population enrolled at a particular HSI? What are their experiences and how do these institutions ensure their success? These are the 
questions that my dissertation study seeks to provide answers to and explore specifically for second-generation Afro-Caribbean women. My study explores their experiences through the use of counterstorytelling, which I will expand on in the next section of this chapter.

\section{Counterstorytelling}

My dissertation study explores the experiences of second-generation AfroCaribbean college women through the use of counterstorytelling (Yosso, 2006) to challenge the narratives of Black women that are rooted in racist and sexist ideas as well as disrupt the monolithic narratives of Black college women. Counterstorytelling involves centering the stories of People of Color, in the case of my study, secondgeneration Afro-Caribbean women. Scholars (Corbin, Smith, \& Garcia, 2018) have used the method of counterstorytelling to share the experiences of Black women through the use of composite storytelling. The work of counterstorytelling is particularly important when noting that racism has primarily privileged the stories and history of the dominant white culture.

Historically, information has been privileged and provided from the viewpoint of the dominant culture, whereas information from People of Color are viewed as antidotal (Yosso, 2006). Counterstorytelling challenges the notion of what Yosso (2006) describes as "majoritarian storytelling" and views and acknowledges the experiences of People of Color as valid. Furthermore, the use of counterstories fills the gap of information and experiences that frequently mischaracterizes or ignores People of Color within the majoritarian storyline. Counterstories challenge notions of post-racial society by sharing the lived experiences of People of Color and shedding light on how they experience and 
navigate racism and oppression. Engaging counterstories within my dissertation study is particularly important given the history of racism in the U.S. and its historical influence on the foundations of U.S. higher education. The narratives of white social scientists who have also privileged the experiences of white college students in traditional universities have been deemed the prevailing authority (voice), which further increases the importance of centering the voices of Black college women. In contrast, I privilege the voices of my nine participants.

An essential piece of counterstorytelling is critical race theory. According to Solorzano (1997), critical race theory involves five essential themes: the intercentricity of race and racism, the challenge to dominant ideology, the commitment to social justice, the centrality of experiential knowledge, and the interdisciplinary perspective. Delgado and Stefancic (2001) describe counterstorytelling as a healing process that liberates those who have experienced discrimination. Furthermore, these stories provide insight into the lives of populations who have been traditionally silenced. As stated by Delgado and Stefancic (2001), "they [counterstorytelling] reduce alienation for members of excluded groups, while offering opportunities for members of the majority group to meet them halfway" (p. 44). By reading counterstories, the reader is provided a new view of secondgeneration Afro-Caribbean college women and Black women in general. Narratives of each participant are presented in Chapter IV, and the stories of the participants, as well as research findings, are further explored in Chapter V. It is through counterstorytelling that I provide insight into the experiences of second-generation Afro-Caribbean college women. 


\section{Summary}

The purpose of my research is to explore how second-generation Afro-Caribbean college women make meaning of their race, ethnicity, and gender. Race, ethnicity, and gender intersect in the lives of Black women, and it is important to understand how those aspects of their social identity interact to inform their experiences. Higher education is continuously diversifying with increasing numbers of students from a variety of backgrounds. One such group is Black women in which within-group differences have not been acknowledged and explored. This chapter provided an overview of the history of the Caribbean as well as explored literature that gives context to the Caribbean migration to the U.S. An examination of the history of racism in the U.S., and higher education was provided to understand the potential experiences of Afro-Caribbean college women. I also provided a brief history of HSIs, given the site of my study. Moreover, I explored literature that provided an understanding of Black women and racial and ethnic identification among Afro-Caribbean students. Lastly, I shared my desire to engage in counterstorytelling as a way to promote the experiences of my participants.

Racism has and continues to play a role in the lives of Black people in the U.S. Higher education is not immune to racism and, in fact, replicates racial stratification. The literature illustrates how Black college women navigate predominantly white institutions, however, what is not known is if these experiences are similar for Afro-Caribbean women who attend HSIs.

This review of the literature shows that there are differences in the notions of racial and ethnic identities of first- and second-generation Afro-Caribbean individuals. Studies on the experience of Afro-Caribbean students are growing, however, researchers 
have acknowledged the limited literature on this group of students. Numerous studies exist that explore the experiences of Black or African American students, however, much can be learned by disaggregating the racial and ethnic identities to show the within-group differences. Additionally, existing studies have explored the experiences of AfroCaribbeans, yet ignoring how gender can play a role in students' experiences. Black women have endured centuries of subjugation through racist and sexist systems of oppression. In spite of these interlocking systems of oppression, Black college women are highly represented on college campuses and women surpass Black men in terms of graduation rates. However, there are limited studies that explore the nuances of racism and patriarchy in the experiences of Black women (Patton \& Croom, 2017). It is essential to examine how the unique backgrounds of second-generation Afro-Caribbean college women influence their experiences on college campuses.

I approach this topic from a non-deficit model. Instead of comparing the African American students to second-generation Afro-Caribbeans, I provide information that debunks the monolithic portrayal of Black students. Furthermore, illuminating the experiences of second-generation Afro-Caribbean college women students can assist higher education practitioners in understanding how this group navigates campus and what unique support they need for academic success.

The number of emerging HSIs (between $15 \%$ to $24 \%$ Hispanic student enrollment) stands at 328 , which demonstrates that the number of HSIs will continue to increase over time. While studies grow in the area of HSIs, what has not been explored is the experiences of Black students attending HSIs. As indicated earlier in this chapter, HSIs enroll a significant percentage of Black students, however, no studies exist that 
provide insight into their experience on these campuses. I illuminate and close the gap of what is known about the second-generation Afro-Caribbean student population while engaging in the act of counterstorytelling. Through counterstorytelling, I have centered the voices and experiences of my participants. I engaged in counterstorytelling in an effort to share the stories of Black women that challenge the narrative of the dominant culture. The next chapter will provide details related to the methodology of my dissertation study, as well as the context, insight into the study's participants, data collection, and analysis process. 


\section{CHAPTER III}

\section{METHODS}

The purpose of my study was to explore how second-generation Afro-Caribbean college women experience and make meaning of their race, ethnicity, and gender. Guy (2002) stated, "due to their [Black Immigrant] physical appearance, they are often seen as part of the black American community, despite differences in language, culture, and religion. Their 'invisibility' means that they are not seen as having to face unique issues or having distinct needs" (p. 18). Furthermore, accent and language distinctions that once signified the immigrant status of first-generation immigrants are no longer discernible in second-generation individuals (Guy, 2002; Waters, 1994; Wiley, Perkins, \& Deaux, 2008). The growing diversity on college campuses requires that higher education administrators know more about the experiences of second-generation Afro-Caribbean college women and factors leading to their persistence and sense of belonging (Gopalan \& Brady, 2019). Hence, Chapter III explains the aspects related to the methodology of my dissertation study including the case study design, context, participant recruitment, interview scheme, and data analysis processes.

\section{Research Design/Methodology}

My dissertation research incorporates a case study approach. There are various approaches to conducting case study research. I chose to follow the work of Merriam (1998) to explore the research topic, which utilizes a constructivist view. According to Merriam (1998), individuals' realities are constructed by their interaction with their social worlds. Additionally, case studies can be used as a tool to gain an understanding of a situation and meaning for those involved (Merriam, 1998, p 19). The previous 
characteristics aligned with what I explored in my research, which led to choosing the case study method.

\section{Case Studies}

My research study is guided by the works of Merriam (1998), who describes case studies as focusing on a phenomenon that has a boundary. Furthermore, she states that case studies are "an intensive, holistic description and analysis of a bounded phenomenon" (p. 12). Case study research can take the form of a single case or multicase study. My dissertation study is a single case study in which the boundedness resides in the institution as an HSI. Within that context, the race and ethnicity of second-generation Afro-Caribbean college women were explored to see how these social identities inform the students' experiences. According to Merriam (1998), utilizing a case study method is appropriate as it is suitable for research that is interested in describing the context and population of the study, which is the intent of my study. Through case study research, I plan on locating the individuals who identify as second-generation Afro-Caribbean women and listen to and document their experience.

Merriam (1998) states, "a case study design is employed to gain an in-depth understanding of the situation and meaning for those involved" (p. 19). Case studies are appropriate for researchers who seek discovery and exploration (Merriam, 1998), which is the intent of my study. Furthermore, qualitative researchers are interested in gaining an understanding from the perspective of the participant (Merriam, 1998). As such, it is imperative for the researcher to be close to those experiencing what is being studied. As a qualitative research approach and methodology, case studies are inductive and are interpretive in nature. Similarly, multiple realities exist, and the role of the researcher is 
to report the multiple realities that are found in their research (Creswell, 2007).

Therefore, through the use of face-to-face interviews, I collected data to make meaning of the realities of second-generation Afro-Caribbean college women.

\section{Role of Researcher}

Guba and Lincoln (2005) state that reflexivity, in other words understanding the role of the researcher, is critical in the work of qualitative researchers. As I spoke to my participants about their early childhood experiences, it brought me back to my childhood that was filled with both happy and some not so happy memories. I remember early experiences in which my neighborhood in Brooklyn, New York, was filled with Caribbean influences. The old tenement-style building that I called home consisted of four floors and 13 apartments. All except two apartments were filled with families with Haitian backgrounds. The private Catholic schools that I attended were made up primarily of those from Caribbean backgrounds such as Haitian, Jamaican, Bajan, among others. Looking back on it, I thought that this was a natural environment. I had no idea that I was living in a bubble.

The August following my sixth-grade year, my mother, two sisters and I moved to Fort Lauderdale because of the rising crime in our neighborhood. We moved in temporarily with one of my mother's cousins, all four of us in one bedroom. I ended up attending a middle school that was predominantly African American, which is where I became aware of my difference. I recall a day when my teacher conducted a roll call. During the process, he asked me the origin of my first name, to which I innocently shared that my parents were from Haiti. I immediately felt the cold shoulder from my classmates. There was one student in particular who started to tease me about being 
Haitian. Peers who would generally speak to me were no longer friendly. I was so confused and remembered developing feelings of not wanting to go to school.

In October, my mother found an apartment that we could call our own in a different part of the city of Fort Lauderdale, which required me to switch schools. The part of the city was populated with more Haitian families than our first home. We had a family member who drove local kids from their homes to surrounding elementary and middle schools and did the same for my sisters and I. The students at my new school were mostly of Haitian descent, which did not make me experience the conflict that I had at the previous school. While I did not experience the same conflict, the new environment brought about different challenges. These challenges included questions of whether or not I was Haitian enough as there are noticeable differences between South Florida and New York Haitians. Nonetheless, I persevered and created a small circle of friends who had similar backgrounds to mine.

While growing up, my parents stressed the importance of education as it was seen as a way to financial independence. My father was a laborer as a machine operator in the plastic bag industry, and my mother was a home health aide. Although they never complained and shared that their occupations were their passion, they hoped and prayed that their children would have a better life. With these thoughts, it was non-negotiable that I would attend college.

As the oldest of three girls, I was limited in my options as my parents' background could not wrap their minds around going away for college. My parents' thoughts were influenced by the examples of other Haitian parents who let their daughters go away to college. They "ALL" returned pregnant. In their minds, there was a 
strong probability that if they let their daughter go away, she would come back pregnant, which would have been the ultimate shame to the family. Through sheer negotiation, I was able to convince them to allow me to attend FIU and live on campus. The pressures to prove them wrong were all-consuming, but I was determined to ensure they made the right choice.

I loved my time at FIU, although there were times when I felt as if I did not belong. From trying to relate to the fight song to navigating the community around the campus, it was all foreign to me. I recall instances when shopping at Walmart, and I could not find anyone who spoke English to help me. I also had issues with my car and felt like I was taken advantage of at a local car shop because I did not speak Spanish. Incidents like these made me feel alienated and expedited my departure from the university. I often wondered if my experiences were unique or if others are experiencing similar feelings. Currently, I am a higher education administrator who works in career services. I frequently think about how college women with similar backgrounds to mine are managing the unique environment of the university and city.

These personal thoughts have influenced the topic of my dissertation. I am curious to know how other second-generation Afro-Caribbean women are experiencing FIU and how their time helps them to make meaning of their race, ethnicity, and gender. I identify as a Black, Haitian-American woman which influences my understanding of the world. My background undoubtedly impacts the way I view and interpret the data collected. Because of my experiences and background, I may be likely to assign meaning to data that align with the way that I view the world. As such, my study employs the four 
validity procedures previously explained: triangulation, rich and thick description, researcher's position, member checks, and ensuring anonymity of research participants.

\section{Setting and Context}

Conducting a study like mine is particularly important given the racial dynamics in Miami. The history of the Black population in Miami dates back to the 17th century with the import of enslaved Africans as well as runaways from neighboring Bahamian islands (Dunn, 1997). Dunn (1997) shares that a significant number of Blacks did not arrive until what was known as the "great freeze" in Jacksonville during the winter of 1895. Many migrated south as a consequence of ruined crops that devastated the agriculture in the southeast. The Black community in Miami continued to expand as a result of the opportunities that were brought into the area by the railroad expansion to South Florida. A combination of immigration of Cubans, Haitians, and other Caribbean islands, have stretched resources of the city. Dunn (1997) explained:

Massive immigration has caused some African Americans to feel increasingly isolated and angry because they believe the immigrants from Haiti and Cuba have displaced them in the job market. Many blacks also feel that immigration has negatively impacted public facilities, such as hospitals and schools. Consequently, among the African-American, Cuban, and Haitian communities exist low-level tension and strong competition for dwindling public resources (p. 2).

Some of these tensions, as well as conflicts brought on by the unfair treatment and the killing of Black men by the local police department has led to numerous riots over the past five decades. Moreover, the decision to build the Interstate 95 through the heart of Overtown, one of the oldest Black communities in South Florida, displaced countless family homes and Black businesses in favor of expanding Miami's business district 
(Dunn, 1997). These events helped to cultivate a unique history of Miami that provides a setting that requires further exploration.

The setting for my research study is Florida International University (FIU), which is a large 4-year public institution with 56,000 students situated in Miami, Florida. Florida International University opened its doors in 1972 and was initially an upper division college. In its relatively short history, FIU has been classified by the Carnegie Classification of Institutions of Higher Education as a Carnegie Very Research Institution. Florida International University is also designated as a Hispanic Serving Institution.

As of the Fall 2019 semester, the student demographic is $64 \%$ of the student population identifying as Hispanic, $12 \%$ as Black, $10 \%$ as White Non-Hispanic, $3 \%$ as Asian or Pacific Islander, and 9\% as other minority groups. Black women make up 13.6 percent of the population of women with 4,582 students. Of this number, 2,961 are undergraduate students. During Fall 2019, FIU housed 3,209 students in their on-campus housing facilities. About 30\% of the total on-campus residents were Black with 957. Additionally, 565 or $59 \%$ of the total Black population identified as women.

Florida International University has two primary campuses - the Modesto Maidique Campus (MMC) and the Biscayne Bay Campus (BBC). The campuses are separated by 25 miles. The complexities of the campuses are very different. The Biscayne Bay Campus is located in North Miami, while MMC is located in the city of Sweetwater. North Miami has a majority of Black residents and Sweetwater is a Hispanic city. These distinctions impact the campus surroundings and the experiences of the students. 
Consequently, the differences between the campuses and interactions with members of the surrounding community did come up during my interviews with my participants.

Florida International University was chosen as the site of my study for multiple reasons. One reason is the convenience as an administrator at FIU. Furthermore, Miami is a top destination for Afro-Caribbean immigrants (Rumbaut, 1996). Florida International University is a commuter institution with a large number of its student population stemming from the local community. As such, it is anticipated that FIU would have a large number of Black students who identify as Afro-Caribbean second-generation students to potentially participate in my study.

Moreover, FIU provides a unique backdrop to explore the experiences of secondgeneration Afro-Caribbean women. As an HSI, FIU is uniquely different when compared to other HSIs. Florida International University has a majority Cuban student population, which is in contrast to most large HSIs located in Texas, New York, New Mexico, California, and Puerto Rico. Therefore, FIU's setting provides a unique environment to explore how second-generation Afro-Caribbean college women make meaning of their race, ethnicity, and gender.

Florida International University is an ideal site for my study as the site provides a different look into the experiences of Afro-Caribbean students. Existing research has explored the experiences of Afro-Caribbean students within the context of PWIs or HBCUs. Florida International University provides numerous opportunities that are not usually found on other college campuses, for involvement and expression for the diverse groups within the African Diaspora. Among the student organizations are the Black Student Union, Caribbean Student Association, Haitian Student Association, African 
Student Association, and seven of the divine nine historically Black fraternities and sororities that fall under the National Pan-Hellenic Council (NPHC). Moreover, students can find numerous academic student groups with race affiliations.

All of my participants were immediately from the state of Florida, however, not all of them were from the Miami area. Of the nine participants, six were from outside of Miami. Those six participants described how the diverse image of Miami drew them to the area. Conversely, they did not expect there to be the segregation among groups that they experienced once they moved to Miami. While here, they feel as if the Black population is ignored and not included in the larger conversation about diversity. Furthermore, some of the participants expected to have a shared minority bond with the Miami Latinx population/community. They were disappointed to learn that solidarity did not exist between Latinx and Black communities. For the three women who grew up in Miami, they grew up in predominantly Black communities. Attending FIU exposed those women to the Hispanic population that exists in Miami.

An understanding of the context is necessary to foster a better understanding of my dissertation study. The history and demographic makeup of Miami and FIU informs the lived experiences of my participants. The context and these women's navigation within it shape their experiences and their understanding of self.

\section{Participants}

The purpose of this study was to explore how second-generation Afro-Caribbean college women make meaning of their race, ethnicity, and gender. Therefore, a purposeful sampling (Patton, 2002) strategy was used to include participants who selfidentified as women and were second-generation Afro-Caribbean undergraduate college 
students with both parents who were born on a Caribbean island or, as I explained previously, Guyana, Surinam, Panama, and Belize. Afro-Caribbean women from Spanish-speaking islands were not excluded from this study.

Dukes (1984) indicates that qualitative interviews should include one to ten participants. Using the Duke strategy, it was my goal to interview up to 10 AfroCaribbean college women for my research study. Ultimately, nine women were identified as participants in my research study. Every effort was made to recruit a diverse participant group, however, I ended up with the majority from Haitian backgrounds with five Haitian, two Jamaican, one Guyanese/Belizean, and one Dominican/Puerto Rican.

Participant recruitment entailed reaching out to the Caribbean Student Association, Haitian Student Association (HSA), Black Student Union (BSU), Honors College, and Women in Computer Science (WiCS), which have members who would meet the demographics that I sought. A flyer was created and shared with student organizations as well as university staff and faculty. The flyer included brief information about my research study, qualifications to participate in the study, as well as my student email address. The various student organizations were contacted through email notifications and announcements during their meetings whenever possible. I also reached out to the Latin American Caribbean Center, Multicultural Programs and Services office, Student Access and Success Center, and the Women's Center to recruit participants who may not be active in student organizations. Furthermore, staff contacts and students that I had personal contacts with were encouraged to share the recruitment emails with others. I hoped to use the snowball strategy (Bertaux, 1981, p. 37) to gain additional participants, however, the snowball strategy was not fruitful. I reached out to participants to 
recommend potential participants who met the specific interview criteria; however, no one was referred.

Students contacted me through my student email to share their interest in participating in my study. There were a couple of women who reached out to me through my staff email as a result of colleagues sharing information about my study. I then replied to them to verify that their parents were born in the Caribbean, that they were undergraduate students at FIU, and that they were born in the United States. Once the qualifications were verified, I replied with several dates and times to hold the first interview. A confirmation email was sent that provided the day, time, and location of the interview along with a copy of the consent form (Appendix A). Each participant was encouraged to read over the consent form prior to our interview, however, I reviewed the consent form at the beginning of our first interview. The form was signed, and a copy was sent to each participant by email. Furthermore, the original copy of the consent forms are kept in a locked filing cabinet in an off-campus location.

Every effort was made to diversify the participants of my study. Diversity was met within the majors and classifications of the students. I had a mixture of classifications, although none of the participants were sophomores or second-year students. The ethnicities of the participants were not as diverse as I would have liked. Most of the participants were of Haitian descent with five women. Additionally, two Jamaicans, one Guyanese/Belizean, and one Dominican/Puerto Rican participated in the study. Table 1 illustrates the demographics of each of the participants. 
Table 1

Participant Demographic Information

\begin{tabular}{|c|c|c|c|c|}
\hline $\begin{array}{l}\text { Participant } \\
\text { Pseudonym }\end{array}$ & Classification & $\begin{array}{l}\text { Mother's } \\
\text { Country }\end{array}$ & $\begin{array}{l}\text { Father's } \\
\text { Country }\end{array}$ & Major \\
\hline Heather* & Senior & Jamaica & Jamaica & $\begin{array}{l}\text { Computer } \\
\text { Science }\end{array}$ \\
\hline Maria* & Freshman & Haiti & Haiti & Sociology \\
\hline Michele* & Freshman & Haiti & Haiti & $\begin{array}{l}\text { Exp - Health } \\
\text { Sciences }\end{array}$ \\
\hline Nadine* & Senior & Belize & Guyana & Sociology \\
\hline Yolette & Senior & Haiti & Haiti & Psychology \\
\hline Danai & Junior & Haiti & Haiti & Anthropology \\
\hline Xiomara* & Senior & $\begin{array}{l}\text { Dominican } \\
\text { Republic }\end{array}$ & Puerto Rico & $\begin{array}{l}\text { Computer } \\
\text { Science }\end{array}$ \\
\hline Serenity Selene & Junior & Jamaica & Jamaica & Psychology \\
\hline Natasha & Junior & Haiti & Haiti & Political Science \\
\hline
\end{tabular}

Key

* Participant did not choose pseudonym so one was selected for the participant

Recruiting participants did prove to be more challenging than anticipated. My difficulty recruiting students could be tied to my not having an established connection to the existing Afro-Caribbean student population at the university. Additionally, the timing of my recruitment may have played a role in the initial response that I received. I started recruiting at the beginning of April which was close to the end of the semester when students are more focused on closing out the semester and final exams. Recruitment 
efforts persisted throughout the Summer 2019 semester and the struggles continued because of the low number of students on campus. I made attempts to reach out to gatekeepers such as the advisors of BSU and the National Panhellenic Council which again did not yield any response or participants. My flyer made the rounds throughout campus which led to two graduate students expressing interest in participating in the study. After consulting with my dissertation chair, I decided that I should move forward with the undergraduate student focus that I initially set out to explore. The topic of including graduate students came up again after only having seven participants. I engaged in another push for participants which included posting my recruitment flyer on LinkedIn and reaching out to additional FIU staff members. The additional participants came from the Honors College and the Student Engagement office. The initial seven participants were referred from the Women's Center, Honors College, and WiCS.

\section{Data Collection}

My dissertation study utilized the case studies qualitative research approach to explore the experiences of second-generation Afro-Caribbean college women. Data collection in case studies can include interviews, observations, and document analysis (Merriam, 1998). For my research, I decided that interviews would be the best way to explore the research topic and questions. According to Seidman (2013), "at the root of indepth interviewing is an interest in understanding the lived experience of other people and the meaning they make of that experience" (p. 9). I approached my study through a constructivist standpoint. As such, I believe that each person has a unique understanding of the world that stems from their experiences (Saldana \& Omasta, 2018). Additionally, it 
is my understanding that the best way to learn about a person's lived experience is from retrieving the information directly from them.

Institutional Review Board (IRB) granted approval for my study in March 2019 (IRB -19-0102). Subsequently, I collected data during the Summer and Fall 2019 semesters through the outreach efforts to the groups mentioned earlier in the chapter. All interviews were transcribed and analyzed during the Summer and Fall semesters as well.

The intent of my research study was to gain an understanding of the experiences of second-generation Afro-Caribbean college women and explore how their racial and ethnic identifications are influenced by their experiences. My study is a modification of the three-phase interview process detailed by Seidman (2013). The modification employed a two-interview scheme in which the first interview focused on the life history of the participant, and the second interview centered on the lived experiences of the participants within the context of FIU. Focusing on the participants' past is vital to my research. Exploring the life history of participants is essential in navigating the research topic as history is an essential factor in the development of racial and ethnic identities (Awokoya, 2012; Deaux, 1993; Erikson, 1968).

Semi-structured interviews were conducted with all nine participants. The interview questions focused on the research question to allow for the true essence of the lived experience of second-generation Afro-Caribbean college women. Probing questions were asked to collect further information from participants. All participants were interviewed twice, and each interview was between 50-90 minutes in length. The first interviews tended to be the shortest as the women were more reserved and we worked through the process of building rapport. The first interviews lasted an average of 50 
minute while the second interviews were an average of 70 minutes. The second interview was held an average of two weeks after their first interview. There were two occasions where the second interview took place four days after the first interview. There were also two times in which the second interview was scheduled two months after the first interview. The timing was determined my participants busy schedules. Additionally, there were times when the interview scheme was impacted by the end of an academic semester. The end of the semester meant that the students were forced to move back home or were not on campus as often. All interviews were audio-recorded and transcribed verbatim. The audio from the first interview was transcribed before the second interview in order to clarify any information from the initial interview during the second interview. Additionally, the interviews were done simultaneously in that the twointerview scheme was not complete with one participant before advancing to the next participant.

All interviews were conducted in-person at either the Modesto Maidique Campus, Biscayne Bay Campus, or Engineering Center. Minimal notes were taken during the interviews to ensure that there were no distractions to the participants. Furthermore, maintaining eye contact was essential to keeping the conversations as natural and conversational as possible. Transcripts from both interviews were shared with each participant through email to ensure member checking. Additional or follow up contact took place through email to clarify information or questions that I had about the data provided during the interviews.

Interview questions (Appendix B) for the initial interview directly targeted the participants' past, including family and peer dynamics, and their influence on the 
participants' identification. The second interview centered on instances in the participants' college career that influenced their racial and ethnic identification and how these events shaped their identity and college experience. The interview questions were open-ended to gather as much information as possible. As stated before, all interviews were audio-recorded, and minimal notes were taken during the actual interviews. Saldana (2009) encourages the act of memoing for future reference (p. 17). Therefore, a separate journal was utilized to memo my thoughts following each interview as well as memo my thoughts during the data analysis process. According to Laverty (2003), the researcher is called, on an ongoing basis, to give considerable thought to their own experience and to explicitly claim how their position or experience relates to the issues being researched. Through memoing, I was able to reflect on the topics discussed during each interview and jot down my reactions to assist with the data analysis process. The memos are kept on a cloud storage site linked to a university-issued email address with password protection.

\section{Data Analysis}

Data analysis is the process of making sense of the data. Moreover, making sense out of data involves consolidating, reducing, and interpreting what people have said and what the researcher has seen and read - it is the process of making meaning (Merriam, 1998, p. 178).

A case study research method was employed to explore the experiences of second-generation Afro-Caribbean college women. I utilized Merriam's (1998) case study approach and instituted her recommendation, which states that data analysis should be performed simultaneously with data collection. The act of simultaneous data analysis allows for adjustments to be made throughout the data collection process, which will, in turn, have positive implications for the overall data that is collected. Operationally, simultaneous data analysis took shape by listening to and transcribing audio from the first 
interviews before conducting the second interview. Furthermore, each interview informed future interviews with participants. As a result, questions were added and modified during the interview process. For example, one participant shared data about dating that I had not initially included in the interview protocol, however, I thought it was interesting to understand gender. As a result, I added a question about dating with the remaining participants to see if it was a common phenomenon among other Afro-Caribbean college women.

The interviews were transcribed originally using Temi and Otter, which are both online resources. While these services were helpful, they were not accurate as they did not make out accents or account for low or muffled voices. Therefore, after receiving the initial transcriptions, I then listened to the audio while making corrections to the transcription. Grammar was not corrected to keep the authenticity of the conversation. Listening to the recordings helped me to remember and become more acquainted with the data. During the process of correcting the transcripts, I removed any identifying information and inserted pseudonyms. While transcribing, I also wrote memos describing any feelings, thoughts, or initial codes that I saw.

As shared previously, data analysis occurred simultaneously as data collection was taking place. I employed In Vivo Coding in the first cycle coding (Kuckartz, 2014; Saldana, 2009) and coded both line by line and block text. In Vivo Coding is the utilization of words from the research participant (Strauss \& Corbin, 1998). The coding procedure applies to my goal of maintaining the voice of my research participants, second-generation Afro-Caribbean college women, who have been largely ignored in educational research. Second cycle coding (Kuckartz, 2014; Saldana, 2009) was 
conducted utilizing Pattern Coding. Miles \& Huberman (1994) state that Pattern Coding is an option for providing explanations for what is occurring in the data. Given the research topic, I believe that this coding option was the best in providing information about this emergent group of students.

I initially planned to conduct the first cycle coding manually, however, I decided to use a computer-assisted data analysis program. NVivo was used to code and organize the data. Each interview was coded independently in NVivo. A codebook which consisted of over 200 codes was created from the codes developed during the first cycle code process. Initially, I coded every line of each transcript. Subsequently, I reviewed each code and identified those that answered or related to my research question (Kuckartz, 2014). From that point, codes were condensed through the process of combining those that seemed similar. The codebook was printed off and cut into strips of paper then grouped together on the basis of similarities. For example, experiences or wording related to being bullied were grouped together and an overarching code was used to identify the corresponding data. The process of organizing the data also included re-reading passages that were tied to each code to determine if they were related or connected in any way to formulate categories. At this stage, I was able to identify patterns that developed into themes that answered the research question. Identifying patterns was done through the use of large flip chart sheets and post-it notes. Each category was written on individual post-it notes and placed on the flip chart sheets which helped in providing a larger view of the categories and allowed for easy manipulation. Initially, seven themes were identified; however, after further consideration, I collapsed some of the themes into others and merged some into sub-themes. In the end, four final 
themes emerged from the data. Rich text from the participants was utilized to answer the research question and bring life to the phenomenon that I am researching. In developing themes, I paid close attention to how the participants discussed race, ethnicity, and gender. Close attention was paid to comments that seemed to be consistent among all or most participants.

\section{Data Integrity}

Merriam (1998) states, "the nature of qualitative research means that this [validity and reliability] accounting takes different forms than in more positivist, quantitative research" (p. 198). Unlike quantitative research, qualitative is concerned with the credibility and trustworthiness of the data collected. To enhance the integrity and credibility of the data that was collected, a series of procedures were utilized in my study. The first procedure involved triangulation, which entails options used to verify the facts of the data collected. Denzin argued that there are four triangulation options available to researchers (as cited in Bogdan \& Biklen, 2016, p. 112). One of the methods includes collecting data in multiple ways. In my study, triangulation took the form of the twophase interview process that I engaged in with my study participants. Additional procedures for increasing integrity and credibility include employing thick description, researcher's position, member checks, and ensuring anonymity of participants (Merriam, 1998). Including rich and thick description is employed throughout my study by presenting findings with sufficient text and quotes from participants that adequately support my findings. The researcher's position is the act of disclosing their interest in the topic and assumptions coming into the research study. As such, my position statement was included earlier in this chapter. 
Member checks involved providing the data and interpretations to participants to corroborate what is being said by the researcher. Transcriptions were shared with all of my participants after the completion of both interviews. Each participant was asked to review both of their transcripts and provide any changes. I did not provide a deadline for the participants to reply with feedback or changes. To date, none of the participants wanted to change any details of the transcripts. In terms of anonymity, all participants were provided the opportunity to choose a pseudonym. Not all participants elected to choose a name, and in those cases, I chose a pseudonym on their behalf. All information that would potentially identify individuals was redacted from the transcripts.

Furthermore, all interview documents were stored on a password-protected computer. Additionally, the interview audio and transcripts were backed up on a cloud storage site linked to a university-issued email address with password protection.

Further assurance of credibility and trustworthiness was done by adopting two of Tracy's (2010) 8 criteria for sound qualitative research methods. The list of criteria includes worthy topic, rich rigor, sincerity, credibility, resonance, significant contribution, ethical, and meaningful coherence. First, I engaged in rich rigor with my research. Rigor includes exhaustive procedures to ensure the collection of enough data to provide insight into the population. This was done through multiple interviews with my research participants as well as ensuring that transcripts were accurate. Lastly, rigor was achieved by being transparent about my data collection and analytic processes.

Second, my study engages in a worthy topic. My topic is worthy as a result of the racial unrest that was propelled by the death of George Floyd at the hands of the Minneapolis police, Breonna Taylor by the Louisville police, Rayshard Brooks by the 
Atlanta police, and Ahmaud Arbery by a former Georgia police officer and his son. These deaths along with the initial decision to not charge the individuals involved spurred nationwide and international protests to bring awareness of state sanctioned violence of Black people as well as systematic racism that exists in the U.S. The nation is reckoning with the racial inequities that exist which has higher education implications. Leaders of higher education institutions have symbolically shown their support of the Black Lives Matter movement through social media posts and position statements have been released to their respective university communities. However, Black students have voiced their experiences of being racialized on college campuses. My study provides insight into the experiences of Black women and recommendations for higher education leadership response.

\section{Summary}

There is limited information on what is known about Afro-Caribbean college students. Most studies reporting the experiences of Black students have done so while not accounting for the within-group differences and heterogeneity of the Black population. My study adds to the existing scholarship by exploring how second-generation AfroCaribbean college women make meaning of their race, ethnicity, and gender within the context of an HSI. FIU and the city of Miami provides a unique environment to explore the experience of second-generation Afro-Caribbean college women as a result of the historical race tensions between the Black and Latinx communities in the city as well as the HSI status of the university. My research topic is examined through the use of the case study approach. My study is situated as a single case study in which the institution was set as the case. Face-to-face interviews were employed to gather information on the 
lived experiences of second-generation Afro-Caribbean college women. Nine women were interviewed twice to explore their experiences and learn more about the role that their intersecting identities play in making meaning of their race, ethnicity, and gender.

A variety of tactics were used to recruit participants. Efforts were made to reach out to student organizations, faculty, and staff. Recruitment did prove to be challenging because of the timing of my efforts. Ultimately, participants were recruited from the Caribbean Student Association, HSA, Honors College, WiCS, the Office of Student Engagement, and the Women's Center. Two semi-structured interviews were conducted with each of the nine participants. The first interview focused on the participants' life history while the second interview centered on their experiences at FIU. The interviews were transcribed and provided to the participants as a means to improve the trustworthiness of the data. Each interview was added to the computer-assisted data analysis program, NVivo, to conduct the coding process. In Vivo Coding was utilized during the first cycle of coding to maintain the voices of my participants while second cycle coding was conducted utilizing Pattern Coding.

The following chapter provides profiles of each of my research participants. An understanding of each of the participants' stories and backgrounds is provided through the use of rich and thick text that was gathered during their interviews. These women had different experiences that led them to FIU which is what guided my desire to provide an understanding of these women prior to moving forward with presenting my findings. It is through the participant profiles, that I hope to provide further context to the experiences of my participants. 


\section{CHAPTER IV}

\section{PARTICIPANT PROFILES}

The purpose of this qualitative study was to explore the experiences of secondgeneration Afro-Caribbean college women and examine how they make meaning of their race, ethnicity, and gender within the context of an HSI. The lived experiences of these women were examined to answer the following research question: How do secondgeneration Afro-Caribbean women college students at FIU experience and make meaning of their race, ethnicity, and gender? Specifically, my study explored the experiences of undergraduate college women. Purposeful sampling was utilized to recruit nine participants for this research study. Data was primarily collected through individual faceto-face interviews with these nine women who identified as second-generation AfroCaribbean women.

This chapter includes a profile for each participant, which details her family and academic background. A summary of demographic information for each of the participants was provided in Chapter 3 in Table 1. The profiles in this chapter expands on the information in Table 1 which were created using the data gathered from the interviews. The profiles are presented alphabetically utilizing the participants' pseudonyms. As a measure to ensure confidentiality, each participant was provided the opportunity to select a pseudonym. When the participant could not think of a pseudonym or did not have a preference, I chose one for them.

\section{Danai's Story}

Danai is a junior majoring in anthropology. She is originally from New York, however, she and her mother moved to Haiti from the time she was 2-months old until 
she was ten years old. Initially, her mother came to the U.S. to have her children in order for them to have better educational and career opportunities. Danai has one younger sister on her mother's side, who is nine years younger than her. She also has a 3-year old sister on her father 's side.

While in Haiti, Danai was raised by both her mother and maternal grandmother. Danai shared that her father was not present between the ages of three and twelve. His absence was a result of his job in the entertainment industry which required him to travel. They have spent the past seven years attempting to repair the damage that his absence has created on their relationship.

After her return to the U.S., Danai grew up in the suburbs of Fort Lauderdale. She currently lives at home while attending college. She lived on campus for the first two years of college, however, she moved back home after a conflict with her roommate. Additionally, she saw going home as an opportunity to help her mother with the responsibilities of raising her little sister. Danai's neighborhood is a predominantly white and older population. This population has created its own set of issues. She said:

So moving here and having somebody just stare at you from their window while you're moving in, it's like, whoa, chill out. I'm just going into my home. Or having, you know, my neighbor called the police on me because I was taking care of my sister at the age of 12 and apparently you're supposed to be 13 in order to take care of a child...So then I was 12 and I have to call my mom on the phone and be like, Mama the police is going to like, you know, arrest you because you made me go pick my sister up from the bus stop, you know, walking and stuff. It was just, it was just a lot. Like they're just very insensitive I think in my neighborhood.

Danai shared that the neighborhood has recently become a little more diverse with more Black families moving in. This change has allowed for the creation of a community 
within the neighborhood that looks out for one another. This is a contrast to the

unwelcome feeling her family received when they initially moved to the area.

Danai describes herself as Haitian-American. She explained that the culture is one made up of lively people who are carefree and loving. Spending some of her life living in Haiti has helped her to have a deeper meaning of what it means to be Haitian-American. She shared:

I think that just knowing about Haitian culture and Haitian history, because I was taught it in Haiti has just made me understand that I am African, Haitian-American, you know, it's like that Haitian part is very significant in who I am.

Danai's time in Haiti was spent in her grandmother's house. The house was filled with her mother, grandmother, aunt, and two cousins, who were all women. The adult women were all working women who had a profound impact on Danai. Additionally, her mother's profession within a non-profit and her grandmother's passion for helping women in the community instilled a passion for social justice work within Danai.

Attending college was not a choice for Danai. She had dreams of moving to New York to attend college, however, she decided to go to FIU in order to be able to help her mother with her sister. She decided to live on campus to have the freedom that she desired for herself. Danai's involvement has included Student Government Association (SGA) and Alternative Breaks. Her love for travel and service influenced her involvement with Alternative Breaks. She was exposed to the organization during freshman orientation and has been involved ever since. Her previous political science major drove her to get involved with SGA. Danai has a passion for teaching and she hopes to teach after graduating from college. 


\section{Heather's Story}

Heather is a senior majoring in computer science. Both of her parents were born in Jamaica and migrated to the U.S. in their twenties. Heather was born in South Florida and has two siblings; one seven years older and another who is two years younger. Heather was raised in a neighborhood that included a sizeable Caribbean population and her elementary and middle school reflected that same demographic. Heather's childhood friends tend to have similar ethnic and racial backgrounds as her.

Heather grew up in a religious household as her father is a pastor and her mother is co-pastor of a church. She described church being a big part of her life. For as long as she can remember, her family attended church on Sunday mornings and nights, Wednesdays, and Fridays. She believes that her religion helped her to avoid many headaches during her high school years but also thinks that it limited her in terms of being in a bubble. Heather also believes that her religious background limited her exposure to her Jamaican culture. She explained:

It's like because of the belief system that was in our household, it was hard to do certain things, go certain places or even, you know, just have certain experiences. So, I think a lot of that really shut me down or shut me out from what my culture might've been...So like I have no background about like say Jamaican music or whatever because again, it's like growing up because you're religious, you're listening to Gospel music all the time...So it's like now if I'm trying to relate with say other Jamaican students or friends, it's hard because if they're talking about something like, Buju, and I'm like, who's that?

Nonetheless, Heather identifies as Jamaican-American. Heather believes that there are other pieces to cultural identity including food, customs, and language. 
Racially, Heather sees herself as Black, however, she has been treated differently

because of how she looks. Her appearance is a result of what Heather described as a

mixture that is very common in Jamaica. She explained:

I grew up hearing a lot that I looked like Pocahontas and in comparison, I guess to the other kids that I knew things like that. So, in my head at the time I thought that made me, you know, special or something. But then I realize like as I guess growing up, I realize how harmful that kind of was in some ways because I hear how people would compare their children to me or something like that. And I didn't like that...They would consider me something called Cooley, which is, from what I understand now, like it's a, I think it's a derogatory term in India, but basically it was basically saying somebody who has a more Indian look to them, right. So, basically I grew up with this idea of okay, so I'm trying to figure out, um, I guess where I belonged and what niche I fit in.

As a result, in high school, Heather decided to explore her "Indian" heritage by joining an Indian student club to learn more about it. However, in recent years she has had a shift in how she views herself. She said:

I'm realizing now, I guess how problematic that was because there were times where who would be like, oh, what are you mixed with, right? And I'd say, well, you know, I'm all over the place because you know, I had like my whole family story. So, it was like, oh Indian blah blah blah, like just listed off and there came a point and I think it kind of happened in high school where I just got tired of that. I was like, at the core, I'm Black.

Heather's self-identification has evolved over time. Instead of identifying as Indian or mixed race, she identifies with more of a racial identity of Black.

For Heather, it was a given that she would attend college. Both of her parents went to college and for her she had to make a decision between attending FIU or FAU. Heather decided to attend FIU, primarily because of her major. She attended a Black technologist conference with her father during her senior year in high school. Heather remembers being inspired by the attendees and thinking that it was possible for her to 
pursue a major in technology. She went to Broward College initially then transferred to FIU. Heather explained:

When I first attended, it was very lonely, I think. Especially cause of what I'm studying, you don't really have, first off, there's a limited amount of females in my area. And then on top of that, there's a limited amount of Black females. I mean, in general, there's maybe a smaller amount of Black people.

Despite being a senior, Heather has struggled to make meaningful relationships with other students during her time at FIU. Her comments speak to how her multiple identities can be isolating. She is a woman in a male-dominated major which is compounded by her race.

Heather lives with her parents and commutes to campus. She currently works on campus. Heather's on-campus involvement has been limited as a result of the demands of her major. Heather has attended a few Black Student Union events, however, it has been a challenge getting involved with BSU since their events do not typically align with her schedule. She has decided to increase her involvement in a couple of organizations that are related to her major.

After graduation, Heather hopes to relocate to Georgia and start a full-time job related to her computer science major. She also hopes to pursue her master's degree at the University of Georgia.

\section{Maria's Story}

Maria is a freshman from Pompano Beach, Florida. She is currently pursuing a degree in sociology. She grew up in a two-parent household to parents who were born in Haiti. Her parents migrated to the U.S. to make a better life for themselves. She has an older brother who she describes as having a close relationship with. Maria's grandmother 
moved from Haiti and lived with her family when she was seven years old. She grew up in what she describes as a strict and religious household. Maria shared, "I always say there was always three places you would find me, it was either at home, school, or at church, anywhere else it was, I didn't go out." Maria admits that religion played a significant role in her life, impacting her morals and values. She also stated that religion had a role in her gender identity:

I say that religion, it helped my morals but at the same time, I feel like being a girl, I was also in a sense like reduce like certain things that girls shouldn't do or certain things a girl should value more, especially when it came to like domestic things. You're supposed to be molded to be a good wife, a good mother. And I feel like my religion played into that. Like certain things you can't do because one day you're going to be a wife and you don't want to look back and be like, you were like this and you know, shame your family.

In addition to religion, or because of religion, Maria characterizes her mother and father as having conservative views. Her mother wanted Maria to dress modestly in what she describes as long dresses and long sleeves. However, she shared that her father had stronger views and recalls the following situation,

I will always be remembered this moment. My friend came from the hospital and I was going to visit her at her house, so I just had gym shorts on and he was like, go back in the house and go change your pants because you can't go out like that. And I'm just saying like, I'm going to see her at her house. It's not like we're going to the hospital. It's just gym shorts. It's not that big of a deal. He's like, well, unless you change your pants, we're not going. And I'm like, it's not that big of a deal. It's just gym shorts. What's wrong with it? And he literally didn't drive me until I changed my pants and I'm like, it's literally, they weren't the shortest. They were probably midway of my thighs. I'm like, I'm going to hang out with my friend. She's a girl.

This incident seemed to frustrate Maria, however, she acquiesced to her father's demands since she lived in his household and also as a sign of respect. 
Although Maria views herself as a strong-minded woman, she believes that her

mother thinks that she can be easily influenced by others, specifically boys. Upon reflecting, Maria believes that her mother's fear could be related to the relationship between her mother and father. She detailed:

I see how in a sense my mom in certain aspects is dependent on my dad and it's not necessarily because she wants to, but in a sense because she has to, and I feel like my mom, although it comes off rough and sometimes just mean, I feel like her goal and intention is just to make sure that I'm very independent. And I feel like because of her experiences and what she's seen, that she thinks that if a man were to come into my life, that I would just be submissive to him and I wouldn't fulfill my life.

Maria's mother appears to be interested in helping her to be an independent woman which seems to be the opposite of the life that she leads. Maria shares that her parents do not think that she is strong, which conflicts with her views of herself.

When reflecting upon her identity, Maria recalls being confused. She felt connected to the Haitian culture since she was raised in a Haitian household, spoke the language, visited Haiti, attended predominantly Haitian schools, and patronized a Haitian Catholic Church. Maria explained:

Who am I? I always questioned that, like who am I? Am I Black and am I American because growing up I wasn't looked at as Black because I didn't have generations of family that lived in this country. To my parents, I was a Black American because I'm their only child that was born here and they always said that this country is mine and that the opportunities are prioritized towards me because I was born here. And so, I was always confused as to can I not be both and do I have to choose one?

Despite feelings of confusion, Maria identifies as Haitian-American. Growing up, her friends had similar backgrounds and values to her. She explained that her pride in her culture has evolved over the years. She shared:

I didn't like my name growing up. I was like it was too Haitian. I didn't like it because I think up until now, I feel like for me that also goes into 
staying in touch with my roots and what it means to me being a Haitian girl, my name. So I'm very prideful in that, but I do get mad if someone messes it up. Like, if you mess it up, no.

In contrast to earlier feelings, Maria fully embraces her name as it is tied to her identification as a Haitian-American woman.

Maria's motivation to attend college was in part, related to her love of learning. She was also driven by her parents' struggle which she attributes to their lack of access to education. Maria also describes, "I feel like it would be disrespectful to my parents and all those other people to not take the initiative to continue or to want to continue". Maria worked in collaboration with her two best friends to apply for college admission. They decided on going to the University of South Florida (USF), however, her friends were admitted, and she was not. They all refocused their energy toward getting admitted into FIU, however, one of her friend's financial aid package was better at USF. The two friends decided to accept the USF admission. Maria was devastated by their decision but took it as an opportunity to grow personally.

Maria took this first year to focus on her academics as she sought to build a strong foundation. However, she did find time to participate in Express Alternative Breaks where students are involved in community service projects in various cities within the state. She has also made time to attend several lectures on social justice issues. Maria has been able to make friends at FIU with students from a variety of backgrounds including Dominican, White, and Trinidadian/Bajan. She was also a member of a larger group of friends which involved a conflict in which Maria did not feel as if they had "her back". Because of this conflict and decreased financial aid package for her sophomore year, Maria has decided to transfer to USF and not return to FIU for her second year. 


\section{Michele's Story}

Michele is a first semester freshman who is an exploratory health sciences major with dreams of becoming a nurse. Both of Michele's parents migrated to South Florida from Haiti in search of a better life. Michele and her younger brother were both born in Pompano. They grew up visiting Haiti often and learned to speak Creole fluently. Michele is one of two children on her mother's side and she has seven siblings on her father's side. Michele was raised in what she describes as a strict and religious household. According to Michele, the cycle included school and church as their priorities. She viewed this strictness as an asset and shared the following:

Even though they were strict, I feel like it was good that they were strict because I feel like they help instill a certain mindset in me. So, I'm not mad that they were strict. I mean sometimes I do wish they let me out, but I'm kinda like, I felt like it was good. It's good that they're strict. Cause now I know to be serious with my work cause I have a certain life outlook cause I want to be a pediatric nurse practitioner.

Michele definitely attributes her discipline to her parents' strict household. Michele grew up in the Catholic faith and attended church in the Little Haiti community. She was baptized and received her first communion at the same church. Her family attends church every Sunday and use ride sharing to make each service.

Michele identifies as a Haitian-American woman. She explains that her identity is tied to the fact that both of her parents were born in Haiti as well as her ability to speak Creole fluently. Michele also points to taking the time to learn about her culture and taking pride in her heritage. She shared:

A lot of people will say, oh they weren't Haitian because they felt embarrassed that they came from Haiti because you know, then people are like, oh hey, Haitians ya'll eat cats and dogs. We do Voodoo, but I mean, I don't do it. ...I felt no reason to be embarrassed. I come from strong people. The island is beautiful. Why would I be embarrassed with that? So 
I wore my [Haitian] shirt faithfully. My mom made sure it was ironed and I was crispy and fresh. Haitian flag day. And I would have fun. I was singing my songs. I would dance to the music. I have no reason to be embarrassed.

Michele believes that her sense of pride in her ethnicity was derived from visiting Haiti numerous times, growing up in a Haitian community and having Haitian teachers. Growing up in a Haitian community and having Haitian teachers helped her to feel comfortable and not alone. She describes her culture as vibrant and strong. Michele's strong sense of pride stems from the history of Haiti being the first Black nation to gain independence. She attended not only predominantly Black schools but predominantly Haitian student population. Most of her friends were either Haitian or Latinx and felt that they were very similar to her background with strict parents and religious backgrounds. Through visiting Haiti, she was able to appreciate the country's beauty for herself.

Michele's desire to go to college was influenced by her parents. She shared:

My parents, well they don't want to say like, explicitly oh you have to go to college, but you know, they made it very clear like you need to go to school to get where you want to get. They just told me go to school. Not specifically what, but they want me to go to school. So I felt like they kind of influenced me.

Michele was inspired to apply to FIU after visiting the campus in high school and doing her own research on the university and their nursing program. She had the desire to attend an $\mathrm{HBCU}$, however, her conservative parents did not want her to go far. She explained:

I'm surprised I'm living on the dorms. Like honestly if they had it their way, I'd be living at home going to Miami-Dade, but you know, that's not what I wanted... when it came down to it that thought of, I'm like, you know, I can actually see myself going to this school. This school is actually nice. Looking at their stats, it's actually a pretty good school. So, let me go here and I don't regret it. I enjoy this school. 
This tension between what Michele wants versus what her parents desire is a key conflict that most of my participants have to navigate.

As a first-semester freshman, Michele has not had the opportunity to get involved yet. She has attended various programs held within her residence hall. Through programming, Michele has been exposed to the Counseling and Psychological Services (CAPS) office which opened her eyes to some of the issues students face. Consequently, she has hopes of becoming a CAPS peer educator. Michele also has the desire to join other social clubs such as BSU and the Haitian Student Association but maintains that academics is her top priority.

\section{Nadine's Story}

Nadine is a senior majoring in sociology. She is originally from Orlando and is the oldest of three girls. Her mother is from Belize and her father is from Guyana. Nadine grew up in what she describes as a pro-Black household as her mother studied African American studies in college and her father is a practicing Rastafarian. Nadine grew up immersed in the Caribbean culture with soca, dancehall, and reggae being played in her household. She realized early on how her Caribbean culture made her different from other Black students. Nadine explained:

I was joking with my friends and like we're listening to reggae, dance hall, soca or listening to the hot 100 , so, you know, I wasn't really exposed to a lot of more urban music and things like that. And even like movies or TV shows I like to watch cause I used to love Will and Grace. Movies that I like, something like Sweet Home Alabama. But movies I grew up on and then my friends would be like, why don't you know this Black movie?

Nadine's exposure to various music, movies, food, and television shows were dictated by her parents. Since her parents are Caribbean, their household was different from other Black people. This difference challenged the definition of the Black experience. 
Nadine identifies as a Caribbean American Black woman. There are times where she identifies as a Latinx American as a result of Belize being a Spanish-speaking country located in Central America and Guyana's location in South American. Nadine's grandmother speaks Spanish, however, she was not taught the language. Both Belize and Guyana are countries with diverse populations comprised of White Hispanics, Black, and Indian, among others. However, most individuals are used to seeing White Hispanics and those of Indian descent from Belize and Guyana, respectively. Because Nadine is Black, she has experienced instances in which she had to "prove" her ethnicity to others. When I asked Nadine to clarify what she meant by prove, she said:

I guess if I said like I was Guyanese as well. Oh, do you eat curry? Do you know what Roti is? Do you know what pholourie is? Like you know, just asking like, oh, well do you know this if you're Guyanese, do you know that if you're Guyanese or if I said that I was Belizean...people always ask me this...People be like, oh, well do you speak Spanish? And I'm like, no, I don't speak Spanish. But how does that relate? For one, I wasn't even born anywhere near Belize.

These questions would sometimes make Nadine feel defensive. At times, these experiences led her to not be as forthcoming to others about her Caribbean background. However, Nadine's best friend encouraged her by saying, "Be proud of what you are. And like if somebody questions you, then that's their thinking or their mind and nothing to do with you." Nadine describes her culture as "vibrant and full of life". Living in Orlando has allowed her to connect with the Guyanese community there which is larger than the community in Miami.

Nadine was driven to attend college to have options to create a better life for herself and make good on the sacrifices that her family has made. Furthermore, Nadine's mother attended college, so it was expected that she would pursue a degree as well. 
Nadine shared that there is a lot of pressure from Caribbean families for their children to be successful. Nadine explained:

But it's not like I did it just for my family. I have goals and things like that and I feel like college was the best way that I could get to my goals. But yeah, definitely, definitely think that the fact that I had those goals and things like that, it was influenced by making my family proud and things like that.

Nadine applied to the University of Central Florida, Florida Agricultural and Mechanical University (FAMU), and Florida International University. She was accepted to FAMU and FIU but ultimately decided to attend FIU. Her decision was based on the fact that her best friend was already an FIU student and the proximity to her grandmother who lives in Fort Lauderdale. Nadine felt that a benefit to attending FIU was the ability to have the support of both her best friend and grandmother if needed.

\section{Natasha's Story}

Natasha is a junior who is double majoring in political science and international relations. She was inspired by the events leading up to the 2016 election to pursue her studies. Her interest in studying immigration influenced her major and the diversity of Miami led her to choose to pursue her studies at FIU. Natasha was born in New York and moved to Haiti when she was one years old. She left Haiti and returned to New York after being diagnosed with lead poisoning when she was five. During that time, Natasha lived with her aunt while she received treatment for her illness. She returned to Haiti when she was in the second grade. After the massive earthquake in 2010, Natasha and her younger sister were brought back to the U.S. but to Palm Beach to live with another aunt. Natasha's parents both had jobs in Haiti that required them to live there, however, her mother made frequent trips back and forth to visit both Natasha and her sister. Currently, 
both of Natasha's parents live permanently in West Palm Beach. Natasha considers herself Haitian-American.

When Natasha attended school in New York, she was bullied because of her accent and her weight which she describes as "big". She explained:

I was bullied because I did get left back because I was supposed to be in first grade and I got pushed back to kindergarten cause I obviously didn't speak English. English is my third language. So, I was bullied because of that. I was also really big...so a lot of people will look at me like, oh, look at that dumb fat girl you know.

Natasha moved to Florida at the age of eleven and started to lose weight which increased her confidence. The move to Florida brought some positive changes for Natasha. She was added to advanced fifth-grade classes which helped her to continue to Honors courses in middle school and Advance Placement classes in high school. She became known as a smart kid as opposed to her previous experience. She also was not bullied as much as she was in New York.

Natasha's friend circle composed of students who had similar backgrounds. She explained:

You kind of stick with the island people. My best friend's Haitian. My other best friend is Haitian. My other one is Jamaican. A lot of the people that are my friends are also second-generation immigrants...because it was always easier. Cause we understood each other struggle.

The similarity among her friends was a source of comfort. This comfort was sought out in response to negative perceptions of Haitians from classmates from different backgrounds.

Similarly to other participants, Natasha shared that she grew up in a strict and conservative household. Her parents were concerned about the trouble that she would get into, so she was not really allowed to do anything that did not center around school. Natasha shared: 
I honestly used school as my excuse. I was in eight clubs. And I was in honor societies. I was on the Executive Board of two clubs. So that helped me travel a lot. I was in this one called FBLA, Future Business Leaders of America. So, we go to Orlando for state competitions. And I was in other clubs that allowed me to kind of spread my wings. So, every time so I wouldn't say I lied. I lied by omission. So, if I wanted to go out to a party, I would use the clubs that I was in as an excuse. My dad actually went to college here [in the U.S.]. So he knew about volunteering and the things that certain colleges look for. So I'd be like yeah it's for volunteer hours and he was like, you gotta go cause that's how you're gonna get money to go off to college.

Her parents' strict household limited Natasha and made her not as open to sharing the activities that she wanted to do. Her parents were very supportive of anything related to academics, so she used that to her advantage to gain a limited amount of freedom. Although her parents were strict, in hindsight, Natasha appreciates their ways. Natasha shared:

When I look at my classmates now who are pregnant, who are on drugs or who are selling drugs, who are strippers, who are in a sense loose, because they had all these privileges in high school and I look back and I'm like, wow I'm kind of grateful that my parents were strict.

To Natasha, her parent's strict household helped to keep her out of trouble and helped her to be focused on her goals.

Natasha felt as if she did not have a choice to go to college. Her father was sponsored by Haiti to attend a college in New York and her mother attended college in Haiti. As a result, it was expected that she would go to college. She explained:

I knew I was gonna go off to college, get myself a degree and make something of myself. But then I also, I felt like even if I was given the choice, I would still go...And that's a lot of times, that's what our parents told us. You need a degree, not just because it makes you stand out, but to secure a future...I feel like not just in the Haitian culture, but American culture we are pushed to go off to college. So my thing was, I don't know what I'm going to do in my life. I don't want to stay home and work. I'm just going off to college. I'll get something and then I'll figure it out from there. 
Natasha decided to attend college in part because of her parents' conservatism. However, Natasha has enjoyed her time at FIU. She is grateful for her program which has exposed her to world leaders as well as students from diverse backgrounds.

\section{Serenity Selene's Story}

Serenity Selene was born and raised in Miami to Jamaican parents. She is currently a senior majoring in psychology with dreams of continuing her education to become a medical doctor. Serenity is the youngest of 5 children and has an 18-year age gap between herself and the oldest. There is a 12-year gap between herself and her youngest sibling. As a result of this age gap, Serenity felt as if she grew up as an only child. At times, she feels like her siblings are just other adults trying to tell her what to do which has led her to not feel as close to them as she would like.

Serenity identifies as Jamaican-American, however, she does admit to not being as connected to her Jamaican identity as she would like. She explained:

So, with Jamaican culture, I feel like that's the one I least identify with just because I didn't live in Jamaica. I've been to Jamaica only for a few times when I was younger. My parents, it's not like they teach me patois. And I hate when people do that. Can you speak it and this and that? And I'm like, truthfully, no, I can't. And I guess if I could, I guess that's probably why I wouldn't be so embarrassed or so upset with it, but I can't speak patois. I understand it. And if I tried, it feels weird and it feels foreign to me. And I feel like I'm faking. And that's one thing you don't want to do around other people especially when they're from the island. They can tell when you're faking.

Experiences like the one that Serenity shares can make Afro-Caribbean women feel alienated from portions of their identity.

Serenity grew up in a mostly Black neighborhood comprised of individuals with Caribbean backgrounds of Jamaican, Haitian, and Guyanese. Her school's population 
was made up of primarily Black and Hispanic students. Similar to some of the other

participants, Serenity grew up in a very religious household. Prior to her parents move to the United States, they converted to Seventh Day Adventist (SDA) and raised their family in the religion. Serenity described the religion as having many rules:

So from Friday night until Saturday night, or more like Friday sunset to Saturday sunset, we will stop doing homework. We stopped going to work. We stop everything that is not related to God...So on Friday, you do your last biddings and then by Friday sunset, you're bringing the Sabbath...It is every single week, every single week you should be observing Sabbath. So we also do not pierce our ears. We do not wear tattoos. We do not wear jewelry and to be more the way they want you to be, like conservative. I have fake nails on. I shouldn't wear fake nails. Some people say you shouldn't wear makeup...We don't eat certain foods. So for me, for example, I do not eat pork. I do not eat shrimp. I don't eat octopus, lobster, all of that.

Nonetheless, Serenity enjoys her religion and one of her favorite things is family time. Most of her childhood friends were made from her time in church. They have similar values and practices as her, which made it easier. Serenity shared that the SDA faith is sometimes misunderstood. She explained:

Sometimes when we mentioned her [Ellen G. White], some people think we're a cult which is weird to me. Because in a sense if you think we're a cult wouldn't every other religion be a cult. And it's not like we're blindly following because some people do eventually leave and some people read the Bible for themselves. But when people say things like that, that's just because they're a hater, and they're not doing their own research.

Because of the misunderstanding, Serenity shies away from discussing religion with friends. She applies this stance not only to those outside the SDA religion but also to those within it who may not be open to healthy critiques of the religion.

Religion played into some of the restrictions that Serenity faced and continues to encounter. These restrictions influenced her desire to go away to college. She initially sought to attend FAMU because her oldest sister attended school there, however, because 
of indiscretions made by her older siblings years ago, Serenity was discouraged from attending. Serenity expressed the frustration of seeming to have to pay for the mistakes that her siblings made years ago. As a result, Serenity decided to attend the University of South Florida in Tampa. Moving away provided Serenity the opportunity to be more independent. Serenity shared:

Generally, everybody wants to go to a college to be grown, to be independent, but a lot of Seventh Day Adventist want to get away because you don't have to practice Sabbath if you're not with your parents. Unless your parents have somebody else that's Seventh Day Adventist that they know is going to the church watching your back. But you're on your own.

Serenity was able to explore her freedom and not be under the watchful eyes of her parents. She did things that she was both proud and not so proud of but has learned from them all.

After two years at USF, Serenity found herself in a tough financial situation which led her to move back home with her parents. Shortly after that, Serenity transferred to FIU. This semester is her first semester at FIU and she is trying to find her way. She misses the community that she had at USF but is looking to make her mark here. She currently lives at home with her parents and commutes to campus. Unfortunately, Serenity does not have her own car which limits what she can do on campus, however, she is working on building her tribe at FIU.

\section{Yolette's Story}

Yolette is a senior majoring in psychology with dreams of completing her degree to help support her mother and family. She was born in South Florida and was raised by a Haitian-born single mother. Yolette has two older sisters who are ten and eight years older and were both born in Haiti. Yolette and her family moved around a great deal but 
spent a good amount of time in the Lake Worth area. There was tension between the siblings that resulted in Yolette spending much of her time alone. During her solitude, she spent a reasonable amount of time reading, writing, and watching anime. Although she found enjoyment in her time alone, she did find herself crying about the treatment that was directed to her from her older sisters. Yolette explained:

I had these two individuals that were supposed to be my sisters, but they didn't feel as such. And I used to cry to her [my cousin] and I used to be like, oh they're being mean to me. Like they're, they were being mean to me. And it was just blatant disrespect and there was nothing that they could really do. And it was just like my mom, she already had a lot of stress on herself. So I guess the stress of the children, it's just like you guys are gonna figure it out amongst yourselves.

The relationship between Yolette and her sisters are still impacted by their earlier treatment of her. It negatively influenced relationships with other girls and women, where she was reluctant to trust. Yolette's experience with her sisters seemed to drive her need for loyalty with the friendships that she developed throughout her time in school. One close friend was one whose family was of Jamaican and African American background. This friendship came easily to her since the friend grew up in a Caribbean household.

Yolette shared that she attended three different elementary schools since her mother moved around often. On one occasion, her mother removed her from a school that was rated as a "D" school. The removal was a result of complaints that detailed Yolette talking excessively in class. Yolette also shared the following story:

We had this packet that we'd work on every day in class. I took it home and I did the entire packet in one night and then I had brought it back, but I had gotten scolded for it and the teacher had yelled in front of me, yelled at me in front of the entire class. 
Yolette was confused by the reaction of her teacher. Furthermore, her mother believed that Yolette was not being challenged enough if she was able to finish a semester's worth of work in one night.

High school was the first time that Yolette attended a high school with a majority Black student population. This experience was eye-opening, and she shared, "there was people, who look like me everywhere people". Yolette also noticed that the high school was underfunded and located in a low-income neighborhood. She ended up at this school through a mailer detailing a No Child Left Behind program that her mother received in the mail. This program would allow Yolette to skip the eighth grade, however, this would require her to leave her current school and friend. Yolette had no desire to attend the program, nonetheless, she did not have a choice.

Yolette describes her culture as "very rich and underappreciated". She even mentioned that the Haitian culture has gained in popularity recently. This popularity is in contrast to her experience growing up. Yolette described experiences being bullied by other students while attending elementary and middle school. In high school, Yolette remembers rivalries between Haitian and Jamaican students. Her recent experience has involved individuals who want to align themselves to the Haitian culture without having any ties to the island. This alignment took the form of doing activities usually reserved for those from those backgrounds, for example, carrying or wearing a Haitian flag. To Yolette, this added to the notions of underappreciation of Haiti. She described:

It [Haiti] was underappreciated a lot of the times it's been something that a lot of the trials and tribulations and something that has been overlooked. It's very rich in a lot of the things and the first Black country to receive its independence. It helped free DR and get its independence. But then now DR flip the script and be like, oh, what did you guys do to help us? And now we, there's Haitians on the border and then even when Haitians go to 
DR, sell products in the marketplace, they're treated like animals and it's just like, it was a country that was like I said, rich, but then it was abused.

For Yolette, these individuals who are "appropriating" the Haitian culture are representative of those who have not shown respect or given credit to the Haitian community for what it has done. Her feelings are also linked to the period when it was not "cool" to be Haitian.

Yolette feels a strong connection to Haiti, although she has never visited the country. Her family helped her to feel a strong association to her Haitian heritage which has influenced her to identify as Haitian-American. Yolette's mother shared stories of Haiti and sang Haitian lullabies to her as a child. Her mother did not enjoy cooking, however, Yolette was able to eat customary dishes when she visited her aunts' homes. Yolette describes her grandmother's home as being teleported to Haiti. She shared:

It's like stepping into Haiti. There's no, AC. The Haitian radio is always playing. She does not speak English...Like we're in Haiti. I've never been to Haiti, but I feel like this is what it's like. That's what it was like to me.

Yolette's grandmother's house connected her further to her Haitian culture. Although

Yolette identifies as Haitian-American, she shared that she is not fluent in speaking

Creole. Not speaking the language has led Yolette to experience challenges to her identity by other Haitians. She described:

Some people like to argue with me and say I'm not Haitian. I come from Haitian parents. But I feel as if that I grew up with my mother raising me with this culture, my family raising me with this culture, hearing these stories. Yes, I've never been there. And given these experiences that I believe that ethnicity wise that I am Haitian.

Yolette has not allowed narrow views of what it means to be Haitian impact her ethnicity. She stands firmly in her Haitian-American identity. 
Yolette's decision to attend FIU was influenced by the university's proximity to her home, which allowed her to be close but far enough to live on campus. Additionally, she had several family members who attended the university and thought it was a "cool" school. Yolette is involved in a few organizations and is a member of a National PanHellenic Council (NPHC) sorority. She was able to build friendships from her involvements and by living on campus. In contrast, Yolette shares that the competitive nature of the classroom serves as a hindrance to building connections in the classroom environment. She has developed friendships with students from a variety of backgrounds, including Afro-Latinx, Trinidadian, Haitian, and African American. She prides herself on keeping a small circle of friends and seeks intentional relationships.

\section{Xiomara's Story}

Xiomara is a senior majoring in computer sciences. She is originally from Puerto Rico and was born to a mother and father from the Dominican Republic and Puerto Rico, respectively. Xiomara is one of four children with one older sister and brother and a younger sister. Her mother migrated to Miami when Xiomara was three-years old to escape hardships in search of creating a better life for herself and her children. As a single mother in a new country, she set-up base in Miami, specifically the Wynwood area, which is currently undergoing gentrification. Growing up in Wynwood was "rough" with what Xiomara describes as drugs, violence, gangs, and poor schools. Xiomara credits her mother for keeping her away from the dangers of her neighborhood. She explained:

I do think it had to do with my family. And like, how my mom was strict and she was not playing games like, you will not do drugs. You will not be involved in this underage drinking, things like that. Like, she was very strict in that kind of who are your friends? Who are you associating with? 
And are they good people? And she kind of gave me kept all of us in that kind of track. So, I do think that I attribute that to I think my family, or my mom, mostly.

Xiomara described her mother as being "very, very, strict". Similar to all of the participants, Xiomara was not allowed to participate in sleepovers. Although Xiomara's mother grew up Catholic in the Dominican Republic, religion was not a big part of Xiomara's life until she was about fifteen years old. Her mother became ill which brought her back to the religion.

Although Xiomara had older siblings who attended college, she did not feel like she could go to them for assistance with the college choice process. Therefore, Xiomara has learned to advocate for herself by asking her teachers and professors for guidance and resources. She described:

In terms of, like when asking for college decisions, things like that, I mostly, if I'm being honest with myself, I mostly had to drive that effort for myself, because I don't think my older siblings, although they went to college, and they studied something, they didn't have a specific drive. I feel like for me, I love kind of school and education. And they didn't have that, you know, they were just, I'm just going to go to school. So, whenever I had a question about, also, my mom didn't really go to college so, she couldn't really explain to me a lot of these things. I had to ask them. But even them they had limited knowledge about, you know, what they were doing, like, they were like sophomores in college and stuff like that. So, I really had to, like, look internally and ask myself what I wanted to do and ask professors and teachers things like that for resources.

Xiomara's experience is similar to many first-generation college students who have found other avenues besides their parents and other family members to navigate college choice and going process. These students have had to be resourceful to find individuals who could help them or find the information independently.

Xiomara's love for math and science came from a couple of great teachers that she had in elementary and middle school. Aside from those few, she felt that she didn't 
have teachers that challenged her and many of her fellow students were not focused on college. This was evidenced when she switched to attend a magnet law school. She detailed the struggles that she experienced at her new school in the following:

Ninth grade, I was in the first couple of weeks of school, I was not used to the level that they wanted us to be here because I wasn't prepared. And so, after I got used to it, obviously, and I was always it was like a shock. In the beginning, like, whoa, I'm not really used to this kind of level of work and work ethic, and the students were a lot more I think there were students who were not great. I mean, that happens, like every school, but a lot more students were interested in going to college and thinking about their future career aspirations, versus a lot of the students that we were thinking about, were no, I don't really need to go to college. There's I don't have to do this, like, my parents, they, they're fine. You know, like, versus there. This was a different mentality. Everybody was expected to go to college and things like that. It's not like, it was not like a luxury kind of thing. It was more like a basic need. And that, like I said, the teachers were a lot more I would say, passionate about their work.

This new environment was very transformational for Xiomara. Not only did she gain access to teachers who challenged her and made learning exciting. She also was surrounded by like-minded students who were college focused.

Xiomara identifies as a Black Hispanic woman. She aligns more with her Dominican ethnicity since her mother is Dominican. Her identity played a role in the group of friends that she had in high school. She had both friends who were Black and friends who were Hispanic, but the groups never intermingled.

Xiomara describes attending college as the "natural thing to do". Since her older siblings attended college, it was expected that she would follow in their footsteps. Her decision to attend FIU was because of her mother's strictness. Xiomara explained:

That really played a big decision because she was like, oh, no, you cannot go to like out of state schools, like you can't go. And I was like, okay, what are nearby schools, things like that. So that really played a decision in terms of like, what schools I was applying for. University of Miami, FIU and Miami Dade were my choices, basically. So, I applied to UM and 
I got scholarship, but it wasn't like enough. Like it was a partial

scholarship. Yeah. And I was so sad. So, I was like, okay, I'm gonna go to FIU.

Xiomara's experience was similar to many of my participants who experienced restrictions on where they could attend college. She and the others worked within those restrictions to make the best decision. Xiomara currently lives at home and commutes to campus. Living at home has restricted some of the things that she has been able to do because of her mother's continued strictness. Nonetheless, he has been able to build a support system on campus through friendships built through her academic program.

\section{Summary}

The participant profiles provide background information to each of the nine participants. I shared information for the participants in this format to provide insight into their upbringing and life story. These life stories help to provide a better understanding of who they are and aspects that worked to make them who they are today. All of the women described being raised in religious and strict households. Both their religions and family dynamics helped mold these women into who they are today and have shaped their experiences. Some of these experiences have introduced the women to ideas of how they should view their gender and what it means to be women and ladies. Some of these ideas have led to conflicts between the women and their parents and or religions. Despite these differences in opinion and views, the women have found ways to thrive as they navigate these restrictive environments.

Most of the participants chose to attend FIU because of its proximity to home. Their college choices were limited primarily as a result of their strict households. Discussions with the participants have led me to believe that these restrictions were 
primarily a result of their gender. All but two participants live on campus, which is remarkable given most of their parents' hesitance in allowing their daughters to "go away" to college. There were some similarities among the participants in realizing that they are different from other Black students. This difference was typically pointed out by African American students during their middle and high school years.

In some cases, the women were challenged by other Caribbean people who thought that they were not Caribbean enough. These challenges typically made individuals buckle down on their ethnic identification. The women had different views of what would make them align more with an ethnic identity. Some pointed to being able to speak the language, others spoke about whether they lived or visited the island, while others saw a value in engaging in cultural activities such as listening to the music. Some simply identified as Caribbean because their parents were born there.

Two of my participants, Nadine and Xiomara identified as Latinx or Hispanic in addition to being Black. Nadine expressed hesitation in claiming a Latinx identity because of the response or reaction from others. She received questions about whether or not she speaks Spanish as a proof to identifying Latinx. These reactions have led her to feel uncomfortable outwardly claiming that part of her identity. In contrast, Xiomara has been embraced by both the Black and Hispanic communities to which she identifies. Her envelopment in the Hispanic community may be a result of her fluency in Spanish as well as being born in Puerto Rico.

Chapter 5 aims to expand on the information that I presented here in Chapter 4. In Chapter 5, I explore the experiences of my nine participants through the themes that emerged from the interview data. The themes aim to answer the research question and 
seek to provide insight into the experiences of second-generation Afro-Caribbean college women at FIU. 


\section{CHAPTER V}

\section{THEMATIC ANALYSIS}

This study explored how second-generation Afro-Caribbean college women make meaning of their race, ethnicity, and gender within the context of Florida International University. Nine second-generation Afro-Caribbean undergraduate women were interviewed as a part of my dissertation study. This study aimed to bring to light the voices of second-generation Afro-Caribbean college women through the sharing of their unique experiences. The following research question guided this research study: How do second-generation Afro-Caribbean college women at FIU experience and make meaning of their race, ethnicity, and gender?

Four overarching themes emerged from the data using In Vivo as the first cycle of coding and Pattern Coding in the second cycle coding. These four themes include Role of Religion and Family Dynamics, Navigating Life as a Black Woman, Questioning Identity, and Exclusion from Diversity. There are also sub-themes attached to Role of Religion and Family Dynamics, Navigating Life as a Black Woman, and Questioning Identity themes. The Role of Religion and Family Dynamics consists of two sub-themes including Understanding of Self through Religion and Understanding of Self through Family Dynamics. Additionally, Navigating Life as a Black Woman includes two subthemes which are Physical Appearance and Hair. Finally, Questioning Identity involves the following sub-themes: Challenging Prejudicial Racial and Ethnic Norms and Finding a Tribe. Figure 1 illustrates the themes and sub-themes. All of the themes and sub-themes capture how my participants made meaning of their experiences as Afro-Caribbean women attending an HSI. This chapter explores the four overarching themes and their 
respective sub-themes which were derived from two individual interviews with each of the nine participants. The themes are presented in order of most relevance and importance to the participants. The use of thick text was used to privilege the participants' voices and to offer counterstorytelling to describe the experiences of second-generation AfroCaribbean women. As I shared before, I identify as a second-generation Afro-Caribbean woman and also attended FIU as an undergraduate student. As such, I weave in some of my personal experiences that relate to the themes and sub-themes.

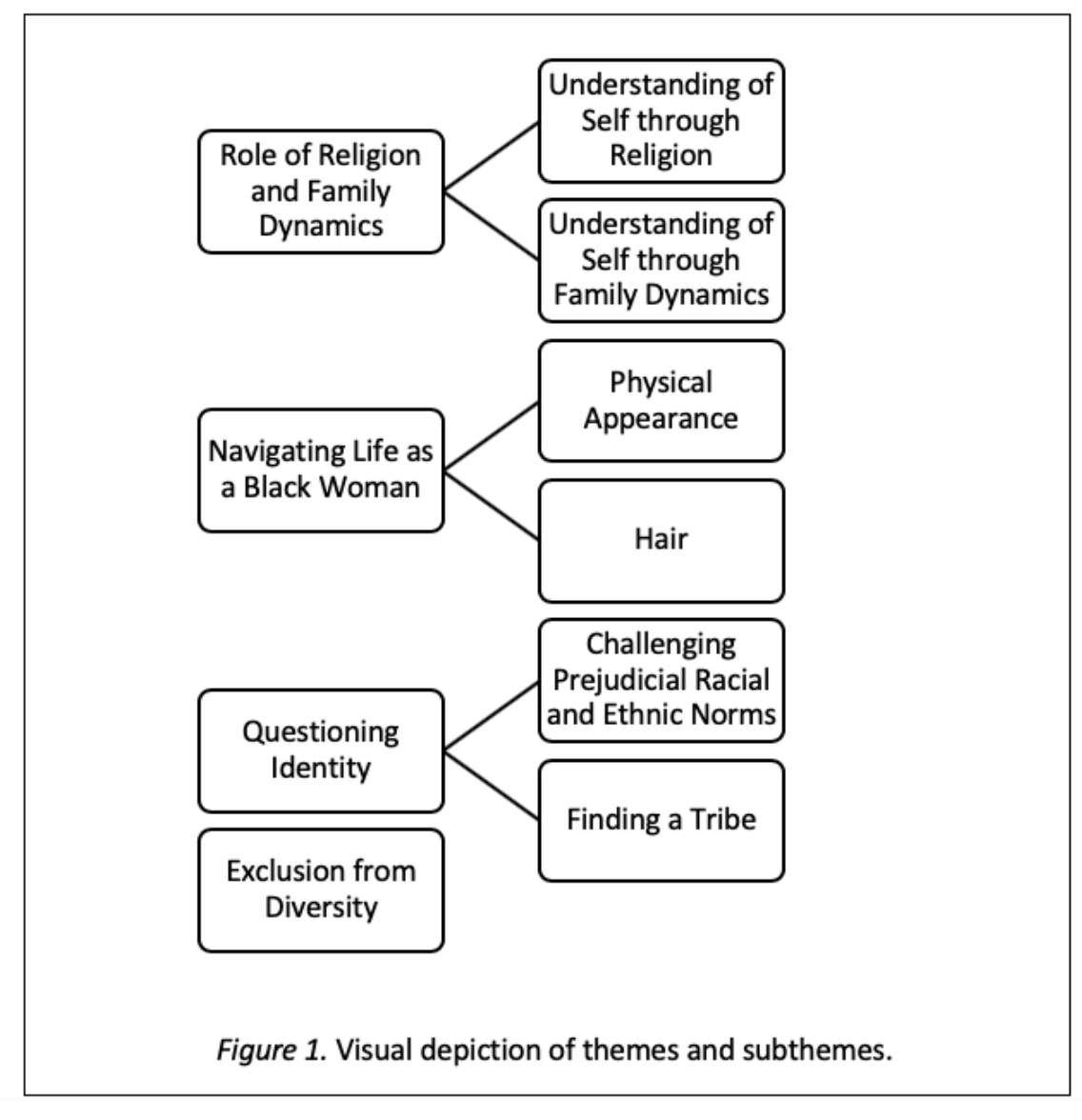

\section{Role of Religion and Family Dynamics}

The first theme is Role of Religion and Family Dynamics which has two subthemes -Understanding of Self through Religion and Understanding of Self Family Dynamics. The overarching theme describes the households of the participants and how 
their religions worked to influence their social identities. These women's upbringing was strongly tied to how they viewed themselves which is consistent with research that ties identity of self to one's upbringing (Rumbaut, 1996). This theme describes gender norms and how they were formed. Littlefield (2003) offers the following gender norm definition: "the division of tasks (labor) as well as to differences in behavior, abilities, preferences, and personality that society expects of men and women" (p. 94). The subtheme, Understanding of Self through Religion, speaks to the strong role that religion played in their lives and their gendered identities. The sub-theme, Understanding of Self through Family Dynamics, encompasses the experiences the women had within their homes and expectations imparted by their parents.

\section{Understanding of Self through Religion}

Six of my participants shared that religion was an important part of their upbringing. Maria, Heather, Michele, and Serenity discussed attending church service faithfully. The strict religious households helped to define many of my participants' thoughts on gender roles. Maria shared:

I grew up in a very strict, discipline, religious family. I always say there was always three places you would find me. It was either at home, school, or at church, anywhere else it was, I didn't go out. I didn't go out. I think it wasn't until I turned 16 that I started gaining a little bit more freedom, but not that much...I say that religion, it helped my morals but at the same time feel like being a girl, I was also in a sense like reduce like certain things that girls shouldn't do or certain things a girl should value more, especially when it came to domestic things. You're supposed to be being molded to be a good wife, a good mother. And I feel like my religion played into that.

Similarly, Danai explained:

So, for me it was first through my religion, well, my parents' religion now. Um, it was just wearing skirts when you go to church not being able to cut my hair, not being able to dye my hair. And it's like all these things where, 
oh, you're supposed to act this certain way in order to look like this or you're going to embarrass our family.

In both of these instances, religion was used as a way to restrict these women and have them buy into ways of being. Danai even expressed thoughts of this kind of control:

And then having that standard I guess, of being a lady, it's constantly put upon you. But then trying to act like people pretend that it's in a way to respect women, but in a way it's to control women and it's to just restrict women from doing things that we would like to do.

To Danai, these expectations work to guilt or pressure women into acting in "appropriate" or "acceptable" behaviors. Danai as well as other participants discussed the pressure to not embarrass or bring shame to their family which were tied to and unique to their gender.

Maria explained that “certain things you can't do because one day you're going to be a wife and you don't want to look back and be like, you were like this and you know, shame your family." Messages similar to what Maria and Danai received were regarded as measures meant to keep women in line. They expressed that many of these messages initially came from their religion then were upheld and reiterated by their parents. Particularly in Danai's case, these controlling messages were in conflict with the independent messages that she received growing up in her grandmother's female dominated household. The conflicting messages spoke of the state of women living in a perpetual state of contradiction.

The religious households of the women also kept some from exploring their cultures and experiences with others from similar backgrounds. Heather explained:

And it's like when, because of the belief system that was in our household, it was hard to do certain things, go certain places or even, you know, just have certain experiences. So, I think a lot of that really shut me down or 
shut me out from what my culture might've been. I do think I have experienced some culture, but there's just a lot I missed out on.

She continued:

So it's like now if I'm trying to relate with say other Jamaican students or friends, it's hard because if they're talking about something like, Buju, and I'm like, who's that? [laughs] Who's that? I'm like, this is and not necessarily that you're going to be into everything, but like, just to have that understanding of what I guess your culture entails or what the music is like or what, you know, certain things are like, I think I missed out a lot on that.

Heather's experience was unique to the other participants. In Heather's case, she identified as Caribbean, however, her religious household encompassed listening to Christian music and didn't include experiencing reggae or dancehall music that is usually linked to the Jamaican and/or Caribbean islands. This difference in upbringing did cause her to feel alienated from those with similar ethnic backgrounds.

Additionally, Maria and Danai both grew up in Haitian households and spoke of the motto "legliz, lekol, la kay" which translates to church, school, and home. In their explanations, they were restricted to those three locations. That sentiment resonated with other participants as well. Natasha explained:

You know, I had like a very conservative strict, I live in a conservative strict household which is like going to parties was not a thing. Hanging out? What was the mall? You don't need friends. You have your family.

Similarly, Yolette shared:

I was the youngest so I also kind of was like, I wasn't allowed to do, like I wasn't allowed to go out. I wasn't allowed to like go to friend's houses. I wasn't allowed to like socialize like younger children did. I was like confined to within the home.

The restrictions placed on these women influenced their lives today. Natasha talked about living her parents' norm when she lived in their home and using college to explore or 
define her own norm. This thought is similar to some of the women who decided to live on campus to explore their independence.

\section{Understanding of Self through Family Dynamics}

Family dynamics played out through strict households that the women had to maneuver. Views of gender were also impacted by the participants' parents and seemed to be separate from the religious notions explored earlier. These views were espoused from early on in their lives and still play a role in how they navigate the world. Specifically, for Danai, she grew up without the significant participation of her father, however, he had very strong views of how she should carry herself as a woman. Danai shared:

But he's also, he's also very Haitian in his mentality. So, he's very strict about gender roles. He's very strict about how women are supposed to act. So, then we have a lot of disagreements in that sense. And sometimes I feel like he doesn't understand me as an individual and that literally frustrates me because I'm like, why is it that I have to work hard on making you understand me when you should've been understanding me for all these years?

When some of my participants discussed their parents' being very Haitian or very

Caribbean, it seemed to be conflated with conservative or strict views. Nadine also expressed expectations that her family had for her as a woman. Nadine explained:

And I was like, cause I forgot to put earrings on today. And I'm literally having a panic attack because I'm like, oh my God, I looked like a little boy because I swear my mom would make me feel like I looked like one day I didn't wear earrings when she was taking me to school. She literally took her earrings off and put them and gave them to me. And I was like, you are so dramatic. She was like here wear my earrings and I was like, oh my God. Am I gonna die if somebody gonna mis-gender me cause I go out into the world without earrings.

Nadine illustrates the pressure that she feels to perform gender roles and norms. She not only has to navigate societal pressures of what it means to be a woman but also the 
pressures imposed by her mother. In both the cases of Nadine and Danai, they

experienced frustration from these imposed beliefs. They also felt stifled from these confining definitions of what it means to be a woman.

The gender of these women seemed to play a role in how they were parented. Maria saw the double standard that took place between how her brother and her were raised. Maria noted:

My brother, I feel like my brother was more lenient. I feel like they were more lenient with him and certain well just him, his personality. He was very structured and discipline and he was always like that. So, I feel like in a sense they trusted him more, a little bit. But I also feel like it goes back to gender roles. How he's a boy. So, since he's a boy he can do certain things or he's capable of doing certain things. So, I was never allowed to go to friends' houses, but he could go to friends' houses. If I wanted to do something or if I wanted to try to do something, it was an automatic no and I couldn't go against that no.

Serenity experienced restrictions on her life as well. She also discussed the challenges she had being the youngest in her family and the expectations and pressure to learn from the mistakes made by her older siblings. She shared similar experiences as Maria of these double standards as her siblings were treated differently for what she viewed as a similar infraction. Serenity shared:

And then to me another issue is my brother, he also had a child out of wedlock, but I don't think the punishment the aftermath, whatever, was as harsh as it was for my sister because she's a girl, but she was also the first out of the family to have a child so I think that's another reason why it was so different. But I guess another reason was her age too she was in her 20s when she first had her child. I think he was in his 30s he already had his college education and so on so forth. But in my eyes, I still didn't think it was fair.

The strict treatment that the women received seemed to be one reserved for women. Maria's and Serenity's experiences are similar to existing literature. Littlefield (2003) shares: 
According to the conventional societal definitions of gender, women's roles are more limited compared to men's, and they have relatively fewer socially acceptable outlets for their aggression. In addition, women are socialized to be cooperative, which may predispose them to stress by causing them to internalize frustration and anger, which can manifest as depression (p. 95).

These women expressed frustration of these gender roles and expectations that have been placed on them. They have made steps to fight these expectations but often find themselves in a losing position as these expectations are powerful and rolled in the overarching notions of parental respect.

The strict household also played into what activities most of the women were able to do. Some of the women talked about being restricted to the home. Serenity said:

I don't feel like I have that autonomy to do what I want. Because number one, I don't have a car. If I had a car that would help with a little independent thing. But I still have to come back home at a certain time. I just can't be out late and about because like I said, certain people made their own decisions and own mistakes before.

Furthermore, Michele shared that some of her African American friends didn't understand some aspects of her ethnicity or the rules that she had to abide by. Michele explained:

But for the most part we were the same and like, I feel like the only differences I have are probably like with the, like the Black kids, cause you know they didn't understand what my parents were so strict or why I eat this or do this.

A few of the other women including Natasha and Nadine also shared similar comments of friends not understanding the rules that their parents imparted. At times, these differences led the women to seek out friends with similar backgrounds who had similar restrictions. 
The gender of these women influenced their parents' views of where they could attend college. Many of the women were limited to attending nearby colleges because of their parents' thoughts and feelings. Natasha provided some insight to her experience and gave an example of a conversation with her mother:

You know a lot of like in the American culture, 18, go off to college have fun. In the Haitian culture, 18, you want to go off why? There's a good university right there. All my friends' kids go there. I want to go there. Why? What do you want to do with your life? I want to do X Y Z. They have that there. But it's not as good as the school I want to go to. It's okay.

Seven of the women expressed hopes of attending colleges that were further away. They also were interested in attending HBCUs. Again, the restrictions of their parents prevented them from exploring institutions that were far away from their home. Michele said:

My parents, they told me they didn't want me to go far cause I wanted to go to an HBCU or whatever. I feel like that'd be cool. That'd be fun, you know. But you know, Haitian parents, they didn't want me to go far...I had FAMU cause I wanted to go to HBCU but that was in Tally [Tallahassee] and Haitians, so that wasn't gonna work out...I was thinking about Spelman and Howard. Like Spelman was in Georgia so that was one, like who's finna let me go out of state? That was a big old stretch...I didn't tell her about FAMU or FSU cause it was in Tally. I didn't bother telling her about that. I already got accepted to those schools. I didn't bother mentioning to her. I'm just like, you know what let me not even do that because she's going to start ranting and I really didn't want to hear the rant.

What seemed to be apparent from the example above and other conversations is that these women strived to avoid "rants" and "lectures" from their parents. This avoidance seemed to be a means of keeping the peace and as a form of agency for harmony between them and their parents.

Additionally, Michele realized that there was a difference between her and her friends' college choice experience. She shared: 
But some of them, like when they were choosing their colleges, they were able to go out of state. That wasn't a problem for them or their parents.

But for mine is like, we want you home. So, I feel like it's different when we're trying to decide a college because they don't, they're not as limited as I am cause I can't go too far cause then it's a problem.

None of the women expressed anger about the limitations their parents gave them in terms of colleges they could consider. The women took it all in stride, knowing that their experience stemmed from their second-generation status as well as their gender.

Ultimately, their college choice options would be more open if they were not women. Their response to the restrictions from their parents could be in part to a lifetime of expectations of parental respect. Their experiences are similar to my story.

As the oldest daughter, I was limited by the options that I could consider for college. By forces unknown to me, I was able to convince my parents to not only allow me to attend FIU but to also let me live on campus, however, the concept caused them great stress. Although the women and myself were limited to attending nearby institutions, we were all satisfied with their choices. They enjoy attending FIU and all have a unique sense of pride in the university.

Serenity was the only participant who had the experience of going away to college. Her parents lived in Miami, yet she was able to move to Tampa to attend USF for the first two-years of college. Her need to go away was tied to her search for freedom which she believes is the case for many students who are Seventh-Day Adventist or come from other strict religious backgrounds. She explained:

When we go away to college, that's mainly sometimes why somebody wants to go away to college. So generally, everybody wants to go to a college to be grown, to be independent, but a lot of Seventh-Day Adventist want to get away because you don't have to practice Sabbath if you're not with your parents. Unless your parents have somebody else, that SeventhDay Adventist that they know is going to the church watching your back. 
But you're on your own. So, when I was away, I practiced it and stuff but sometimes I was like, I don't want to go to church today. I wanted to go to a party or I did this or I did that...And then I came home, I did what I want and probably went out to parties Saturday night too. So, since I'm living home now, I definitely cannot do that. To get out of the house and go to a party. Oh, no, I don't even have a car. So that's just one thing that's also holding me back. So, it's really rude, but Saturday nights to go out it's not too bad but the Friday night is really disrespectful.

Financial issues brought Serenity home and back to the restrictive rules of her parent's household. These restrictions have played a negative role in her campus engagement. Since she does not have a car of her own, she is dependent on her parents who drive her to and from school. Serenity lives close to the Biscayne Bay Campus, so her parents drive her to that campus. From there, Serenity catches the shuttle that makes the 40-60-minute drive between the two campuses.

The theme Role of Religion and Family Dynamics shows how early childhood experiences played a significant role in how my participants viewed themselves and saw the world. Specifically, family dynamics as it relates to gender identity and religion's influence on sense of self were salient. My participants' religions provided cues for how they should conduct themselves as women or ladies. Some of the women viewed these rules as a way to control them and preserve their purity to be good wives in the future. Furthermore, a few were limited in exposure to some aspects of their culture because of their religion. This separation from their culture caused frustration within some of the women who wanted a stronger connection with their ethnicity. The women were also restricted in terms of college choice and activities open to them simply because of their gender. Nonetheless, my participants found ways to exist within the restrictions and oppressive measures placed on them. 


\section{Navigating Life as a Black Woman}

The second theme is Navigating Life as a Black Woman. This theme encompasses the physical appearance of my participants which played into how they made meaning of their race, ethnicity, and gender. The Navigating Life as a Black Woman theme is further expanded through two sub-themes - Physical Appearance and Hair. Physical Appearance relates to how these women are seen as a result of their very visible appearance as Black and as a woman. The hair sub-theme was a topic that was brought up by all of my participants. I did contemplate listing hair as its own theme because of its importance among my participants. In the end, I included hair under the Navigating Life as a Black Woman theme since it is related to how these women are seen and the way that these women express themselves.

\section{Physical Appearance}

Most of the women discussed how their appearance impacted their experiences and how they view themselves. Natasha stated:

I feel like it would have been different maybe if I was a different skin tone. But I know what it's like to be looked at, you know, because I'm a double minority. I'm a Black woman. And then on top of that, I'm a Black woman with an immigrant culture. So, I'm looked weird at from Americans.

Natasha is fully aware of the space that she and other Black women take up. Moreover, she is keenly aware of the negative thoughts and messages that are out there about Black women. As a "double minority," she is both Black and a woman. As such, she, as well as other Black women, are exposed to both racism and patriarchal systems of oppression that inform their experiences. Nonetheless, she believes that there is nothing that she can do. Nadine also expressed thoughts related to her appearance: 
I just happen to have pretty brown parents and with that, I was just like, well, I can't really try to pretend that I'm not a Black person. Guess I'm very physically Black. And then having parents that are very pro Black, very proudly Black, teaching me that there's nothing wrong with being Black. We know that was a good thing. And basically, complimenting being Black and basically teaching me a lot about our culture. I feel like even since I little I learned a lot about different historical Black people outside of school because of my parents. They're very big on that kind of thing.

For Nadine, she was the only participant to share that her parents were "pro Black." Essentially, being "pro Black" meant being proud to be Black despite the existing negative messages about being Black throughout the media and society.

Being "pro Black" also included learning various aspects of Black history that is not necessarily taught in schools. This upbringing seemed to have a profound impact on how Nadine viewed herself early on and presently. The early teachings of her parents were also used to combat negative views or stereotypes that she encountered throughout her life. In other words, the teachings were used to prevent internalizing negative stereotypes. Nadine has a positive view of what it means to be Black because of her parents' influence. Nadine shared:

They're [people] going to recognize that I'm a Black woman because I have Black hair and have Black skin. I'm very much not, like, I'm not somebody who's not easily identifiable as Black and I'm proud of that. And I feel like when I enter a space, people see a Black woman. And I'm proud to take up that space as a Black woman. So, I have not entered a space feeling, other. I feel like a Black woman.

Nadine's pride which was nurtured by her parents, helps her to navigate environments that may not be welcoming for Black women. It was powerful to hear Nadine's confidence in her identity in the face of existing, negative messages about Black women.

Xiomara shared how her physical appearance plays a role in how she views herself. However, she had a unique take because of her identity as Black Hispanic. She 
expressed frustration when others ignore her Black identity. When I probed further, she explained:

I don't know. It makes me feel like I don't know, kind of a little bit uncomfortable or weird. Only because I'm literally physically Black. I appear as a Black person. So, I don't know why you wouldn't consider me as a Black person. Even though I'm physically Black. Maybe my cultural origins are not, but I am and if I didn't like say anything, if you didn't look at my name or anything, you would just think of me as a Black person.

Xiomara very much identifies as both Black and Hispanic, however, her friends and others deny her Black identity. She continued:

Even like some of my friends here. They're like, no, she's not really Black. And I'm like, what do you mean? I'm clearly Black...But you have like that Afro Latina, I would say, mix where you have, which sometimes kind of sucks to be honest, because you're like, sometimes you don't really fit in both cultures. So, it's like, the Hispanic culture doesn't really sometime, include you in every way because you don't really look like a typical Hispanic. And the Black culture doesn't really fit you in either because you're not really from the culture, like the Black culture.

Xiomara's multiple identities challenge her sense of belonging in both the Black and Hispanic spaces. Similarly, Nadine discussed how she reconciles her multiple identities. Nadine shared, "I am proud to be Caribbean. I am proud to consider myself Latinx American, but I have to remember that first and foremost, I'm Black, and I'm navigating this world, this country as a Black woman." In the previous quote, Nadine expresses how race is oftentimes the prevailing way that she is viewed by others. This sentiment was expressed by other participants as well. Viewing race as the most significant of an individual's multiple identities is consistent with previous research that focuses on the experiences of Black women.

Danai brought to light how various aspects of her identification lead her to engage in behaviors where she is policing her behavior. She shared: 
I laugh loud sometimes. So then I just was like, okay, let me laugh like this. Hahaha, you know, and it was like, I just try to, like, I used to try to censor myself so much more. And to try to, you know, fit in that box again. It's like, you know, you have to continuously watch what you're doing and how you're acting or how you're talking. And, you know, my accent sometimes comes out, and then I'm like, I'm sorry, but why am I apologizing? You know, it's like, so I feel like you're just more aware of who you are. Because you have all these identities that have so many, like stereotypes on them, you know, like, there are stereotypes of black women, their stereotypes on black people, the stereotypes on Haitian people, you know.

Danai brought to light the internal messages that these women tell themselves to make others feel comfortable. While they try to make others feel comfortable, they themselves are not able to be themselves.

Being a Black woman has been historically linked to violence towards the Black woman's body (Davies, 2003). Michele explicitly voiced the anxiety she experienced when viewing videos on social media of Black women who are subjected to verbal or physical violence. These videos make her hyper-aware of the possibility of these forms of violence happening to her. Michele explained:

I think, so I watch videos. Like what if some. What if this were to happen to me? Like, what if someone would try me because I'm Black or something? How would I go about this? Would I react? Would I not react? What would I do? So, I think about it...So feel like watching those videos, I learned from their mistakes. If there was mistakes, I tried to learn from them. Like okay, I know not to do that or I need to do this when this happens to me, if it does.

Michele uses these viral examples as lessons to learn from to help her should she encounter similar racist incidences. Viewing violence on Black bodies creates an awareness that the same thing could happen to her because of racist thoughts about her skin color. Conversations with other women did not explicitly raise the same concerns about violence. However, most of my participants did bring up the topic of safety which 
is tied to them being Black women. They seem to be cognizant of how being a woman might impact them. Yolette discussed the messages she received about safety and how that hasn’t stopped her from living. Yolette shared:

But in terms of my gender, I don't know cause even living on campus, people would be like, oh, you know, be careful going out at night. I used to be walking up and down FIU at like three o'clock in the morning and going on walks because after a while I'd feel very trapped in my room. So, I didn't really, I never ran into a problem like at all. I was always, I always felt safe.

Finding ways to live in the midst of mixed messages about race and gender is a commonality among my participants. These women are aware but are navigating the world in spite of it. They are armed with knowledge should their worst nightmare come to fruition. Through these conversations, I've learned that my participants are hyper aware of their safety and being careful, however, it is unknown if men are recipients of similar warnings.

Being Black women at FIU also means that there will be times when the women find themselves as the only Black woman in a class. Several of my participants described cases in which they were the only. Sometimes, my participants were asked to provide their opinion on issues that were related to race. In many cases, they felt the pressure to speak for the whole race or Black women in general. Maria shared:

Especially sometimes being the only Black female in a class, I feel like I have to do extra to stand out more. I know sometimes when it comes to certain topics or certain situations, the spotlight is going to be put on me because in a sense I am representing Black people as a whole, even though I cannot represent Black people as a whole.

Maria's need to do extra could be tied to attempt to counter negative stereotypes by classmates and professors. Natasha also found herself involved in a frustrating class discussion. She explained: 
Actually, that conversation came up yesterday in my Supreme Court class. We were talking about Plessy versus Ferguson, and, you know, separate but equal. And one question was asked was, is there a change. Have you seen progression? And one of the other African American students in the class, she was like, yes, there is change. We have these laws. But when you look at society now and you're looking back, we're kind of going backwards is what she said, because of the oppression and the brutality that Black people are facing. You know and this other girl, she's Hispanic, but she looks white. And she said, it's ignorant of you guys to believe that because a lot of African Americans, minorities such as Asians, they have jobs. They're successful.

Natasha goes on to continue:

I think we were talking about police brutality and she was like, you know, police should be scared because of these stereotypes and a lot, you know? And you're looking at her like, if only you knew the type of stuff that is in our society that yeah, before we go out, our parents are like, listen, you need to dress a certain way. And if you see a police you need to be obedient. Do not be ignorant. Do not do this, you know? Or if a car starts pulling up, this is what you need to do. Girls are getting kidnapped. You know, you're gonna get cat calls. You're gonna be said like these negative slurs.

Both of these examples placed these women in uncomfortable positions that are unique to Black students. In the case of Natasha, she was frustrated that her classmate did not understand the plight of the Black population in the U.S. Additionally, she was left to argue her point to her classmate without the interjection or support of her professor. Maria's example brings light to the pressure that could be felt by Black college women. This could prove to be taxing and can further alienate them from classmates who either think that they are confrontational, always making things about race, or may not agree with their views.

A couple of the women expressed that their identity plays into what they want to see in society. Nadine believes that as a Black woman, she has a responsibility to help 
others reach their full potential. Specifically, Nadine discussed her thoughts in the following passage:

I'm always trying to encourage other people and I feel like being a Black woman has shaped a lot of those things for me because I care about pushing other people forward and things like that and wanting to see not just me succeed but those around me. And I feel like a lot of those things have a lot to do with me being a Black woman in my role in society has shaped who I am as a person.

Similarly, Michele expressed the responsibility of the Black woman to help others. When

I asked Michele what it meant to be a Black woman, she shared the following:

For me that means I am a strong resilient person. I'm not gonna take your crap, I'm going to do whatever I have to do to get what I need done. Cause looking back at the Black women in history, you like, you know what they risked. Like Harriet Tubman, they risked their lives, you know, trying to help other people. And I feel like as a Black woman that's what you should be about. I mean obviously you don't want to, don't risk your life, you know, for dumb people. But I feel like it's good that I feel like a lot of Black women, they help their families even. They're like the strongest person even though they're the least loved. They still stand tall for anybody because when them Black men, you know they're getting shot up. Who is right there for them? A Black woman, their kids. When they're hurt who's right there? And their Black mamas. So, I don't understand why they don't like Black women. But that's again, that's another topic for another day. But I feel like a Black woman, like you're strong, you don't take no one's crap.

Nadine and Michele's views provided some insight to Black women's role in pushing the Black community forward through encouraging others to succeed and supporting those who have been wronged. Both comments align with Daniel Barnes (2016) idea of racework which relates to the historical aspects associated with Black women's sacrifice for the advancement of the Black race. According to Daniel Barnes (2016), "These women combined their public engagement with racial uplift with their mothering practices in their own homes, viewing their importance to the race as one in the same" (p. 52). Some of the race-work dates back to slavery yet it appears that my participants have adopted 
some of the beliefs and characteristics associated with the movement. Michele's note about being the "least loved" offers a unique view of Black women providing love and support to the community yet not receiving it in return as a result of anti-Black racism and patriarchal systems of oppression.

Another aspect of the physical appearance sub-theme was college choice. The participants' identity played a significant role in the type of university they considered and where they applied. In a conversation with Nadine, she shared a moment when she realized the difference between her and her non-Black peers. Nadine said:

One time, I said the phrase PWI in a class, or in a position I was, I can't remember if it was classmates, or maybe it was just peers...And people were like, what is that? And I was like, you've never heard the phrase PWI? And they were just like, no. And I was like, PWI is a predominantly white institution. And they were like, oh, well, what does that mean? I was like, a school that's mostly white people. And then I was like an HBCU, historically, Black college or university. Those are schools, but mostly Black people. And they're like, well, what is FIU and I was like, you don't even know what FIU is? I'm like FIU is an HSI, Hispanic Serving Institution. And I was just like, ohhh chile. You guys don't even know what these simple things are. Then I explained it. I was like, well maybe it's just something that Black people know these terms because it's something that we consider when we're applying to colleges, and some people just go to whatever college they want to go to. But I'm like that even something like that was really weird to me, because I was just, it's showing that we have very different perspective of life. When I was going to college, I was thinking about that and considered, do I want to go to a PWI? Do I want to go to an HBCU? Do I want to go to this?

Nadine's comments shed light on the considerations Black women make when deciding where to attend college. Although not explicitly shared by all of my participants, diversity was something that they sought in a campus that they considered. This was something that sets them apart from other students who have other priorities for needs and wants from an institution of higher education based on their identity. Most of my participants also shared their interest in attending an HBCU. Their desire could be tied to 
wanting to be in an inclusive environment and one in which they could learn more about their racial history.

\section{Hair}

As stated previously, hair is a topic that was mentioned by all of my participants. Specifically, the issue of hair is the idea of keeping it or transitioning it to its natural state. Furthermore, the topic of hair involves other's reactions and their view of natural hair. Natural hair is in opposition to what has been culturally acceptable as the professional version of Black hair, relaxed hair. In the Black hair community, relaxed hair is the common method used by Black women to straighten their generally naturally tight coils. The natural hair movement became popular during the Black Power movement of the $60 \mathrm{~s}$ and $70 \mathrm{~s}$ and has experienced a resurgence over the last 10 years. The natural hair topic is a point of contention between the participants and their families as well as individuals who do not share the same racial identity as they do. For Maria, her hair made her hypervisible in Miami’s mostly Latinx population. She shared:

So, I know in this part of Miami, if I need anything for my hair, no, no. I know that for sure. I know from the experiences I've had in this part of Miami that I'm probably going to get looks when going into the store. I know that I'm probably going to have to use Google translate at some point so that's one. Oh, a third one is, well, if my hair natural hair is out, I get looks from people that are not my skin color or don't have my hair type.

Maria's hair garnered looks that make her feel different and as if she doesn't belong. Additionally, her needs are ignored as a Black woman since she is not able to find products near campus that are specific to her hair type.

The topic of hair caused conflict between the women and their parents. For Danai, she wears her hair in its natural state and chooses to express herself through her hair. She 
enjoys dying her hair various colors which prompts her mother to cry and ask, "What

have I done wrong [as a parent]?" Danai further described the response that she has

received from her classmates:

So, it's like, if I want to chop my hair and I'm going to chop my hair and then it becomes this big deal with people. It's like, oh, my gosh, she's bald. I remember when I first chopped my hair. The people I knew, they were like, oh, my God, it looks good. Oh, my God, you know, I mean, oh, my God, you're so brave. I was like, I'm brave for cutting my hair? I was like why? Cause I had a big afro...I had to chop it. So to me, it wasn't a big deal. I just chopped my hair. And then, my best friend, even he was like, oh my God, you're so brave. You cut your hair. And I was like, I just don't understand why that's a conversation. So, I feel like womanhood is kind of like, at FIU, it's kind of like, if you do something that's out of the norm, just like in the world, it becomes like, Oh my gosh. Wow, you're someone to look up to or you're, I don't know. I just feel like, it's just why am I put on a stage because I chopped my hair?

In the previous quote, Danai brings up how hair is tied to gender. How one keeps their hair is linked to how they are viewed by the general society. Additionally, going outside of what is expected is seen as radical action. This notion seems to be particularly noteworthy for Black women who have not been considered to fit the white definition of beauty.

Similarly to Dania, Maria shared her own story about transitioning to natural hair and her father's reaction:

My dad was very, very conservative, very concerned...my dad wanted the clean nit girl that from the way she, like my hair, I would say was a big thing. I realized, growing up, my mom always relaxed my hair, so my hair was always straight. And then up until February, no, even like last March, that's when I started experimenting with different hairstyles that I would never do like getting sew ins or getting braids and he didn't necessarily like the idea of me having hair that's not mine and he didn't like that at all. And then in February, I fully went natural and everyone was like, oh my gosh, like you're natural. It's so pretty. He was like, so you cut your hair? Why did you cut your hair? What was wrong with your hair? And I'm just like, my hair was damaged. It's not my real, I want to know my hair. That's not my hair. So, he was very conservative about that and didn't, to 
him, the natural hair is like being radical. And even before I went natural, my mom went natural like two years prior. So, when my mom cut her hair, I saw his initial reaction when he didn't like it. And so, with that, he was always like the straight hair, that's the pretty girl, that pretty respectful girl.

Maria's story is specifically tied to colonial views and beliefs about aesthetics and who is determined to be considered a lady. These women are battling messages of natural hair being radical and unprofessional. My participants' experience with natural hair mirrors mine. I transitioned to natural hair much later in life when compared to my participants, however, my parents held and projected their colonial and white supremist views about standards of beauty. I recall being on the receiving end of my parents' negative opinions about my hair which caused me to have to do the internal work to counter their thoughts.

Hair also seemed to cause friction between the women and friends with different racial identities. Yolette described the difficulty she experienced with friends who were different and didn't necessarily understand her general and hair struggles as a Black woman. Yolette shared:

Cause when I was younger, I used to have a lot of white friends or like a lot of Asian friends. I had Asian friends, I had Hispanic friends and it's like, yeah, it's cool, you guys can joke, you guys can have a good time. But there comes a point where there's only so much that they can understand. You're not going to understand why I'm crying for 15 minutes about my hair. You're not, like you're saying my hair looks fine. No, it does not, you can't, you don't, you don't understand the different struggles of feeling like, okay, there's a Black Lives Matter movement starting. Why is that so important for me?

Yolette specifically experienced a revelation when her non-Black friends did not seem to understand her struggle as a Black woman. For one, diminishing the importance of her hair which she views as an entry point to not understanding greater societal issues, for example, Black Lives Matter Movement, is in conflict of what are important to her and 
her race. For all of these women, they challenged the definitions and standards of beauty as defined by the dominate society and the women's parents. Their need to have their hair in its natural state is a political statement. During Danai's interviews, she discussed her mother making the decision to relax her hair at a young age without her consent. She consciously chooses to wear her hair as an act of exercising control over her life and as a way she would like to present herself.

In my conversations with Natasha, she expressed the balance of having to navigate other's views of natural hair. She explained:

I'm natural, you know? I have to have my hair a certain way. Don't leave your hair out. Don't do this, whereas, people who have straight hair, you can just leave it out. It's fine. Me, I have a whole Afro. You know, it has to be kempt. You know, California is the first state that put in a law that people with natural hair can wear their natural hair to work...Like when I get braids, I gotta make sure I get the right braids. You know? I can't shouldn't be getting burgundy or, you know, because that just doesn't look right. But someone that has natural brown or Black or orange, it's so yeah, there's certain things that I do have to think about. Because I have to not live up to the stereotype but live above those stereotypes, prove people that, you know, I am more than that.

In Natasha's case, she acknowledges that negative stereotypes exist about Black hair. Those stereotypes appear to influence choices that she makes in styling her hair. In her view, some individuals view certain styles as unprofessional and in attempting to challenge those stereotypes, she appears to have adopted that view as well. Natasha's view seems to be related to the racial uplift literature (Glass, 2005) related to race and behavior as a result of discrimination.

For Michele, she expresses and internalizes positive messages about her hair. She described being a Black woman in terms of hair. Michele said:

We're intelligent, we're beautiful, we have nice hair, we can grow our hair. Our hair is not everybody. We don't have short little hair. Our hair 
can grow. It's long. There's many Black women with long hair. We're just full of magic.

Michele's view was remarkable as she and other participants were often on the receiving end of negative thoughts about natural hair.

Navigating Life as a Black Woman was an important aspect that contributed to how my participants made meaning of their social identities. Under the theme of Navigating Life as a Black Woman were the sub-themes - Physical Appearance and Hair. Physical appearance is crucial as it is the first thing that others notice when they see Black women. As such, their physical appearance impact how others viewed and interacted with these women. Some of the women verbalized that their Blackness is something that they are not able to hide from. They acknowledged that there are messaging in media that paint Black women in a negative light, however, various experiences have helped some to develop positive self-images. One of those examples is Nadine's experience growing up in a Pro Black household. Nadine's upbringing provided her with a foundation to view herself as Black first before identifying as her ethnic identity. Additionally, Nadine was taught to take pride in her race which influences her positive view of being Black.

Hair was also an important topic for my participants. All of the women had complicated relationships with their hair. Most of these emotions stemmed from standards of beauty that are filled with anti-Black messages. Moreover, messages of beauty did not include Black women or their natural hair. All of the women wore their hair naturally which was a process and journey towards self-love. The self-love was to counter the messaging of what professional or even how women should wear their hair. I saw my participants' act of self-love as radical given the messages that continuously 
communicate that Black women are not valued. Some of the women experienced conflict with their parents about their natural hair. Some of their parents did not believe that natural hair was beautiful and even voiced their thoughts to my participants. Some of the women shared reactions from their friends that ranged from viewing the women as brave for their hairstyles or just not understanding their struggles. Nonetheless, my participants moved forward with maintaining their natural hair. Natasha seemed to internalize some of the negative messages about hair when she shared her need to rise above stereotypes and not wearing certain hair styles to prove to others that she is "beyond that". These experiences showcase the various thoughts that these women have when interacting with others. In general, my participants' thoughts include learning to love oneself in spite of negative messages from the media and those around them.

\section{Questioning Identity}

The third theme is Questioning Identity and includes two sub-themes which are Challenging Prejudicial Racial and Ethnic Norms and Finding a Tribe. This overarching theme and corresponding sub-themes stem from conversations where the women experienced challenges to their sense of self. These challenges were at times frustrating which led to occurrences where these women questioned aspects of their identity.

\section{Challenging Prejudicial Racial and Ethnic Norms}

Challenging prejudicial racial and ethnic norms includes instances in which my participants felt othered because they did not fit into narrow ideas of what it meant to be Black or Caribbean. Four of my participants mentioned the term "oreo" and their experience being on the receiving end of the term. Serenity shared the following story:

So going to middle school, I was in sixth grade. I remember this Hispanic girl, white Hispanic. I wasn't talking to her. I was just standing in line 
getting food during lunch and she just turns around to me and says, oh, you know, Serenity, you're like an oreo but like don't take it in the bad way or whatever. And I was like what? I heard about the word oreo before but I was just like, what this gotta do with anything. I'm just getting chocolate milk, sis, mind your business over there. And then she goes back to her conversation. And I always get mad that I didn't say anything to her. But I don't know, I think it's because I wanted to be nice. Like I know I was mad that she said it, but I guess I laughed it off. And I hate that sometimes I still do that. But definitely I was like, I can't believe she said that.

Nadine also shared her experience of fellow Black students and the "oreo" term:

Just kind of like, oh, you want to be white, or you're an oreo or whatever. Cause like I said, that was until like, I didn't know, every single Black artist and things like that. So, it was the only time that I would kind of felt like I didn't really a hundred percent fit in.

Both of the women were labeled "oreo" by Black, Latinx, and White classmates because of their proper speech and/or propensity to enjoy reading or academics. Fields and Fields (2012) shared "Sumptuary rules produce a regular supply of circumstantial evidence about what the world is made of and who belongs where within it" (p. 37). The act of labeling some Black students "oreo" implies that the activity that they are partaking in or their behavior is more lighted with white people. Serenity's response to the comment was interesting as the need to be nice could be tied to avoiding the angry Black woman label. Instead of addressing her peer, she remained silent and is still presently upset for not confronting her. Serenity's example illustrates the invisible and lasting effects of microaggressions.

Additionally, Serenity's experience led her to question her identity. It even caused her to portray the stereotypical behaviors and images of Black women that her classmates expected from her. Serenity explained:

I tried to be like what I thought other Black people are like, so I tried to be ghetto. I tried to be hood cool, whatever. And I tried to know about these 
rap songs and do all those little dances that everybody does, because I thought that's what Black people are like, because I'm in a Black area. I feel like I had to fit in. How do I go to Black school and I don't want to be that Black girl that is white or acts white or she thinks she's white or something. And I remember people would say I talk like a white girl and that kind of stuff used to really hurt my feelings because I was like, no, I don't. I talk like me.

Within this context, being a Black woman is perceived to be a singular way of being. In this way, when Black women present conflicting portrayals, they are therefore interpreted as "other". In Serenity's case, she did not want to be perceived as "other" which led to adopting and unintentionally perpetuating stereotypical ideas and behaviors of what it means to be a Black woman. Danai also expressed an experience in which she was not accepted for who she was. She resorted to situating herself in a role of providing entertainment to her group of friends. She explained:

But I'm open, I'm always joking around and honestly, at that point, it just became me like making a fool of myself so that I can build connections with people, which was more detrimental to me than anything. So, then I don't really feel like I had friends. Because I feel like those were just people that were there just to laugh at me or laugh with me because I was making a joke of myself in order to feel like I belonged, I guess.

Danai continued:

So, none of us speak now because I know who I am more. And so, I'm not trying to be funny for you just for your entertainment. You know what I'm saying? So yeah, I was the funny Black girl. I was smart. I was intelligent. I'd you know, I was always in AP classes. But oh, Danai, she's so funny. Oh, Danai she's the comedian. I literally got the superlative of the funniest person in my class in eighth grade. And it was just because I was making a fool of myself. It was so sad. It really was it was a dark time.

Danai's statement illustrates the challenges experienced by Black women with non-Black friends.

Xiomara's experience was unique because of her Black Hispanic identity. She discussed the ease she had in navigating two distinct friend groups. Xiomara explained: 
And just a couple, like different groups of people, honestly, they were kind of segregated, I would say to be honest. They were like the Black kids. And then they were like the Hispanic kids. And then there was the population of white people. There was like barely any white people in the school just because I think Miami has very little. I think there's a lot more Hispanic population. And yeah, so I had my Hispanic friends and then I had my Black friends.

When we discussed this further, Xiomara was not able to express why she seemed to easily move between these separate groups that did not converge. She had not given the idea much thought until we discussed it. I believe that her experience highlighted the divide between Black and Hispanic ethnic groups. Additionally, Xiomara's lived experience correlates to comments that she received that ignored her Black identity. Her Hispanic friends did not view her as Black while her Black friends viewed her as such.

Heather and Nadine both described their journey to identifying as Black. Nadine is Black presenting and her parents are from countries that are a part of the Caribbean but are physically located in both Latin America and South America. When she shares her background of Belizean and Guyanese with others, she was met with questions. As a result of challenges to her identity, Nadine made a conscious decision to simply tell people that she was Black. She shared:

For a long time, like when I was in middle school and high school, people would ask me, what I am and I would just say that I'm Black. And I wouldn't say, oh, I'm Guyanese or I'm Belizean and I'm Caribbean because I just, well one, I felt like people didn't understand.

Nadine's friend was the person that encouraged her to express and claim all aspects of her ethnic identity even if others question it. For Nadine, although she was proud of her Caribbean heritage, she did not want to have to continuously "defend" that part of her identity. She realized that, "even though I'm Black and I'm dark skin, I'm still Guyanese, I'm still Belizean." Yolette also fought questions about her identity. She described: 
I think in general with people, it's always that like there's a level or gauge they like to level it and then it's just like, oh well I'm more Haitian than you are and all this other stuff. And it's just like, not really cause as you said, I'm a second generation so like my family just came here too so. Just because I was born here and when you meet people whose parents were actually born here too, and it's just like, so what, how can you really talk shit on me? But anyways, I digress.

Yolette brings to light the conflict that second-generation students feel within their ethnic groups. The conflict consists of constant questions to prove one's ethnicity according to an arbitrary scale. Yolette's story is similar to my own experience in which I was graded by others on how proficient I was in speaking Creole. The experience has led me to feel alienated from my own culture and has led me to feel self-conscious about my ethnicity.

Heather's experience was similar but unique to Nadine's. In Heather's case, she tended to share more information about her identity. In high school, she even attended the Indian student organization meetings to learn more about that side of her identity.

Heather discussed that she realizes that her thinking was problematic and explained that her thinking has evolved to identify racially as Black. Heather explained:

I just came to a place where I was like, you know what, I'm Black. That's what I am. And not that there's any issue with that. I'm okay with that. So, I became tired of people assuming I have mixture or like assuming that I'm this foreign object or foreign body because my hair is different or whatever have you. At the end of the day, I'm just Black, you know.

Moreover, Natasha spoke about denying her Haitian background when she was in high school. She would tell individuals that she was mixed to set herself apart from the stereotypes associated with Haitians. She said:

I feel like I said it to make a difference, like to distance myself from my Haitian culture. My parents are Haitian, but I'm American, you know. I would back it up because my dad's mom is biracial. So, if I slipped out I was like, oh, I'm Haitian, but my grandma is mixed. You know what I'm saying? It was that fear even if the person probably didn't even care. You try to in a sense, it's like a defense mechanism. Yeah, but I have 
something else and that's a lot of Haitians do that. You don't see my hair? And it be like Haitians can't have nice hair. You don't see my color? Not all Haitians are dark skin. And that's the thing though you don't look Haitian. What do Haitians look like? My aunt, she bout the whitest person I've done ever seen in my life. That lady is so white but my mom. Like and it's crazy. My mom has nice hair. Long hair. You know, my dad has blue eyes. So, what's a Haitian? But to everybody else, we're just Black and crusty with nappy hair. You know, so then an offense I feel like a lot of us use a defense mechanism.

Natasha brings to the surface the powerful force of stereotypes and anti-Black racism. In her experience, the negative stereotypes associated with Haitians at the time, led her to align herself with attributes and highlight her proximity to those with coveted features that were more acceptable such as lighter skin tones and being mixed race. In contrast to Natasha's experience, Michele shared the pride that she had in being Haitian:

When I was in elementary, I didn't tell people I wasn't Haitian cause I was embarrassed. I wore my Haitian flag faithfully, every single Haitian flag day. It was no one's business because no one was going to check me about it.

Michele credits her immersion in the Haitian culture for her strong Haitian pride. Michele visited Haiti often, spoke fluent Creole, attended a Haitian church, ate Haitian food, and spent time learning about the Haitian culture.

All of my participants discussed at length the challenges they had as secondgeneration Afro-Caribbean women. The difference seemed to be more profound among the participants who identified as Haitian-American given that they grew up in a home environment that involved a language other than English. Natasha explained:

There's some things that they say, or they do and I'm like, what's that? Like certain movies? Wow, I didn't know that's the name of that movie or a slang and I'm like, we don't use that. You know, for instance, food. Like malanga. There's a lot of vegetables and food I don't know how to say them in English, but I'm American...So there's sometimes I would be in school and I'll be like, how do you say this? And they looked at me like, what do you mean? And I'm like, we don't say it like that at home. 
Natasha illustrations how her ethnicity makes her experience as a Black woman different. Specifically for Natasha and the other Haitian-American women, they have to navigate their racial identity in addition to the difference in language. However, Nadine did share thoughts around not having a shared Black experience as Black American students. She explained:

I was never ashamed to be Black, or I never didn't think I was Black. But just because I didn't always relate to the African American experience, like, the Black experience. Like, you know, I didn't go home and eat the same thing. I didn't go home and watch the same movies, my parents didn't listen to the same music, you know, my parents listened to what's on the radio, Caribbean music and that's it. So, you know, it's like, I didn't really know, let's say, all the hip-hop artists, or the Florida artists that other people might have known, or I didn't see every single Black movie, or things like that. So, culturally, there was things I couldn't really relate to.

Similarly, Xiomara shared:

Some of my friends who are Black, they're like, oh, didn't your parents ever play like these music? And I was like, no, I don't know what you're talking about. Like, I've never heard this. And they're like, it was a classic. And like, the Black culture is like, the classic song you play, like, never heard of these things in my life. And it's kind of different to be in the middle in between, like these two kind of cultures, and sometimes you just don't feel like you fit in.

These experiences truly highlighted the differences felt by my participants. Specifically, there were times that they knew they were Black but received messages that they were not Black enough because of arbitrary markers that had not been experienced. As a second-generation Afro-Caribbean woman, I experienced similar situations in which I could not relate with Black American classmates and was made to feel othered. The experiences of my participants and myself illustrate how pervasive the notion of one monolith experience for Black is within society. The Black monolith narrative is not an 
idea that is only held by the dominant culture, but one that has also been adopted within the Black community.

Although these women were born in the U.S., most of them shared a profound connection to their parents' countries. Natasha shared:

But I'm not just cultivated in my American culture. I'm heavily involved in my Haitian culture, and I want to see my country you know what I'm saying? I don't say, oh, I want to see my parents country get better for the future. No, I want to see my country get better for the future. That's not something my friends or my cousin when we talk about Haiti. No, oh my gosh, look at our country. We don't say look at our parents' country. It's our country. We weren't born there but our roots are there.

Six of the women have visited their parents' countries while others have not. Even still, the connection to the countries was still strong. In the words of Nadine, "I'm Caribbean and that's my culture. And that's something I'm very proud of. Never going to stop being proud of it." The women still identified as Caribbean given that their parents exposed them to either foods, customs, and languages that were tied to their ethnic identities.

The notion of "both" or "everything" at the same time was common among the participants. Danai also talked about navigating her ethnic identification:

There's a duality, so it's like you're either not Haitian enough or you're not American enough, but I'll say for those people that are in between and like those of us that understand that, you know, we are both at the same time.

When I asked Natasha about how she identified, she voiced hesitation in choosing. Although, I never told her that she had to choose one identity, she thought that she had to. Natasha defines herself as diverse and stated, "I'm whatever I need to be at the moment, but I am always all those things. Yes, I think that's something that's really important to remember." She also shared that these various aspects of her identity, allow her to see things from different perspectives. This idea mirrors existing research that speaks to the 
intersecting identities and how Black women are not able to separate or divorce from parts of their identity.

\section{Finding a Tribe}

Tribes are supportive circles where individuals are accepted and can be their authentic selves. Everyone is in search of creating tribes to sustain them throughout life's celebrations and challenges and these second-generation Afro-Caribbean women were no different. These women struggled to find their tribe both during adolescence and within the walls of FIU.

Three of the women expressed experiences of being bullied while growing up. All three women identified as Haitian-American and discussed how it was not "cool" to be from a Haitian background when they were growing up. Danai shared:

So, then I skipped fourth grade and got straight to fifth grade and then it was like I was the youngest person. So then, obviously, people picked on me for that. But then they also picked on me for being Haitian. And even though I had learned English when I was in Haiti cause I was privileged. That's a privilege. So, I learned that when I was in Haiti, but then I still had a little bit of an accent and sometimes I still have it. So it was like they made fun of me for my accent and then they also made fun of me for my hair because before coming here, I was like, Mama, I want to cut my hair for the first time. So, then it was like, I was like bald, you know.

Similarly, Natasha described:

I was bullied. You know because of my accent. I got left back when I came. And I'm always a happy person. So, I feel like I've always been a people pleaser because I know what it's like to be bullied and to be made fun of in school and out of school.

Yolette also explained, "In elementary school, I would get bullied for being Haitian. Even in high school it would be like this Haitians versus Jamaican thing. Bullied.” The experience of being bullied because of their ethnic identification had lasting effects on my participants. During my interview with Danai, she shared that she had not thought 
about those experiences until our conversation and sees the impact in her life today.

When reflecting on her feelings, Danai described the following:

I was very angry. I'll say that. I hate that label of angry Black woman, but when you have so many reasons to be angry, you should be angry and should feel out those emotions. You know, I feel like that's one thing we don't allow Black women to do. But you know, so I was very angry and I just didn't want to talk to people. I didn't want to be around people until around like middle school.

Although, I did not experience being bullied because of my ethnic identification, I do remember being treated differently. It was not "cool" to be Haitian during the early nineties and I received the cold shoulder from my middle school classmates when they discovered my ethnicity. From our conversations, Danai and Yolette seem to still be hurt by being bullied. They believe that their experiences are tied to the small circle of friends that they currently keep. Their past has also played into their hesitancy in trusting individuals. Furthermore, Danai's comments shed light on the need to express your feelings but being held back as a result of the ideas associated with the angry Black woman stereotype.

Despite the stronghold to their ethnic identities, the women still experienced challenges to their identities. These challenges mostly came from within their own communities. Some of these challenges have also taken place on campus when these women have attempted to get involved with student organizations that matched their Caribbean backgrounds such as the Haitian Student Association. Yolette explained:

I've attended the events not necessarily the meetings, but yeah, cause it's like my creole isn't the strongest. And then even in high school, I've always heard that, cause I went to a predominantly Black school or there was a huge population of Haitian and Jamaicans and African-Americans. So, in those conversations I was always met with, well you're not Haitian enough. So, it's just like, oh, how am I not Haitian enough? I don't know. When I talk creole, they're like, oh, you sound like a moun blan [white 
person]. Like you sound like the ones that learn creole to do the missionary trips. And I'm just like you know what, I'm kinda tired of you sizing me. So, I was just like forget it.

Danai also verbalized her frustrations:

Because you have all these identities that have so many stereotypes on them, you know? There are stereotypes of Black women, they're stereotypes on Black people, they're stereotypes on Haitian people, you know? And then also, when I first came here, I wasn't immediately invited into the HSA, or the, you know, just because North Miami is also with a lot of Haitians, but some of them are also Haitian born, right? So, it was just like, oh, you're not Haitian enough, because you don't speak with an accent often. Or you're not Haitian enough, because you know, so I was like, I wanted to be part of HSA but the person that was on the e-board of HSA, she was on the e-board of HSA. And they just made me feel uncomfortable, cause they had meetings, where they would meet, and they're people are all welcome, you know.

Danai initially felt invited by HSA members which influenced her to attend a meeting.

However, Danai's feelings about the organization shifted. Danai explained:

And so, I went to one [HSA meeting], I was like, oh, my God, I love this. And then, identify myself, most of the time, I don't even say Haitian American. But I just say I'm Haitian. So somebody asked me, where are you from? And I was like, my parents are Haitian. And then it's like, somebody was like, oh, my God, where were you born though? Then they were like, where were you born though? Oh, and I was born in New York but and I didn't finish my sentence because I was gonna tell her I was raised in Haiti for 10 years. And she was like, oh, girl, you not Haitian and I was like, girl I am. It was like passive aggressive, but you can tell that she was like, you know, just their biases, I guess. So then I was I'm never joining HSA.

For both Yolette and Danai, these messages caused them to disengage from HSA. For them, the organization was not welcoming. The members were not accepting of different forms of being Haitian or Haitian-American. This was hurtful to both women given how excited they were about getting connected to their culture and others with similar cultural backgrounds. 
Heather spoke specifically about her challenges while in college. She transferred to FIU after receiving her associate's degree from a local state college. Heather currently lives with her parents while commuting to campus and has found it difficult to build friendships. She shared:

I'd say recently, I've been kind of able to develop some pretty decent relationships, so that's good. It does still feel a bit lonely at times, because again, I don't know if I mentioned earlier, but I do commute. So that also sometimes doesn't help but it's not too bad. We have a friendly group of people. But there are sometimes just instances where people might not be aware of what they're saying or doing, and you know, might offend somebody.

Heather experienced roadblocks to developing relationships because of her status as a commuter student as well as her identity as a Black woman. In the tail end of the previous quote, Heather refers to a specific example where she heard a peer yell out the "N" word while studying in an on-campus building lobby. The racist and derogatory slur was not directed to Heather and she did not know exactly who said it. She did feel irritated by the incident. Racist events and microaggressions such as the one outlined by Heather accumulate over time leading to anxiety disorders and depression (Oluo, 2018).

For Natasha, it was different, prior to attending college, she decided that if there was a Haitian student organization, she did not want to be a part of it. Natasha detailed her thoughts in the following:

Cause my thing was the stereotype is that Haitians love drama. And there's always like zin [drama]. I was like I don't have time for drama. I don't have time for gossip. So, I was always trying to stay far away from the Haitian student organization if it existed. Then when I found out it existed, I was like uh uh, not for me. I was like I don't like drama and I don't want to be in the middle of it.

After winning an FIU Haitian Student Association Instagram contest that included payment to attend a conference, Natasha felt that she should attend a meeting. Her need 
to protect her peace, kept her away from the organization at first. Upon attending, she felt at home. She regrets not getting involved earlier in her college career. Through the organization, she has met great individuals who are open minded and have welcomed her which is different from the experience of Yolette and Danai.

Serenity discussed the need to connect with others who share her Jamaican or Caribbean background. This search sometimes made her feel alienated. She shared:

I remember when I again went off to USF. So, they have the Caribbean culture exchange. So that's a club for students from the Caribbean. But it doesn't have to only be people that are from the Caribbean, so anyone can go there. So, I go there. And a lot of the times, I really just wanted someone to know that I was Jamaican, too. I just didn't want to say it because they'll probably ask me, or they'll probably try to talk to me. Like I say, someone doesn't know you're Jamaican, if you're talking like this all the time in an American accent. That's how I sound. I can try. I don't say wa gwan or whatever all the time because it's not common to me. It feels weird. Feels like, I'm trying on to somebody else's shoes and they're not gonna fit. So, a lot of times, I just don't try it and I want them to talk to me like, with their regular accent, what they're born with, how they usually speak to everyone else. But they're not going to do that just because of how I sound and I can't force them to do it. That's gonna be so weird but a lot of times in my head, I'm like I wish they just talked me in their regular accent because I understand you.

Serenity's experience supports research that illuminates the difference between first- and second-generation Afro-Caribbeans. The accent borne by first-generation individuals signals difference and belonging among those with Caribbean backgrounds. Secondgeneration individuals typically lack an accent that can identify them as Caribbean. Serenity sought the connection from other Caribbean students, however, she was conscious and seemed to have an internal struggle of how she might be perceived by them. We did not discuss what influenced her thoughts, however, I believe that it may have stemmed from past experience of not being fully accepted by other Caribbean students, particularly first-generation Caribbean populations. 
In terms of dating, my participants shared the challenges that they have as Afro-

Caribbean women attending FIU and living in the Miami area in general. Maria shared:

I would say within my peers, college peers, like the girls that usually get the most attention or the girls that are usually the ones that people are always saying pretty, those are usually the girls that are more fair skin. They have straight hair. If they don't have straight hair and they do have curly hair, it's the loose curls. It's not the tight coils. Um, girls that usually look like me, they do get attention, they're the ones who have the weave, the wigs, the, just everything.

Again, the White standards of beauty impact the experiences of my participants. Physical attributes such as hair and shade of skin color bleed into various aspects of their lives including dating and romantic relationships. Nadine also discussed:

Being a Black woman in any place, being a Black woman in Miami is interesting, because I was just having a conversation one day with a coworker. We were just talking about how Black woman experiences in the Miami and Black man's experience in Miami is kind of different. I mean, we were talking about desirability politics, and all that kind of good stuff. Which kind of came out with being a Black woman versus being a Black man and our desirability in a place like Miami, and how it differs and what we experience. So that's the way that I feel like my gender has played a role in my experience in Miami.

With Nadine's story, she points to the research that the pool of available partners for men are much larger than that available for Black women (Collins, 2000). Historical racist and sexist depictions of Black women have negatively influenced how potential partners view Black women and their desire to date or marry Black women.

Also, the views of romantic relationships were impacted by what these women saw in their homes while growing up. Maria spoke about her mother's push for her to be independent so that she wouldn't have to rely on a man. Danai also provided a deeper view on the topic of dating while being a Black woman at FIU. She shared the following:

I don't care about ethnicity, or race or gender, or sex like when I'm dating someone. But I feel like, this is similar for most Black women as well. It's 
like, at times you feel like only Black men are attracted to you, it's kind of weird...There was this person, and he was Hispanic. And we were cool...And he was just very nice and very kind, you know? And so, we like hung out with our group because we had a group to like presentations...And I told him, I really think you're really cool. Do you want to go out sometime, like without, you know, being in this environment? And he was like, oh, yeah, but I like white girls. So I was like, oh okay cool. Which was like very shocking to me. I've never heard somebody say it like that, you know? Okay, he was, I just like white girls and I said cool. He has a preference.

Danai continued:

And then I started dating, hanging out with this Black Haitian man. And this guy comes along, and he's like, oh, I've broaden my horizons. And oh, you're such queen. The same person that rejected me because he likes white girls. Apparently, now, I'm dating this guy. This king. Okay, no, he wants to talk to me about oh, I'm a queen. And he just broadened his horizons. And he had some time to think during the winter break. I was like you did not have three weeks to think about that. You need to stop playing me...Like, I feel more comfortable approaching or being approached by, you know, Black men.

She went on to say:

Cause when I got approached by a white guy once, and this is my own fault, because he was actually really nice. But then I was like, oh, he has ulterior motives. And it's like, sometimes when they speak, I don't want to be mean, but sometimes when white guys speak about Black women and dating Black women, it sounds like they're fetishizing us. You know, it's like, stop calling me a queen every day. Stop. Stop doing that. It's like don't. Why are you talking about my caramel skin? What does that have to do with anything? Like, if you want to talk about traveling? I'll talk about that. You want to talk about animals and veganism? I'll talk about that. But stop talking about oh, how cute our babies would look. It's like, no, I was made from two Black people. I'm cute. So, I don't understand why you have to match with me in order for our babies to be cute. My babies still gonna be cute. I don't understand that. So it's kind of like your between that am I not desired? Or am I being fetishized?

Danai brings up multiple topics in this quote. For her, dating is not a simple act. The limited pool of Black male students limits her pool of dating candidates. While she is open to dating men from various backgrounds, she has not seen that reciprocated by men 
from other racial and ethnic backgrounds. Danai also admits to skepticism that she has when men from other backgrounds approach her.

Natasha discussed the push to get married if you get pregnant that she says is prevalent within the Caribbean culture. Natasha believes that the push leads to unhappy and unhealthy relationships that she sees in many first-generation immigrant populations. In contrast, Natasha shared that second-generation immigrants have different views of marriage:

So, when you look at second generation immigrants, a lot of them, a lot of us, are single. We're not ready to settle down. We're trying to make a place for ourself in this world, which makes us very different from my parents. For a lot of us are still in college getting masters, $\mathrm{PhDs}$, bachelors, traveling. It's because we see how the first generation is kind of tied down. There are a lot that are happy and they're married, but they're in their second or third marriage. A lot of them that are still in their first marriage, they're not happy.

As a result, Natasha is focused on self-discovery which was also shared by Maria and Michele. They do so while enduring messages from their mothers about the desire to see them married and produce grandchildren for them.

My participants came to college with hopes of building lasting friendships. They all found friends in a variety of ways. Yolette attended an event called BSU after dark which exposed her to the many organizations that were focused on supporting Black students. Upon arriving at the event, she was surprised by the number of Black students who were in attendance. Yolette shared:

And I was like, all the Black students are all around the pit, all in GC. And it was like, dang there's a lot of Black people right now. And then you just see all the other ones that kind of passing by and it's like, oh, what's going on? And then you just see the music and it's like, oh okay these are my people, this is my tribe. This is my tribe right here. 
Xiomara was able to create friendships through her academic program. From her initial major courses, she was put into a group and became friends with those members.

Xiomara explained:

So, I had a smaller group of friends, which I made because of programming one where we have to spend long hours during our assignments. So, that's my group of friends when there. And then programming II, I kind of carried the same group of friends, but not the same sort of group of friends. They kind of expanded my circle.

While this was Xiomara's experience, some of my participants did not find their tribe through classroom interactions. Yolette shared:

So, whenever you asked someone for help, it would either be like they didn't know, just like you didn't know or they would act like you were stealing their answers. And it's like, no, help me, please. But then once I became a psych major, it was just kinda like, okay, yes, you can kind of make friends. But then it was like weird. So, I pretty much made friends in the involvements that I did or living on campus.

Yolette described the classroom as being competitive and not conducive to fostering true friendships. As a result, she had to rely on her involvements and her residence hall to create the support system that she desired.

Throughout their lives, the women in my study found it difficult to make friends as they did not fit the "typical" description of what it means to be a Black woman or Afro-Caribbean woman. Several of them discussed not fitting the norm and struggling to find a friend group where they felt comfortable and could be their true selves. Nadine explained:

It was like meeting more people that like the same thing as me. I started being friends with and sort of make friends with other Black girls who like to read books, and like Paramore, and like watching theater and stuff like that. And I just realized that it doesn't make us better than people that don't like those things. It's just that we're different. And we like those things. And you can like your things. And we can all be Black and proud. 
Yolette voiced similar concerns when she shared the following:

I identify with the weird Black girl movement, like allow Black girls to be weird. Allow Black girls to be authentic. Allow them to be themselves and like the things that you like. There's a female rapper out right now that I really like, that was like Tierra Whack. And it's kind of like in the vein of Missy Elliot, she was very Afro-futuristic, like very like different from everyone else, all the female rappers of her time and very like forward. I'm not saying I'm forward, who, but I'm just saying I'm very different. It's different.

In these examples, relationships challenged these women's sense of self. In the end, the women strove to find spaces where they could be their full selves. They also challenged others definition of what it means to be a Black woman.

The third theme of Questioning Identity includes two sub-themes - Challenging Prejudicial Racial and Ethnic Norms and Finding a Tribe. Within the overarching theme of Questioning Identity, my study participants encountered various situations that challenged their sense of self. Challenging Prejudicial Racial and Ethnic Norms encompassed a journey marked by denying parts of their identity, battling stereotypes and at times perpetuating them. Stereotypes included instances when others challenged my participants' Blackness. Some felt the need to take on stereotypical characteristics to fit in. Similar to the literature, some of my participants engaged in stereotype lift in which they worked to negate negative stereotypes about their ethnic group (as cited by Deaux et al., 2007). Over time, the women have found ways to be their authentic selves. All but two of my participants have also been challenged in terms of their ethnicity which has led a couple to distance themselves from their ethnic identification. On the other hand, the remaining participants have doubled down on their ethnic identification and have questioned linear ideas of what it means to be Afro-Caribbean. 
Finding a Tribe was a major concern for my participants. Their racial and ethnic identifications seemed to play a central role in how these women found supportive groups where they could be their true and authentic selves. Some found their tribes in the classrooms while others found the classroom environment as an obstacle to fostering friendships. Finding a Tribe included the struggles of finding romantic relationships which was a challenge for all of my participants which they believed was tied to their race. White standards of beauty as well as anti-Black racism and sexism were shared as a conflict to finding the right partner. Moreover, one participant voiced concerns of those outside her race fetishizing her as a Black woman.

\section{Exclusion from Diversity}

The fourth theme is Exclusion from Diversity. When it came to the experiences of these women on the FIU campus, they often felt excluded from the term and definition of diversity. Four of my participants referenced the university's pride in diversity which seemed to stem from and mostly include those from the Hispanic or Latinx communities. Nadine detailed:

Where's this diversity? This school is not as diverse as we act like it is sometimes. Especially, if you look at some of things like SGA. That is not really a very diverse population of people. Or if you look at like, the entire faculty and staff, and like the hierarchy of it. It's a HSI a Hispanic Serving Institution but then the most of the faculty and staff are not really people of color...So it's like, you know, I mean, if I went to a PWI and I felt excluded or I felt like I was being treated differently, like I was being othered, I was being judged, or looked down upon, it would kind of make sense. Because I'll be like, well it's a PWI and this is what happens. This is what we fight against and like this or that. But here, it's like, you can't really say, oh, I feel like I'm being treated weird. Because, we're all supposed to be like, you know, Black and brown people and people of color. I don't really feel $100 \%$ solidarity. I don't feel that it feels like us and them which is really weird. 
Nadine felt that the larger Black student population does not, "feel like we're seen or heard sometimes." As an HSI, Nadine feels that the university has focused resources mostly to Hispanic students. Moreover, Nadine expected that there would be shared goals between the Black and Latinx student body given that they are part of the larger people of color population. Nadine has been disappointed in the lack of community between the groups. Maria also had similar thoughts. She shared:

And I learned that yes, I am a minority and coming to FIU, I in a sense, I felt like I couldn't relate to people that are not like me on the basis of like we're minorities and we're going to push through. But I learned that there is still, there are levels of it. So, and it goes off the basis of how you, not only physically but also culturally.

Above, Maria was referencing a hierarchy that she perceives exists a FIU based on ethnicity and race. A few of the women also discussed not feeling catered to by the university. This topic was sometimes expressed through the kinds of foods that are available on or around campus. This seemingly small slight had greater implications by making these women feel invisible. Maria provided the following thoughts on the topic:

I just want to say this, being at FIU was the first time like being in college was the first time where I didn't eat Haitian food at all and that was like a little bit sad, it was. I felt, too, when it was Easter and I was here and I wanted Haitian food but nowhere around here had Haitian restaurants. So, I ate Cuban food, but it was good. But it was just like, wow, oh my gosh, I really want to go home. Like this is not home. I may get comfortable, but this is not home.

Similarly, Nadine shared:

Why none of the food places think about people? Not to say that I don't like eating Pollo. But at the same time, you are going to put Pollo on campus, then Sergios and then three more places to eat rice and beans when I can eat rice and beans at 17 places as soon as I set one foot either direction of this campus. But there's nowhere that I can eat anything that seems like something from back home. I will be okay with a super whitewashed version of Jamaican food somewhere. Just one little, like tiny, like tinier than Almazar. But we can't have anything like that. 
They're not catering towards the Black students. Are they asking us what we want, what will make us feel more comfortable here?

These women voiced thoughts of not feeling welcomed on campus. Actions that are interpreted as ignoring their specific needs have led my participants to harbor feelings associated with not belonging. Nadine shared that the majority of students who live on campus are Black yet they feel like their needs are disregarded. It has led her to wonder if there would be any difference if she attended a PWI. In her view, she didn't know "if it would be better or not" to attend a PWI. Nadine discussed:

For example, BBC does [cater to Black women] in a lot of ways because that is a very majority Black campus. So, like something for example, inside of their bookstore, they sell some Black hair products. And there's nowhere on this campus where I could find something for my hair. I don't even know if I can find anything for my hair at the closest Walmart you know, or the CVS or the Walgreens when it was on campus. Most of the time I buy stuff for my hair, or things that I need as a Black woman when I go home to Orlando. And I'm like, you guys see those statistics? Why don't you cater towards your Black students who live here?

The notion of invisibility was particularly troubling for those students who live oncampus. Black students live on-campus and felt as if all of their needs were not fully being met. Danai also spoke to the difference between the Biscayne Bay Campus and Modesto Maidique Campus. She shared that the Biscayne Bay Campus has been inviting but she has not really connected with the Modesto Maidique Campus. The topic of invisibility played a role in how my participants were viewed by faculty members and the support or lack of support they received. Yolette struggled and sought the assistance of her professor but was not helped. She shared:

I've had battles with my mental health throughout my tenure here at FIU for that first, I don't think I 100\% was understanding like how is it affecting me or that I really had a problem and it was one barrier because of the stigmas around it. It was a barrier as to why I didn't get help at first especially talking to my mom about it. But then it's like when I 
approached professors about it, it was just kinda like, oh well, you just need to do better. Like you're not doing enough and I felt like it was like a, you're looking at me and saying that I'm probably just not doing what I'm supposed to and I'm trying to finesse you but like, no, like I'm genuinely struggling. It would be like, you don't understand what it took me to get out of bed right now. Like, so having those conversations but like them not understanding, I think I feel like my race did play a role in that, like looking at me as like a Black person maybe.

The referral of a friend helped Yolette to connect with the CAPS to get the assistance that she needed. However, it is not clear how Yolette's race and/or gender played a role the way that the professor handled her concerns.

Along with this invisibility, is the notion that all Black students are African American. My participants did not view being African American as negative. However, only being seen as African American seemed to somehow overlook a part of who they were. The women described the slight in terms of individuals' ignorance to the heterogeneity of the African Diaspora. Yolette detailed:

I've always just been labeled as Black. Like it's, they don't care. Like, oh, I'm Haitian. When you first see me, you're Black. So, I think that's just what it is. But then my experience has, then when I get into those spaces of, okay, these are other Black kids who were involved. And then it's like, okay, I am Trinidadian and I'm from Ghana, I'm from Nigeria. We have this opportunity to express ourselves through our culture and talk about this is our experiences, but just in the greater mass of FIU, you're just a Black kid.

Yolette voiced thoughts that align with research that presents the Black population as a monolith. Not all participants pointed to this thought, however, what was interesting though through student organizations and campus activities these diverse Black students were able to connect with one another and learn about each other's cultures.

The experience of my participants was also impacted by their navigation of the surrounding area of campus or general city of Miami. Nadine shared, "I experience 
racism in Miami all the time." Some of the participants expressed instances where they were treated differently because they were Black. Yolette had the following incident to share:

I'm in the middle of a little Cuba. Nobody speaks English. I can't even begin to talk about how I just want to go, like, I'm just looking for something in Walmart...And it's a process or even I've been to a couple of Latin restaurants before...There was one time, I was with my boyfriend and another time I was with my friends and we were like the only Black people there. And then service to us was always like really trash or then if there was that language barrier it would be like, okay, we're trying to convey our message to them and it was just completely missblown and then it's like the order was fucked up and it's, okay, no. Do I even want to fight with you that you messed up my food or do I want to sit here and eat this?

Maria also shared the following example:

If I were to go to a Hispanic run beauty salon, I don't speak Spanish and they probably don't think I do. And they were right. they take advantage of that. So, they would let people skip. They would skip over me and my friends, they'll charge us extra, they won't have us like they don't go based off their price value. You would say to them like, I'm sorry, excuse me, I don't speak Spanish. And then it's the attitude or like, you know, like the look, you don't speak Spanish and you're in Miami and I learned like depending on what you are gets you better position or better treatment, I would say.

Maria's experience taught her that as a Black woman in Miami, she will not be treated equally. Not speaking English was a particularly sore subject with her as her parents are from Haiti and are expected to know how to speak the language. She believes that there is a double standard when it comes to language in Miami.

Similarly, Nadine encountered some difficulty communicating with individuals

out in the community when completing regular errands. She discussed her experiences:

So, like if I'm in Publix, and I'm like, do you know where the canned beans are, and I get this look of, oh my gosh, why is this girl trying to talk to me? I don't speak English. And that's like the energy that I'm feeling from you that's not a good feeling. Because I'm not mad at you for not 
speaking English. And I know that maybe you had a lot of experiences where people are rude cause you don't speak English. But it's awkward when it's, you already are tired of me or interacting with me before we even have any type of interaction if that makes sense. It's like, as soon as you come to the register, it's like, here we go. We don't have to speak the same language to just get through this transaction, you can still say like, hola, and smile at me. Cause I'm gonna say hi and smile at you. We may not be able to say anything else to each other. But we both know what hi and hola means.

Natasha also shared:

I think that's the only problem I had in Miami. When I want a Publix sub, I really gotta sit there and be like, okay, pollo is chicken. So, I'm like how do I say chicken tenders, you know, like certain situations like that. I don't understand Spanish. That's the only barrier. Like, I feel like I should have learned Spanish to be here. Cause sometimes I feel like I really do miss out.

Experience with Spanish only speaking individuals were not restricted to off campus. A couple of my participants mentioned times when they were not able to communicate with campus staff. Serenity shared:

I think some people that are Hispanic, they get a little offended when we feel that way. But it's seen, I can't tell them this is how I feel because maybe to them it's prejudice. But it's really hard for people that only speak English, or only have a limited knowledge of another language to communicate. And I'm not saying you have to learn this language or get out of the country...Because I remember one time I was at the nail salon here on campus, and I was like, I want to do this that that that and she's like, um excuse me, and she called the receptionist because she didn't understand everything I was saying. She's probably catching a few words and I don't know enough to tell her this is what I want. When you take a Spanish class they're not going to go and tell you, this is how you say nail color and this how you say, pink in different shades.

The language barrier was a consistent challenge for my participants to maneuver. Not being able to communicate while completing seemingly everyday tasks was stressful for these women. My participants' stories were parallel to what I experienced as a student in Miami. I became frustrated when shopping at Walmart or Publix and not being able to 
find someone who could help me find the items that I was searching for because of the language barrier. Additionally, my participants' very visible Black identity does not afford them the best experience when interacting with the immediate community. These challenging interactions seem to come about before they are given the opportunity to debunk expectations which may be tied to negative stereotypes or anti-Black or racist views. While most of the participants believe that Black students were not included in diversity, Xiomara, Heather, and Michele did not express feelings of exclusion.

Exclusion from diversity included experiences in which the needs of my participants were not met and instances in which they did not feel welcomed. Most of my participants felt as if the needs of Black students were ignored. Some pointed to examples such as meal options on campus focusing more on the Hispanic and Latinx student population with no options that catered to the Black student population. Others discussed the difficulty in finding products for their hair. Some even pointed to the irony of attending an HSI, yet the majority of faculty and staff are not individuals of color. Additionally, student organizations and their leaders were not viewed as diverse groups of students. My participants experienced language barriers both on and off campus with members of the Latinx community. At times, my participants felt as if they were treated differently because of their race. These experiences have led to feelings of frustration and isolation.

\section{Summary}

The purpose of this study was to explore how second-generation Afro-Caribbean college women experience and make meaning of their race, ethnicity, and gender. Interviews were conducted with nine second-generation Afro-Caribbean college women. 
Data from those interviews were analyzed to reveal four overarching themes that provide insight into the experiences of second-generation Afro-Caribbean women. The themes included Role of Religion and Family Dynamics, Navigating Life as a Black Woman, Questioning Identity, and Exclusion from Diversity. Role of Religion and Family Dynamics encompassed the sub-themes: Understanding of Self through Religion and Understanding of Self through Family Dynamics. Navigating Life as a Black Woman included two sub-themes which are Physical Appearance and Hair while Questioning Identity encompassed the sub-themes Challenging Prejudicial Racial and Ethnic Norms and Finding a Tribe. The themes and sub-themes provide insight into how the women made meaning of their race, ethnicity, and gender.

The participants' early childhood experiences influenced their thoughts about their social identities. Early experiences were particularly impactful in how my participants formed ideas of their gender identity. Religion was a major part of most of my participants' upbringing. Their parents imposed restrictions in terms of who they could affiliate with, what activities they could engage in, how they dressed, and how they should behave as girls and women. Interestingly, the participants who have brothers noticed that their brothers did not have similar limitations. In one case, one of the participants felt alienated because her religion kept her from experiencing the music that was central to her ethnic identity. For most of my participants, family dynamics and religious households led them to seek opportunities to leave their parent's homes. Consequently, the strictness of their households limited their college choices to nearby colleges and universities. The women's upbringing also influenced their conservative views, which limited their activity on campus, choosing to focus more on academics. 
My participants' physical appearance impacts how they view and interact with the world. Specifically, the women were challenged by how they navigated as a Black women and ideas surrounding their hair. Their visible Black features - phenotype, bodies, and hair elicit various reactions from people. The women have experienced a number of prejudices and negative messaging around what it means to be a Black woman. It appears that one of my participants was able to combat the negative stereotypes by the pro Black upbringing of her parents which helped her to have a sense of pride in her race. There were times when the women found themselves in situations where they had to either represent or speak for their race. This specifically took place in classrooms when they were the only Black women which created a sense of frustration and taxation. There also seemed to be some disparity in how the women viewed themselves and how society views them. Society tends to view Black women in terms of stereotypes and sexist ways. Meanwhile, these women view themselves in terms of helping others. Moreover, the women have challenged the definition of beauty whether it be in media or even from their family and friends. All of the women engaged in the political act of wearing their hair in its natural state despite the questions and oppositions. Although my participants have experienced various levels of prejudices and stereotypes, they have defied them by defining themselves in terms of beauty and what they want to see in the world.

My participants shared experiences where their racial and ethnic identifications were challenged. Some were labeled "oreo" because others from various racial backgrounds did not believe that they exhibited arbitrary characteristics associated with being Black. Similarly, some of my participants encountered questions regarding their ethnicity. Challenges to their ethnic identification were tied to the need for these women 
to prove their ethnicity. This caused some of the women to lean into their ethnicity or race, distance themselves from their ethnicity, or take on stereotypical characteristics of what it means to be Black. The differences in action seemed to be linked to how strongly they identified with their racial and ethnic identification and seemed to evolve over time.

Finding a tribe was of great importance to the women's identity. Some of the women were bullied prior to their college years which continues to influence the women in terms of their relationship with others. Nonetheless, the women were able to find individuals and create groups that supported them being their authentic selves. The topic of romantic relationships was a sore point for my participants as they found it difficult to date in Miami. Some of the women were open to dating outside of their race, however, there were concerns about being fetishized by non-Black males.

Some of the participants' comments expressed concern of feeling excluded from notions of diversity within the university. As a result of the university's HSI status, some of the women believed that the needs of Black students, in general, are not being met. Additionally, some women commented on the broader scope of diversity in terms of lack of representation within the faculty and administrative ranks. Not all of the women voiced concerns about being excluded. The differences reflect how different the lived experiences of individuals can be given their backgrounds. Additionally, the women experienced challenges in terms of language barriers and being discriminated against when they engaged with individuals both on campus and off campus. None of the participants shared any experiences with blatant racism. However, they did share experiences with microaggressions and stereotypes from a variety of avenues. Either 
way, all of my participants' social identities help them to navigate and see the world in unique ways. 


\section{CHAPTER VI}

\section{DISCUSSION AND CONCLUSION}

The purpose of this study was to explore how second-generation Afro-Caribbean college women experience and make meaning of their race, ethnicity, and gender. As the institutions of higher education student population continue to diversify, it is critical to learn more about these populations. One largely ignored group in higher education research is Afro-Caribbean students. This slight is a result of the frequent act of combining Black students and ignoring the heterogeneity that exists among Black populations. Ignoring the within-group difference is particularly troubling as data has shown that the second-generation Afro-Caribbean student population is increasing on college campuses. Studies focused on race, thereby ignoring ethnicity and the impact that it can have on the lives of individuals. Additionally, there is little known about the experiences of Black college women. Given this information, I chose to center my dissertation study on second-generation Afro-Caribbean women. My study is different as it examines both race, ethnicity, as well as gender. Also, my study's site was an HSI which offered a unique setting to explore the experiences of Black college women.

This single-case study was situated within FIU and involved the participation of nine second-generation Afro-Caribbean women. Nine women were engaged in my study and agreed to be interviewed twice for up to 90-minutes. I conducted semi-structured interviews with the goal of answering the research question - How do second-generation Afro-Caribbean college women at FIU experience and make meaning of their race, ethnicity, and gender? The interviews were between 50-90 minutes long, with the first interview focusing on the historical aspect of the participants' lives while the second 
interview centered on their college experience. Numerous strategies were instituted to improve the credibility and trustworthiness of my study, including the use of thick descriptions from the data, sharing the researcher's position, verifying data with participants through member checks, and ensuring the anonymity of my participants.

The results of the interviews shed light on the various experiences that help second-generation Afro-Caribbean women make meaning of their social identities. Early childhood experiences, particularly with family, upbringing, and religion had profound influences on these women's sense of self. These early experiences helped them to formulate ideas about their race, ethnicity, and gender. Physical appearance also played an important role in the lives of my participants. Their physical appearance was an aspect of their being that all of the women felt they could not escape as it was very visible to others. The women's visibility impacted how they were treated by others and was intertwined with their race and gender to the point of not knowing if they were being treated poorly as a result of their race or their gender. The women also had moments when their identity was questioned either by others outside or within their racial or ethnic identity. The women responded to these questions in a number of ways. Furthermore, many of the women were bullied because of their ethnic identification, which has present day implications in their lives.

My participants shared sentiments that they felt excluded from the diversity of the university, which impacted how these women viewed themselves. The exclusion was not limited to the university as the women had similar experiences when they engaged with members of the surrounding community. The women felt discriminated against and treated differently off-campus because they were Black and did not speak Spanish. Their 
experiences on-campus led them to feel as though their needs were not being met or ignored. Additionally, they found themselves in situations where they had to speak for or represent their race.

The discussions with my participants reveal unique experiences that should be explored for further understanding. For these second-generation Afro-Caribbean college women, they are aware of their race, ethnicity, and gender and, for the most part, view all three as equally important aspects of their identity. Naturally, all aspects of their identity play a role and shape their experiences on campus. This discovery is consistent with existing studies, which indicate the inability to separate oneself from other parts of your identity.

\section{Findings and Interpretations}

While seeking answers to the research question, four overarching themes emerged from the data: Role of Religion and Family Dynamics, Navigating Life as a Black Woman, Questioning Identity, and Exclusion from Diversity. Role of Religion and Family Dynamics consists of two sub-themes: Understanding of Self through Religion and Understanding Self through Family Dynamics. Navigating Life as a Black Woman includes two sub-themes, which are Physical Appearance and Hair. Questioning Identity involves the following sub-themes: Challenging Prejudicial Racial and Ethnic Norms and Finding a Tribe. For the purpose of organization, I will discuss the research findings by the overarching themes that emerged from the study. 


\section{Religion and Family Dynamics Play a Significant Role for Afro-Caribbean College}

\section{Women}

Similar to Waters' (1999) study of the Afro-Caribbean population in New York, my participants expressed the importance of religion in their lives. All participants described their households as either very religious, strict, or conservative. This strict religious upbringing had a profound impact on my participants. Their ideas of self were formed and molded through the strictness, which was driven by their religion. Gender norms and expectations were also tied to their religion. My participants received messages of what it means to be a respectable woman through both their religion and their parents. These messages have been restrictive, and some of the women mentioned how these are used as a means to control them. There were directives on how to dress and behave, as well as limitations on dating. Studies point to how religion helps Black women to survive and cope (Chatters et al., 2008, \& Harris-Perry, 2011), however, I was not able to locate literature that highlights how gender norms and inequalities are perpetuated through religion. My dissertation study provides some insight into how religion and family dynamics form gender understandings for second-generation Afro-Caribbean college women. Religion and strict household rules were used as methods to oppress daughters and make them subservient to fitting expectations of girls and women. My participants have learned to navigate within these oppressive tactics by either internalizing or pushing back on some of the gender normative messages. Moreover, my participants credited strictness for their focus on education from an early age. Education was linked to their sense of identity as many of them shared that a focus on education was a characteristic tied to their ethnicity. 
The family dynamics also played a part in my participants' college choice. All of the women were restricted in the colleges that they could consider after high school. Some of the restrictions were tied to the gender of my participants. The women shared that their college limitations were based on their parents' need to have their daughters closer to home as well as pregnancies of the daughters of other family members or friends. In short, if these women were men, they would not have the same conditions as to what colleges they could apply to and attend. For the most part, the women seem to move on-campus to escape the controlling aspects of their parents' households. Keeping their campus activities separate from their parents was used as a means to keep the peace. I view this search for independence as a form of resistance. It is tradition for women in Caribbean households to live with their parents until they get married. The women viewed going away for school as a way to escape their parents' gaze and gain independence. Their search for independence allows them to live out their own expectations for themselves and start to carve out their own definition of womanhood.

\section{Physical Appearance and Ideas of Race and Gender for Afro-Caribbean College}

\section{Women}

Navigating Life as a Black Woman included two sub-themes - Physical Appearance and Hair. The women's appearance played a role in how others receive them. Their physical appearance, which includes their skin color as well as their natural hair, are viewed negatively by non-Blacks as well as some of their parents. These women were acutely aware of both the anti-Black and sexist messages that work to mold their experiences in the world. Nonetheless, my participants work on challenging the negative messages about Black women. Wearing their hair natural was both political and an 
expression of who they are as individuals. It also seemed like something they could exert control over and was a way to challenge ideas of beauty that are based off of white supremacy beliefs. Wearing a natural hairstyle was done as they battled messages of natural hair being unprofessional and not beautiful.

Additionally, the notion of the Angry Black Woman adds to the pressures these women face. In her 2016 New York Bestselling book on race, Robinson (2016) shared, "Angry. Black. Woman. Just three little words, but combined, they become a scarlet letter, tarnishing its wearer as hateful, irrational, emotional - someone to avoid at all costs" (p. 228). Hooks (2014) states, “The 'evilness' of a given black woman may merely be the facade she presents to a sexist-racist world that she realizes would only exploit her if she were to appear vulnerable" (p. 86). Hooks illuminates the predicament of Black women attempting not to appear to be angry while also avoiding being taken advantage of. As my participants move through campus, they are constantly questioning their responses to incidents as not to be labeled an angry Black woman. Furthermore, these women receive messages about threats to their safety through social media and other forms of media. These situations and messages negatively impact Black women's mental state (Shahid, Nelson, \& Cardemil, 2017) and contribute to further oppress them. The views of others conflict with how my participants viewed themselves.

Some of the women expressed their desire to help others and a pull to attempt to improve society which relates to previous research on Black women engaging in racework (Daniel Barnes, 2016). Within the race-work framework, the women are practicing "mothering" behaviors through their support and desire to see a historically exploited and oppressed community improve. Additionally, the women expressed engaging in race- 
work through their need to provide safe spaces for their peers which indicates a need that the university has not met. Relatedly, two of my participants brought up the topic of Black Lives Matter and Black men being killed. As a reminder, the participant interviews took place between April 2019 and December 2019 which is before the current racial unrest and Black Lives Matter movement. The women's comments show how salient this topic is for Black women and potentially the larger Black community. In both cases, the women wanted to either surround themselves with individuals who understood the issues they faced as Black women, or they saw themselves as pivotal to the support that Black men receive within their community.

\section{Questioning Identity}

Questioning Identity included the sub-themes - Challenging Prejudicial Racial and Ethnic Norms and Finding a Tribe. Both of these sub-themes influenced how my participants made meaning of their race, ethnicity, and gender. Similarly to Erikson (1968) and Deaux (1993), I found that early childhood experiences had profound influences on these women's identification. Some of the women detailed experiences being bullied in school as a result of their ethnic identification. The bullying came in the form of others questioning their Blackness and Caribbean identity. Being bullied provides cues into other's views of their ethnicity and how it is situated in the greater society in terms of oppressive structures. Hooks (2014) provides an understanding when she states, "In an imperialist racist patriarchal society that supports and condones oppression, it is not surprising that men and women judge their worth, their personal power, by their ability to oppress others" (p. 104). Within the society that Hooks describes, my 
participants' classmates exhibited the behaviors ingrained in them that states that you gain power from the oppression of others who you deem to be inferior.

In some cases, the women faced challenges to their ethnic and racial identifications because they did not match the narrow views of others. These challenges led the women to question their identity. Despite challenges to self, these women claimed identities that were tied to both their race and ethnicity. This discovery is similar to those that find that second-generation Afro-Caribbean individuals tend to identify with a hyphenated (Portes \& Rumbaut, 2001; Vickerman, 2001; Waters, 1999). Contrary to some research that highlights the Caribbean population's tendency of not focusing on race or wanting to differentiate themselves from African Americans (Vickerman, 2001; Waters, 1999), one of my participants discussed the importance of race in her upbringing. In all cases, these women persevered and found ways to be authentically them and not fit into narrow definitions of Blackness or Caribbeanness.

Of particular importance was the relationships with peer groups, which is encompassed within the Finding a Tribe sub-theme. Peer support involved the discovery of their tribes. Moreover, it included the participants' building groups where they could bring their full authentic selves. Some of the women shared that they experienced some challenges on campus when attempting to become involved with ethnic student organizations. As a result, the women decided not to be a part of the groups. In turn, they formed their support groups with individuals who had similar ethnic backgrounds and other interests. These findings are consistent with that of Griffin and McIntosh (2015), which explored the involvement of Black immigrant student populations of various generations. 
While the participants spoke about how their race, ethnicity, and gender were all important, race seemed to take precedence over other aspects of their identity. Rogers (2001) shared that first-generation Afro-Caribbean immigrants do not have a strong sense of racial identity because of their limited affiliation with Black institutional networks such as fraternities, BSU, and other Black organizations. My research highlights the difference between the experiences of first- and second-generation Afro-Caribbean populations. My participants were involved in several Black institutions that helped to inform their race, ethnicity, and gender. They have found refuge among Black institutional networks such as the Black Student Union and Council of Negro Women. Through these organizations, my participants have learned more about the history of the Black race within the United States and they have gravitated toward a balance between an ethnic and racial identification.

While gaining racial and ethnicity were important to my participants, gender also carried implications for second-generation women. Some of my participants described comments of you're not Haitian enough which I believe to be challenges to their role as women who are charged with the task of passing traditions (i.e. language, food, etc.) of their culture to their children. Such expectations are not put on men and I would anticipate that the reactions that my participants received from members of the Haitian student organization would not have been the same for men. My participants have challenged patriarchal systems by rejecting the belief of those members and forging their own groups that will accept them for who they are.

Additionally, Danai's feelings and comments about her Latinx male classmate expressing that he does not date Black women are in line with Black women not being 
seen as viable marriage partners by white men (Hooks, 2014). Although her example is a Latinx man, similar notions can be applied as it appears that this young man has accepted messages that Black women are not desirable. Danai was not able to accept the newfound interest in her as she questioned how he could change his views on dating Black women over a small amount of time. Hooks (2014) shared "Phobic fear is not a solution to the problem of sexual exploitation or rape. It is a symptom" (p. 68). Danai immediately thought that it was a result of some type of fetish that he wanted to explore. As pointed out by Danai, ideas of anti-Black racism are developed over a lifetime of negative messages about Black women. This is tied to the history of white men and media sexually exploiting Black women.

\section{Exclusion from Diversity}

Exclusion from Diversity was exclusively related to the FIU experience of these second-generation Afro-Caribbean women. Since FIU is designated as an HSI, these women expected that they would have some level of solidarity around the general struggle specific to people of color. They were surprised by the segregation that exists between the Hispanic/Latinx and Black populations on campus. As a result, they do not feel as if there are aspects of campus that cater to their demographic. Some of my participants felt as if the university did not meet their specific needs. Additionally, some participants felt as if their presence was not acknowledged. These experiences have led my participants to feel invisible on campus. The feelings of invisibility are similar to those expressed by Black women who attend PWIs (Shaw, 2017) and left my participants wondering if the university knows that they are there. Examples of not having products on campus that are specific to their hair type and not including food options that Black or 
Caribbean students would enjoy were just a few of the concerns that my participants voiced.

My dissertation study offers a unique view of how a college campus' surrounding community plays a role in second-generation Afro-Caribbean college women's views of self. The women's interaction with the community was not a surprise given the history of race relations in the greater Miami area. Encountering individuals who do not speak English who treat them differently because of either their race or their inability to speak Spanish, all played into the experiences of these second-generation Afro-Caribbean women.

The women encountered discrimination and microaggressions that were rooted in anti-Black racism and white supremacy. My participants shared how they get looks when they wear their natural hair, that store clerks are tired of them before they interact with them, and that there are times when they are taken advantage of because they do not speak Spanish. The incidents with the community that my participants detailed illustrate how they have been socialized through messaging and media to understand that Black people cannot be trusted and that Black women are difficult. Hurtado et al. (1998) challenged institutions to evaluate how minority groups feel on campus in an effort to create a diverse campus climate. The interviews shed light on the experiences of secondgeneration Afro-Caribbean college women and expose issues that hinder welcoming environments for the population both on and off campus. The findings also provide some insight into how higher education leaders and faculty can improve the experience for second-generation Afro-Caribbean college women and Black college women in general. 


\section{Limitations}

Naturally, there are limitations to all research studies. Specifically, for my research, there were several limitations. First, my role as an administrator could have played a role in how the students responded to me. I believe that the slow response that I received from potential participants were a result of my limited connection to the student organizations on campus. My difficulty in recruiting participants could be related to the indifference experienced by Black women attending FIU. It appears that there is a lack of concern by the institution about Black women's issues. The women have found pockets of individuals who care about them but in general they feel like their concerns are largely ignored by the institution. Their response to my dual role as an administrator and researcher could have influenced their responses.

Second, opening up the participant pool to all undergraduate levels could have impacted the data collected. For example, two of my participants were freshmen who had limited experience on campus. By virtue, they were not able to draw from years of experience navigating campus and the surrounding city. Therefore, their relative youth, compared to seniors, could impact where they are in their self-identification and selfawareness. As a result of their age and limited time on campus, they may not have experienced challenges to self or may not have the vocabulary to express various situations they have found themselves in. Therefore, they could interpret the overall campus environment differently from those who have been there longer. Furthermore, expanding the pool to including graduate students could have added to the depth of the data collected. Two graduate students expressed interest in participating in the study, however, because of the specifications of the IRB, they were excluded from participation. 


\section{Implications for Practice}

There is countless research that examines the experiences of Black students on college campuses, however, most focus on that of men. Of those that focus on Black women, they have done so rarely accounting for the within-group diversity that exists. Moreover, the research has explored the experiences within a PWI or HBCU setting. Through my study, I illuminated the experiences of second-generation Afro-Caribbean women within an HSI. Understanding the experiences of this population will aid in informing practices that impact the sense of belonging of second-generation AfroCaribbean college women and Black college women in general.

The implications of this study are aligned with the findings. First, higher education administrators should understand the importance of religion and family dynamics in the lives of second-generation Afro-Caribbean college women. My participants described how their religion and family dynamics played significant roles in how they view their gender and ethnicity. These women arrive at college campuses with these unique perspectives, which impacts how they see themselves and the world. These experiences also play a role in where they decide to attend college. The generally conservative views of their parents limit how far they can "go away" for college. The women themselves have adopted some of the conservative views which have impacted their campus involvement because of their desire and the pressure imposed on them by their parents to focus on their academics. As a result, second-generation Afro-Caribbean women may not see the value or be as involved at least during the beginning of their college tenure. Consequently, it may be prudent for institutions to find ways to 
communicate the importance of campus involvement to second-generation AfroCaribbean college women and their parents early in the college recruitment process.

Additionally, my participants shared stories that involved discrimination and bullying that occurred during their time in primary and secondary education. The findings have implications for curriculum for pre-service teachers to be more culturally competent and support students similar to those in my research before they arrive to college. There have been movements in the United States to remove courses addressing social injustice from teacher-training curricula. Therefore, I call on institutions of higher education to reinvest in courses that focus on racism and other systems of oppression and infuse these topics throughout the pre-service teacher curriculum. It is necessary for institutions to fight the trend to divest in diversity courses that encourage future teachers to engage in necessary social justice work and better equipped to help second-generation AfroCaribbean students.

Second, Navigating Life as a Black Woman ties into the participants' physical appearance and hair. My participants shared powerful stories of how their physical appearance and hair influence how they are viewed and treated. Specifically, these women spoke of engaging in the process of self-love and challenging traditional white standards of beauty and professionalism in the media as well within their circle of family and friends. All of the women wore their hair in its natural state which created internal battles. Classmates also reacted to the natural hair styles in ways that made my participants feel hyper visible and othered. As such, it is important that diversity training is provided to professionals and career development staff to address implicit bias and understand the internal struggles that Black women endure that have implications for 
their job search process. Additionally, separate training should be available for both students and professionals to understand that natural hair is not exotic and is not an act of bravery. Sensitivity training can help individuals to normalize natural hair to reduce the exotification of Black hair.

Third, my participants had experiences where they questioned their identity. Some of these negative experiences took place during their time in college while engaging with groups that should serve as a place of support. It is vital to provide training to help these students understand their role in assisting with student success as well as creating welcoming environments. Griffin \& McIntosh (2017) found similar results in their study and also recommended resources and training for these organizations that have missions to provide safe spaces for second-generation Afro-Caribbean students. The discussions with my participants shed light on the importance of peer groups with similar backgrounds. Selene was the only participant to attend a PWI prior to coming to FIU. She shared how easy it was for her to make connections to the Black student population at her prior institution. There were chat groups, the Black carpet, and other ways for Black students to connect. She noticed that those things do not exist at FIU which has made it a challenge to connect with other Black students. Institutions should establish opportunities for Afro-Caribbean students to engage with one another. Higher Education practitioners must interrogate if their institutions have organizations beyond the Black Student Union that can provide support for second-generation Afro-Caribbean women. These organizations are most likely the first ones that second-generation Afro-Caribbean women seek out to join. Furthermore, it is essential for practitioners to be aware of these 
organizations and be able to refer these groups to Afro-Caribbean women who may not know they exist.

Fourth, my participants expressed feelings of being excluded from diversity. My study was conducted at an HSI, and while the university prides itself on diversity, some of my participants feel as if that diversity does not include them. A few of my participants expressed not being able to find products on campus or nearby for their hair type. University officials should work to assess the needs of second-generation AfroCaribbean women to provide and work with local stores to supply needed products. As noted by Hurtado et al. (1998), institutions should go beyond increasing representation of minority students. In the process of creating diverse and inclusive campuses, institutions should work to recognize these groups of students and identify ways to support them. Although Hurtado et al. (1998) spoke specifically about the steps that PWIs can take to work with diverse student populations, their recommendations can apply to HSIs. For instance, one particular participant shared that she wondered if her experience would be different if she were attending a PWI. Support for second-generation Afro-Caribbean college women should consist of reaching out to the population to learn more about their experience, needs, and pain points. For that reason, identifying second-generation AfroCaribbean women is essential, yet it is data that is not typically collected by universities. It is critical to ask these women about their experience then take real action to help them know that they are being heard. Efforts should be made to provide specific programming that addresses the concerns of second-generation Afro-Caribbean women. Moreover, support involves creating processes for the second-generation Afro-Caribbean community to voice concerns on a continuous basis and making a commitment to address 
racial and climate issues as they arise. Also, practitioners should question the makeup of their campus student leaders, administrators, faculty, and staff to ensure that it represents their commitment to diversity. What processes exist that systemically exclude secondgeneration Afro-Caribbean college women and Black students from participation? What hiring process does the university have that systematically exclude Black applicants from being considered for high level roles.

Specifically, at FIU, second-generation Afro-Caribbean college women highlighted the segregation of the various ethnic student groups on campus. While these segregated groups offer positive benefits to assist students in the process of belonging, efforts should be made to help students to interact with and learn from students with different backgrounds. Providing opportunities for various ethnic groups to engage with, learn from, and about the second-generation Afro-Caribbean student population is critical. To further address the issue of student segregation, higher education leaders should discuss the establishment of at least one required course to include curriculum around tackling systemic and anti-Black racism, sexism, and other forms of oppression. There are currently no required diversity courses for all college students. Developing required course(s) could lead to better understanding of others, challenging stereotypes and racist views, and better relations among students on campus. Specifically, the courses should include content that exposes the experiences of second-generation Afro-Caribbean women and the intersecting identities that complicate understandings of Black women. A diversity course can help to foster alliances among students to dismantle institutional and anti-Black racism. Although a course would be helpful, it is important to note that one course will not resolve the complex systemic issues that exist. 
What was clear with my study is the participants felt that they could not detach themselves from parts of their social identities. To revisit what Natasha shared, 'I'm whatever I need to be at the moment, but I am always all those things." My participants view all aspects of themselves as essential, and practitioners and faculty should make every effort to understand them. Universities should provide more nuanced sensitivity training that cover information about Black women to include details about secondgeneration Afro-Caribbean women. Moreover, these trainings should include content that addresses anti-Black racism. Only one of my participants, Yolette, expressed challenges with a professor dismissing her cry for help as she struggled through mental health issues. While I only had one woman explicitly share her struggle during the interview, a couple of the participants expressed the desire to seek counseling. Yolette's experience with her professor directly tied to notions of the strong Black woman and illuminates the bias experienced by Black women. Her experience is consistent with the ideas of the strong Black woman that states that Black women do not require support. Furthermore, Yolette's experience correlates with that of Shahid, Nelson, and Cardemil (2017) that relate to negative campus experiences playing an active role in the mental health of Black college women. Bias training should be explored for both faculty and staff to recognize intentional and unintentional bias that leads to ignoring the mental health needs of Black women.

\section{Recommendations for Future Research}

My research provides a unique view as it examines how second-generation AfroCaribbean college women make meaning of their race, ethnicity, and gender within the context of an HSI. Many of the women shared how grateful they were of the research 
topic, and the women appreciated the opportunity to vocalize their unique experiences and needs. As such, I believe that much can be gleaned from studying the experiences of Afro-Caribbean women with various functional areas within higher education. For example, what is the experience of Afro-Caribbean women who seek the assistance of campus psychological centers? While exploring this topic, the need for a safe space seemed to be of priority for these women. Given today's climate with race conflict, further exploration into how second-generation Afro-Caribbean women search and find safe spaces would prove to be an interesting topic and may further illuminate the experiences of Afro-Caribbean women on college campuses.

My study specifically examined the experiences of these women enrolled in an HSI. Further work can include learning about the experiences of second-generation AfroCaribbean women at PWIs or HBCUs or even in a rural or non-minority majority location or institution. Examining these different institution types through a multi-case study would prove beneficial as well. Examining the experiences of second-generation Afro-Caribbean women in different environments will help us to understand this group further.

While this study focuses on Afro-Caribbeans, the findings can help in understanding other second-generation populations. Specifically, future research needs to examine specific ethnic groups. Although my study illuminates the experiences of second-generation Afro-Caribbean women, the population can be segmented further, for example, looking specifically at the experiences of second-generation Jamaican or Haitian women. Rumbaut (1996) stated the following:

Procrustean, one-size-fits-all panethnic labels - such as Asian, Hispanic, black are imposed willy-nilly by the society at large to lump ethnic groups together that 
may hail variously from Vietnam or Korea, India or China, Guatemala or Cuba, Haiti or Jamaica, and that differ widely in national and class origins, phenotypes, languages, cultures, generations, migration histories, and modes of incorporation in the United States (p. 120).

Rumbaut's thoughts point to the importance of segmenting populations to understand their experiences better. It is critical for future research focused on ethnic groups to refrain from lumping ethnic groups.

My study illuminated the importance of religion and family dynamics in the lives of second-generation Afro-Caribbean women. Future research should examine this topic further and attempt to understand the implications. I found that family influenced the college choice of my participants, however, future research should explore all aspects that influence the choices of second-generation Afro-Caribbean women to close the gap that exists on this subject.

Mental health is a topic of concern across college campuses and it did come up during my conversation with Yolette. Yolette shared that the faculty ignored her cries for help. In her case, a friend encouraged her to seek assistance. Future research should explore how second-generation Afro-Caribbean college women advocate for themselves and/or what roles their support systems take during times of mental health crisis. Additionally, more could be gleaned from studying how second-generation AfroCaribbean college women manage when they do not seek the help of a mental health professional.

\section{Conclusion}

The purpose of my study was to explore the experiences of second-generation Afro-Caribbean college women to discover how their experiences shape how they make meaning of their race, ethnicity, and gender. It is important to provide counterstorytelling 
to illuminate the experiences of Black women given how stereotypes have shaped how they are viewed by others. Counterstorytelling provides a different narrative that brings forth a call to action for universities. Black women are successful on college campuses with them accounting for sixty-four percent of bachelor's degrees awarded to Black students during the 2015-2016 academic year (U.S. Department of Education, National Center for Education Statistics, 2017). Therefore, Black women are often ignored in higher education research. The counterstories from my participants illustrate that secondgeneration Afro-Caribbean women have unique experiences that show that they are experiencing challenges while on college campuses that require attention from higher education professionals.

It is essential to understand how the upbringing of second-generation AfroCaribbean women are different and directly influences the way that they navigate and experience college campuses. While there are studies that focused on the experiences of Black college women, there are none that explicitly examine those of second-generation Afro-Caribbean college women. Moreover, none of the research explores their experiences within an HSI. This research attempts to fill that gap and is unique as it points to how their multiple social identities shape their experiences on college campuses.

An exploration of data revealed four themes: Role of Religion and Family Dynamics (including the sub-themes - Understanding of Self through Religion and Understanding of Self through Family Dynamics), Navigating Life as a Black Woman (including the sub-themes - Physical Appearance and Hair), Questioning Identity (including the sub-themes - Challenging Prejudicial Racial and Ethnic Norms and Finding a Tribe), and Exclusion from Diversity. The findings highlight how these women 
make meaning of their intersecting identities. In addition to their history, the campus and surrounding environment play a role in how the women experience campus and how they make meaning of their social identities.

Religion and family dynamics were important to formulating ideas of gender norms. Bell Hooks (2014) shared that white colonizers used Christianity as a way to suppress sexuality among women and taught these same beliefs to enslaved Africans. These teachings continue today as messages are forwarded that women are responsible for how they present themselves. Early on, they received messages regarding appropriate behaviors for women, however, today, they view these as oppressive tools to control them and their actions. Some of these restrictive views that were reserved to daughters limited the college choices of my participants.

As the student population continues to increase in diversity, it is particularly important to understand the aspects that impact their sense of belonging. In their retention strategies, institutions of higher education often assume that students need to learn to be resilient. My participants, however, shared stories which illustrate they were already resilient in facing the myriad systems of oppression. The women cultivated tribes that supported them through times of difficulty and helped them to persist. Seeking a better life for themselves and their families were also sources of motivation for my participants to push through their college education in spite of the challenges they encountered.

My participants arrive at FIU with a set of views concerning their multiple identities. Overall, my participants feel excluded from the university's thoughts of diversity as their specific needs are not being met. While there were no explicit experiences with racism on campus or the surrounding community, the women did voice 
experiences with microaggressions and biases. Instances of microaggressions and other forms of discrimination impacted my participants differently. Things related to my participants' hair or the space that they take up as Black women influence how they are viewed and treated by others. My dissertation shows that these microaggressions and cases of discrimination create internal battles within the participants that challenge their sense of self, cause stress, and increase mental health issues. Moreover, my study transcends the Black and White binary to include Hispanic/Latinx and how these communities internalize anti-Black racist ideas about Black women.

While the basis for the research site was because of convenience and the large Afro-Caribbean student population attending the university, what was clear when speaking to the students was that they did not feel included in the diversity of the institution. Like most institutions, FIU may not have a strategic focus on diversification of its student population. This is ironic given the university's status as an HSI, however, it speaks to the concerns of researchers (Garcia, 2019; Nunez, Hurtado, \& Calderon, 2015) that HSIs are enrollment based and not necessarily mission-driven. The idea was specific to Hispanic populations, however, the same could be said for the Black student population enrolled at HSIs. Specific to my study, Afro-Caribbean college women are enrolled at the university, yet not much is thought of as to why this population chooses to attend the institution or their experiences at the institution. Moreover, data is not collected to illustrate the within-group differences of the Black population. As such, it appears that little attention or resources are allocated towards the Afro-Caribbean student population. 
Throughout the course of navigating campus, my participants' sense of identity has transformed and morphed into their current understandings of self, which is in a state of constant evolution. This study strove to explore my participants' social identities at a particular point in time. It is important to note that their multiple identities and lived experiences lead to diverse findings. This study provides a glimpse into the lived experiences of second-generation Afro-Caribbean college women and offers some insight into their complex identities. An understanding of this population is heightened given the Black Lives Matter movement that is not only calling for the end of police brutality of Black people but is also challenging systemic racism and white supremacy. Higher education is not exempt from the calls to dismantle systems of oppression as Black students are voicing their experiences with racism. How institutions chose to address the concerns of Black students will be critical. Choosing not to acknowledge the Black student community and their concerns is denying their existence and unique experiences which in effect, upholds white supremacy. 


\section{REFERENCES}

Allen, W. R., McLewis, C., Jones, C., \& Harris, D. (2018). From Bakke to Fisher: African American students in U.S. higher education over forty years. The Russell Sage Foundation Journal of the Social Sciences, 4(6), 41-72.

Anderson, M. (2015). A rising share of the U.S. Black population is foreign born; 9 percent are immigrants; and while most are from the Caribbean, Africans drive recent growth. Washington, DC: Pew Research Center.

Awokoya, J. T. (2012). Identity constructions and negotiations among 1.5- and secondgeneration Nigerians: The impact of family, school, and peer context. Harvard Educational Review, 82(2), 255-281.

Bashi Bobb, V. E., \& Clarke, A. Y. (2001). Experiencing success: Structuring the perception of opportunities for West Indians. In Nancy Foner (Ed), Islands in the city: West Indian migration to New York (pp. 216-236). Berkeley, CA: University of California Press.

Benson, J. E. (2006). Exploring the racial identities of Black immigrants in the United States. Sociological Forums, 21(2), 219-247.

Berry, J. W., Phinney, J. S., Sam, D. L., \& Vedder, P. (2006). Immigrant youth: Acculturation, identity, and adaptation. Applied Psychology: An International Review, 55(3), 303-332.

Bertaux, D. (1981). Biography and society: The life history approach in the social sciences. Beverly Hills, CA: SAGE.

Blackmon, D. A. (2008). Slavery by another name: The re-enslavement of Black Americans from the civil war to world war II. New York, NY: Anchor.

Bogdan, R. C., \& Biklen, S. K. (2016). Qualitative research for education: An introduction to theories and methods ( $5^{\text {th }}$ ed.). Pearson.

Butterfield, S. P. (2004). Challenging American conceptions of race and ethnicity: Second generation West Indian immigrants. International Journal of Sociology and Social Policy, 24(7/8), 75-102.

Carter, D. E. (2006). Key Issues in the persistence of underrepresented minority students. New Directions for Institutional Research, 130, 33-46.

Chatters, L. M., Taylor, R. J., Jackson, J. S., \& Lincoln, K. D. (2008). Religious coping among African Americans, Caribbean Blacks and Non-Hispanic. Journal of Community Psychology, 36(3), 371-386. 
Chen, C. P. (2001). On exploring meanings: Combining humanistic and career psychology theories in counselling. Counselling Psychology Quarterly, 14(4), 317-330.

Coates, T. (2017). We were eight years in power: An American tragedy. New York, NY: One World.

Collins, P. H. (1990). Black feminist thought: Knowledge, consciousness, and the politics of empowerment. New York, NY: Routledge.

Collins, P. H. (2000). Gender, Black feminism, and Black political economy. The Annals of the American Academy of Political and Social Science,568, 41-53.

Conway, K. M. (2009). Exploring persistence of immigrant and native students in an urban community college. The Review of Higher Education, 32(3), 321-352.

Cooper, B. (2018). Eloquent rage: A Black feminist discovers her superpower. New York, NY: St. Martin's Press.

Cooper, C. W. (2007). School choice as 'motherwork': Valuing African-American women's educational advocacy and resistance. International Journal of Qualitative Studies in Education, 20(5), 491-512.

Corbin, N. A., Smith, W. A., \& Garcia, J. R. (2018). Trapped between justified anger and being the strong Black woman: Black college women coping with racial battle fatigue at historically and predominantly White institutions. International Journal of Qualitative Studies in Education, 31(7), 626-643.

Creswell, J. W. (2007). Qualitative inquiry \& research design: Choosing among five approaches. Thousand Oaks, CA: SAGE.

Daniel Barnes, R. J. (2016). She was a twin: Black strategic mothering, race-work, and the politics of survival. Journal of the Association of Black Anthropologists, 24(1), 49-60.

Daoud, N., George Mwangi, C. A., English, S., \& Griffin, K. A. (2018). Beyond stereotypes: Examining the role of social identities in the motivation patterns of Black immigrant and Black native students. American Journal of Education, 124, 285-312.

Davies, C. B. (2003). Black women, writing and identity: Migrations of the subject. London: Routledge.

Deaux, K. (1993). Reconstructing social identity. Society for Personality and Social Psychology, 19(1), 4-12. 
Deaux, K. (2008). To be an American: Immigration, hyphenation, and incorporation. Journal of Social Issues, 64(4), 925-943.

Deaux, K., Bikmen, N., Gilkes, A., Ventuneac, A., Joseph, Y., Payne, Y. A., \& Steele, C. M. (2007). Becoming American: Stereotype threat effects in Afro-Caribbean immigrant groups. Social Psychology Quarterly, 70(4), 384-404.

Delgado, R., \& Stefancic, J. (2001). Critical race theory: An Introduction. New York, NY: New York University Press.

Dukes, S. (1984). Phenomenological methodology in the human sciences. Journal of Religion \& Health, 23(3), 197-203.

Dunn, M. (1997). Black Miami in the twentieth century. Gainesville, FL: University Press of Florida.

Erikson, E. H. (1968). Identity: Youth and crisis. New York, NY: WW Norton \& Company.

Excelencia in Education (2019). Emerging Hispanic-Serving Institutions (HSIs): 201718. Retrieved from https://www.edexcelencia.org/media/900.

Fields, K. E., \& Fields, B. J. (2014). Racecraft: The soul of inequality in American life. London, UK: Verso.

Fleming, J., \& Garcia, N. (1998). Are standardized tests fair to African Americans?: Predictive validity of the SAT in black and white institutions. Journal of Higher Education, 69(5), 471-495.

Foner, N. (2001). Islands in the city: West Indian migration to New York. Berkeley, CA: University of California Press.

Forde, F. D. (2002). Caribbean Americans in New York City 1895-1975. Charleston, SC: Arcadia.

Fries-Britt, S., George Mwangi, C. A., \& Peralta, A. M. (2014). Learning race in a U.S. context: An emergent framework on the perceptions of race among foreign-born students of color. Journal of Diversity in Higher Education, 7(1), 1-13.

Fries-Britt, S., \& Griffin, K. (2007). The Black box: How high-achieving Blacks resist stereotypes about Black Americans. Journal of College Student Development, 48(5), 509-524.

Galdeano, E. C., Flores, A. R., \& Moder, J. (2012). The Hispanic association of colleges and universities and Hispanic-serving institutions: Partners in the advancement of Hispanic higher education. Journal of Latinos and Education, 11, 157-162. 
Garcia, G. A. (2019). Becoming Hispanic-Serving Institutions: Opportunities for colleges and universities. Baltimore, MD: Johns Hopkins University Press.

Gates, H. L., Jr. (2019). Stony the road: Reconstruction, white supremacy, and the rise of Jim Crow. New York, NY: Penguin Press.

George Mwangi, C. A. (2014). Complicating Blackness: Black immigrants \& racial positioning in U.S. higher education. Journal of Critical Thought and Praxis, 3, $1-27$.

George Mwangi, C. A., \& Fries-Britt, S. (2015). Black within Black: The perceptions of Black immigrant collegians and their U.S. college experience. About Campus, 20(2), 16-23.

Gilkes, A. D. (2007). The West Indian diaspora: Experiences in the United States and Canada. New York, NY: LFB Scholarly Publishing.

Glass, K. L. (2005). Tending to the roots: Anna Julia Cooper's sociopolitical thought and activism. Meridians, 6(1), 23-55.

Gopalan, M., \& Brady, S. T. (2019). College students' sense of belonging: A national perspective. Educational Researcher, 1-4.

Griffin, K. A., George Mwangi, C. A., \& Patterson, S. M. (2017). The experiences of Black immigrant women transitioning into college: Moving in and moving through. In L. D. Patton, \& N. N. Croom (Eds.), Critical perspectives on Black women and college success (pp. 115-126). Routledge.

Griffin, K. A., \& McIntosh, K. L. (2015). Finding a fit: Understanding Black immigrant students' engagement in campus activities. Journal of College Student Development, 56(3), 243-260.

Guba, E. G., \& Lincoln, Y. S. (2005). Paradigmatic controversies, contradictions, and emerging confluences. In N. K. Denzin, \& Y. S. Lincoln (Eds.). The SAGE handbook to qualitative research (pp. 191-216). Thousand Oaks, CA: SAGE.

Guy, T. (2002). Black immigrants of the Caribbean: An invisible and forgotten group. Adult Learning, 13(1), 18-21.

Harris-Perry, M. V. (2011). Sister citizen: Shame, stereotypes, and Black women in America. New Haven, CT: Yale University Press.

Hintzen, P. C., \& Rahier, J. M. (2003). Problematizing Blackness: Self-ethnographies by Black immigrants to the United States. New York, NY: Routledge. 
Hispanic Association of Colleges and Universities. (2018). HACU 2018 Annual Report. Retrieved from https://www.hacu.net/hacu/Annual_Report.asp.

Hooks, B. (2014). Ain't i a woman: Black women and feminism. Retrieved from https://ebookcentral.proquest.com.

Hurtado, S., Milem, J. F., Clayton-Pedersen, A. R., \& Allen, W. R. (1998). Enhancing campus climates for racial/ethnic diversity: Educational policy and practice. The Review of Higher Education, 21(3), 279-302.

James Alexander, S. A. (2014). African diasporic women's narratives: Politics of resistance, survival, and citizenship. Gainesville, FL: University Press of Florida.

Jaret, C., \& Reitzes, D. C. (2009). Currents in a stream: College student identities and ethnic identities and their relationship with self-esteem, efficacy, and grade point average in an urban university. Social Science Quarterly, 90(2), 345-367.

Johnston-Guerrero, M. P. (2016). Embracing the messiness: Critical and diverse perspectives on racial and ethnic identity development. New Directions for Student Services, 154, 43-55.

Jones, S. R., \& McEwen, M. K. (2000). A conceptual model of multiple dimensions of identity. Journal of College Student Development, 41(4), 405-414.

Kegan, R. (1982). The evolving self. Cambridge, MA: Harvard University.

Kendi, I. X. (2016). Stamped from the beginning: The definitive history of racist ideas in America. New York, NY: Bold Type Books.

Kent, M. M. (2007). Immigration and America's Black population. Population Bulletin, 62(4), 3-16.

Kuckartz, U. (2014). Qualitative text analysis: A guide to methods, practice \& using software. Los Angeles, CA: Sage.

Laverty, S. M. (2003). Hermeneutic phenomenology and phenomenology: A comparison of historical and methodological considerations. International Journal of Qualitative Methods, 2(3), 21-35.

Littlefield, M. B. (2003). Gender role identity and stress in African American women. Journal of Human Behavior in the Social Environment, 8(4), 93-104.

Massey, D., Mooney, M., Torres, K. C., \& Charles, C. Z. (2007). Black immigrants and Black natives attending selective colleges and universities in the United States., American Journal of Education, 113(2), 243-271. 
Merriam, S. B. (1998). Qualitative research and case study application in education: Revised and expanded from case study research in education. San Francisco, CA: Jossey Bass.

Miles, M. B., \& Huberman, A. M. (1994). Qualitative data analysis ( $2^{\text {nd }}$ ed.). Thousand Oaks, CA: Sage.

Morgan, M., \& Bennett, D. (2006). Getting off of Black women's backs: Love her or leave her alone. Du Bois Review, 3(2), 485-502.

Nelson Laird, T. F., Williams, J. M., Bridges, B. K., Holmes, M. S., \& Morelon-Quainoo, C. L. (2007). African American and Hispanic student engagement at minority serving and predominantly white institutions. Journal of College Student Development, 48(1), 39-56.

Nunez, A. M., Hurtado, S., \& Galdeano, E. C. (2015). Why study Hispanic-Serving Institutions? In A. M. Nunez, S. Hurtado, \& E. C. Galdeano (Eds.), HispanicServing Institutions: Advancing research and transformative practice (p.p. 1-22). Rutledge.

Oluo, I. (2018). So you want to talk about race. New York, NY: Seal Press.

Osha, S. (2008). Venus and white desire. Transition, 99, 80-93.

Patton, L. D., \& Croom, N. N. (2017). Critical perspectives on undergraduate Black women. In L. D. Patton, \& N. N. Croom (Eds.), Critical perspectives on Black women and college success (pp.1-13). Routledge.

Patton, M. Q. (2002). Two decades of developments in qualitative inquiry. Qualitative Social Work, 1(3), 261-283.

Perkins, L. M. (2017). Race, Gender, and Class at Fisk, Howard, and Tuskegee. In L. D. Patton, \& N. N. Croom (Eds.), Critical perspectives on Black women and college success (pp. 17-30). Routledge.

Phinney, J. S. (1990). Ethnic identity in adolescents and adults: Review of Research. Psychological Bulletin, 108(3), 499-514.

Phinney, J. S. (1992). The multigroup ethnic identity measure: A new scale for use with diverse groups. Journal of Adolescent Research, 7(2), 156-176.

Phinney, J. S. (1996). When we talk about American ethnic groups, what do we mean? American Psychologist, 51(9), 918-927.

Pierre, J. (2004). Black immigrants in the United States and the "cultural narratives" of ethnicity. Identities: Global Studies in Culture and Power, 11, 141-170. 
Porter, C. J. (2017). Articulation of identity in Black undergraduate women: Influences, interactions, and intersections. In L. D. Patton, \& N. N. Croom (Eds.). Critical perspectives on Black women and college success (pp. 88-100). Routledge.

Portes, A., \& Rumbaut, R. G. (2001). Legacies.: The story of the immigrant second generation. Berkeley: University of California Press; New York: Russell Sage Foundation, 2001. Retrieved from http://search.ebscohost.com/login.aspx?direct=true \&db=cat06026a\&AN=fiu.0329 $18460 \&$ site $=$ eds-live

Redd, K. E. (1998). Historically Black colleges and universities: Making a comeback. New Directions for Higher Education, 102, 33-43.

Rimer, S., \& Arenson, K. W. (2004, June 24). Top colleges take more Blacks, but which ones? The New York Times. Retrieved from https://www.nytimes.com.

Robinson, P. (2016). You can't touch my hair: And other things I still have to explain. New York, NY: Penguin Random House.

Rogers, R. (2001). "Black like who?": Afro-Caribbean immigrants, African Americans, and the politics of group identity. In N. Foner (Ed), Islands in the city: West Indian migration to New York (pp. 163-192). University of California Press.

Rogers, R. R. (2006). Afro-Caribbean immigrants and the politics of incorporation: Ethnicity, exception, or exit. New York, NY: Cambridge University Press.

Rumbaut, R. G. (1996). The crucible within: Ethnic identity, self-esteem, and segmented assimilation among children of immigrants. In A. Portes (Ed), The new second generation (pp. 119-170). Russell Sage Foundation.

Saldana, J. (2009). The Coding Manual for Qualitative Researchers. Thousand Oaks, CA: SAGE.

Saldana, J., \& Omasta, M. (2018). Qualitative research: Analyzing life. Los Angeles, CA: SAGE.

Seidman, I. (2013). Interviewing as qualitative research: A guide for researchers in education \& the social sciences. New York, NY: Teachers College Press.

Shahid, N. N., Nelson, T., \& Cardemil, E. V. (2017). Lift every voice: exploring the stressors and coping mechanisms of Black college women attending predominantly white institutions. Journal of Black Psychology, 44(1), 3-24.

Shaw, M. D. (2017). Supporting students who struggle successfully: Developing and institutionalizing support for Black undergraduate women. In L. D. Patton \& N. 
N. Croom (Eds.), Critical perspectives on Black women and college success (pp. 200-212). Routledge.

Showers Johnson, V. M. (2008). What, then, is the African-American? African and AfroCaribbean identities in Black America. Journal of American Ethnic History, 28(1), 77-103.

Singh, R. (1990). Ethnic minority experience in higher education. Higher Education Quarterly, 44(4), 344-359.

Solorzano, D. G. (1997). Images and words that wound: Critical Race Theory, racial stereotyping, and teacher education. Teacher Education Quarterly, 24(3), 5-15.

Stebleton, M. J., Soria, K. M., Huesman, R. L. \& Torres, V. (2014). Recent immigrant students at research universities: The relationship between campus climate and sense of belonging, Journal of College Student Development, 55(2), 196-202.

Stewart, D. L. (2017). (In)visibility, involvement, and success: A counternarrative of Black women in predominantly white liberal arts colleges, 1945-1965. In L. D. Patton \& N. N. Croom (Eds.), Critical perspectives on Black women and college success (pp. 31-43). Routledge.

Strauss, A., \& Corbin, J. (1998). Basics of qualitative research: Techniques and procedures for developing grounded theory. Thousand Oaks, CA: SAGE.

Sublette, N., \& Sublette, C. (2015). American slave coast: A history of the slave-breeding industry. Chicago, IL: Chicago Review Press.

The Combahee River Collective. (2015). A Black feminist statement. In A. Hull, P. BellScott, \& B. Smith (Eds.), All the women are white, all the Black are meant, but some of us are brave: Black women's studies (pp. 13-33). Feminist Press.

Tracey, S. J. (2010). Qualitative quality: Eight "big-tent" criteria for excellent qualitative research. Qualitative Inquiry, 16(10), 837-851.

U.S. Department of Education, National Center for Education Statistics. (2017). Bachelor's degrees conferred by postsecondary institutions, by racelethnicity and sex of student. Retrieved from https://nces.ed.gov/programs/digest/d17/tables/dt17_322.20.asp?referer=raceindic ators

Vickerman, M. (2001). Tweaking a monolith: The West Indian immigrant encounter with "Blackness". In N. Foner (Ed), Islands in the city: West Indian migration to New York (pp. 237-256). University of California Press. 
Waters, M. C. (1994). Ethnic and racial identities of second-generation Black immigrants in New York City. The International Migration Review, 28(4), 795-820.

Waters, M. C. (1999). Black identities: West Indian immigrant dreams and American realities. Cambridge, MA: Harvard University Press.

Wiley, S., Perkins, K., \& Deaux, K. (2008). Through the looking glass: Ethnic and generational patterns of immigrant identity. International Journal of Intercultural Relations, 32, 385-398.

Willie, S. S. (2003). Acting Black: College, identity, and the performance of race. New York, NY: Routledge.

Winkle-Wagner, R. (2009). The unchosen me: Race, gender, and identity among Black women in college. Baltimore, MD: Johns Hopkins University Press.

Woodfield, R. (2017). Undergraduate students who are required to withdraw from university: The role of ethnicity. British Educational Research Association, 43(2), 230-252.

Yosso, T. J. (2006). Critical race counterstories along the Chicana/Chicano educational pipeline. New York, NY: Routledge. 
Appendices 
Appendix A

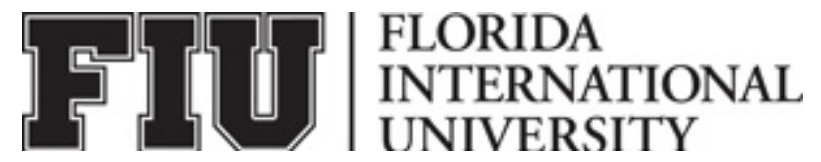
ADULT CONSENT TO PARTICIPATE IN A RESEARCH STUDY
A Case Study on how $2^{\text {nd }}$ generation Afro-Caribbean college women make sense of their race, ethnicity, and gender

\section{SUMMARY INFORMATION}

Things you should know about this study:

- Purpose: The purpose of the study is to explore how second-generation AfroCaribbean undergraduate women make sense of their race, ethnicity, and gender. The study will also examine how these identities may inform students' sense of belonging.

- Procedures: If you choose to participate, you will be asked to participate in no more than two, 60-90 minute semi-structured interviews. These interviews will be audio-recorded and then transcribed into a word document. A third interview of up to 30 minutes may be requested to follow up on any questions that need clarification from the initial interviews.

- Duration: This will take about two- three hours.

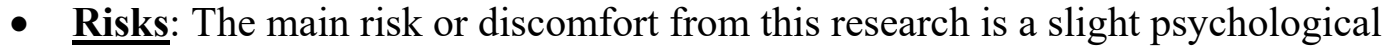
discomfort as a result of reflection on your identity during or after the interview process.

- Benefits: The main benefit to you from this research is from additional reflection on your race, ethnicity, and gender as well as your sense of belonging.

- Alternatives: There are no known alternatives available to you other than not taking part in this study.

- Participation: Taking part in this research project is voluntary.

Please carefully read the entire document before agreeing to participate.

\section{PURPOSE OF THE STUDY}

The purpose of this study is to explore how second-generation Afro-Caribbean undergraduate women make sense of their race, ethnicity, and gender. The study will also examine how these identities may inform students' sense of belonging. 


\section{NUMBER OF STUDY PARTICIPANTS}

If you decide to be in this study, you will be one of up to 10 people in this research study.

\section{DURATION OF THE STUDY}

Your participation will involve no more than three hours of your time over one academic semester.

\section{PROCEDURES}

If you agree to be in the study, we will ask you to do the following things:

1. Participate in no more than two, 60-90-minute semi-structured interviews. These interviews will be audio-recorded and then transcribed into a word document.

a. The first interview will ask you questions about your past including family and peer dynamics and how these relate to your identity.

b. The second interview will involve instances in your college career that influenced your racial and ethnic identity.

\section{RISKS AND/OR DISCOMFORTS}

The study has the following possible risks to you: First, a slight psychological discomfort as a result of reflection on your identity during or after the interview process. The risk to this discomfort is minimal but you are allowed to withdraw from this study at any time without any penalty. Should you experience any psychological discomfort I have provided contact information for the IRB office and for additional support outside of FIU should that be necessary

\section{BENEFITS}

The study has the following possible benefits to you: additional reflection on your race, ethnicity, and gender and experience in college.

\section{ALTERNATIVES}

There are no known alternatives available to you other than not taking part in this study. Any significant new findings developed during the course of the research which may relate to your willingness to continue participation will be provided to you.

\section{CONFIDENTIALITY}

The records of this study will be kept private and will be protected to the fullest extent provided by law. In any sort of report we might publish, we will not include any information that will make it possible to identify you. Research records will be stored securely, and only the researcher team will have access to the records. However, your 
records may be inspected by authorized University or other agents who will also keep the information confidential.

\section{USE OF YOUR INFORMATION}

- Your information collected as part of the research will not be used or distributed for future research studies even if identifiers are removed.

\section{COMPENSATION \& COSTS}

There are no costs to you for participating in this study.

\section{RIGHT TO DECLINE OR WITHDRAW}

Your participation in this study is voluntary. You are free to participate in the study or withdraw your consent at any time during the study. You will not lose any benefits if you decide not to participate or if you quit the study early. The investigator reserves the right to remove you without your consent at such time that he/she feels it is in the best interest.

\section{RESEARCHER CONTACT INFORMATION}

If you have any questions about the purpose, procedures, or any other issues relating to this research study you may contact Emmanuela Stanislaus at 954-632-4392 or estan016@fiu.edu.

\section{IRB CONTACT INFORMATION}

If you would like to talk with someone about your rights of being a subject in this research study or about ethical issues with this research study, you may contact the FIU Office of Research Integrity by phone at 305-348-2494 or by email at ori@fiu.edu.

\section{PARTICIPANT AGREEMENT}

I have read the information in this consent form and agree to participate in this study. I have had a chance to ask any questions I have about this study, and they have been answered for me. I understand that I will be given a copy of this form for my records.

Signature of Participant

Date

Printed Name of Participant

Signature of Person Obtaining Consent

Date 


\section{Appendix B}

Interview Protocol

\section{Introduction}

\section{a. Instructions:}

Good morning (afternoon). My name is __. Thank you for coming. This interview is part of a qualitative research study. The purpose is to explore the experiences of secondgeneration Afro-Caribbean college women to see how they make sense of their race, ethnicity, and gender. There are no right or wrong or desirable or undesirable answers. I would like you to feel comfortable with saying what you really think and how you really feel.

\section{b. Recording:}

If it is okay with you, I will be tape-recording our conversation. The purpose of this is so that I can get all the details but at the same time be able to carry on an attentive conversation with you. I assure you that all your comments will remain confidential. I will be compiling a report which will contain all students' comments without any reference to individuals.

\section{c. Consent:}

I would like you to express your consent to volunteering to participate in this research project.

Yes----- No---

\section{First Interview - Historical Context}

Interview Questions:

- Tell me a little bit about yourself and about how you grew up.

- Please tell me a little bit about your family.

- How would you describe your culture?

- What was your neighborhood like growing up?

- What does it mean to be ?

- What influenced you to go to college?

- What influenced your decision to attend FIU?

- Is there anything else you would like to share?

- Do you have any questions?

Probing Questions:

- How did that make you feel?

- Can you provide me with an example?

- What else can you tell me about that?

- It sounds like you are saying

- Why does that stand out to you?

- Why do you think you noticed that? 


\section{$\underline{\text { Second Interview - College Experience }}$}

Interview Questions:

- What is it like being a student at FIU?

- What are your friends like at FIU?

- Tell me about any extra-curricular activities you participate in on campus.

- How do you define yourself?

- In what ways do you see your race, ethnicity, and gender affecting your experiences at FIU?

- What does it mean to be at FIU?

- What experiences keep you here at FIU?

- How are your experiences different from other women at FIU?

- What have you learned from participating in these interviews?

- Tell me about your plans after college?

- Is there anything else you would like to share?

- Do you have any questions?

d. Closing:

That concludes our interview.

To keep your anonymity, I will be providing you with a pseudonym. Is there a particular pseudonym that you would like me to use for you if I quote anything that you have shared?

Thank you for your participation. 


\section{VITA}

\section{EMMANUELA PIERRE STANISLAUS}

1999-2003

2003-2005

2014 -present

$2011-2014$
B.S., Public Administration

Florida International University

Miami, Florida

M.S., Higher Education Administration

Florida State University

Tallahassee, Florida

Associate Director

Career \& Talent Development

Florida International University

Miami, Florida

Assistant Director

Career \& Talent Development

Florida International University

Miami, Florida

\section{PUBLICATIONS AND PRESENTATIONS}

Hodge, L. S., Wilkerson, A., \& Stanislaus, E. P. (2020). How many clicks?: An exploration of expectancy value theory and what institutional websites reveal about firstgeneration support services. Metropolitan Universities Journal, 31 (1):92-112.

Stanislaus, E. P., (April, 2020). An exploration of how second-generation Afro-Caribbean college women make meaning of their race, ethnicity, and gender. Paper accepted for the meeting of the American Educational Research Association (AERA).

Stanislaus, E. P., (March, 2020). Exploring race, ethnicity, and gender among secondgeneration Afro-Caribbean women. Paper accepted for the meeting of the Comparative and International Education Society (CIES).

Hodge, L. S., Stanislaus, E. P., \& Wilkerson, A. (Under Review). Make space for us: An exploration of Black college women fictive kinship. International Journal of Qualitative Studies in Education.

Wilkerson, A., Krsmanovic, M., \& Stanislaus, E. P. (Under Review). Culturally relevant pedagogy as a teaching strategy: A case study of HBCU first year seminar pedagogical practices. Journal of The First-Year Experience \& Students in Transition. 